\title{
Age-associated insolubility of parkin in human midbrain is linked to redox balance and sequestration of reactive dopamine metabolites
}

\author{
Jacqueline M. Tokarew ${ }^{1,2}$. Daniel N. El-Kodsi ${ }^{1,2} \cdot$ Nathalie A. Lengacher ${ }^{1,2} \cdot$ Travis K. Fehr $^{1,2}$. Angela P. Nguyen ${ }^{1}$. \\ Bojan Shutinoski ${ }^{1}$ - Brian O'Nuallain ${ }^{3} \cdot$ Ming Jin $^{3}$. Jasmine M. Khan ${ }^{1}$. Andy C. H. Ng ${ }^{1}$. Juan $\mathrm{Li}^{1}$. Qiubo Jiang ${ }^{1}$. \\ Mei Zhang ${ }^{4}$. Liqun Wang ${ }^{3}$. Rajib Sengupta ${ }^{5,6} \cdot$ Kathryn R. Barber $^{7}$. An Tran ${ }^{7}$. Doo Soon Im $^{20,21}$. Steve Callaghan ${ }^{20}$. \\ David S. Park ${ }^{20,21} \cdot$ Stephanie Zandee $^{8} \cdot$ Xiajun Dong $^{9} \cdot$ Clemens R. Scherzer $^{9} \cdot$ Alexandre Prat $^{8} \cdot$ Eve C. Tsai $^{1,10}$. \\ Masashi Takanashi' ${ }^{11}$. Nobutaka Hattori ${ }^{11}$. Jennifer A. Chan ${ }^{12} \cdot$ Luigi Zecca $^{13}$. Andrew B. West ${ }^{14,15}$. Arne Holmgren ${ }^{5}$. \\ Lawrence Puente $^{16}$. Gary S. Shaw ${ }^{7}$. Gergely Toth ${ }^{17}$. John M. Woulfe ${ }^{1,4} \cdot$ Peggy Taylor $^{3}$. Julianna J. Tomlinson ${ }^{1,18}$. \\ Michael G. Schlossmacher ${ }^{1,18,19}$
}

Received: 20 November 2020 / Revised: 11 January 2021 / Accepted: 13 January 2021 / Published online: 10 March 2021

(c) The Author(s) 2021

\begin{abstract}
The mechanisms by which parkin protects the adult human brain from Parkinson disease remain incompletely understood. We hypothesized that parkin cysteines participate in redox reactions and that these are reflected in its posttranslational modifications. We found that in post mortem human brain, including in the Substantia nigra, parkin is largely insoluble after age 40 years; this transition is linked to its oxidation, such as at residues Cys95 and Cys253. In mice, oxidative stress induces posttranslational modifications of parkin cysteines that lower its solubility in vivo. Similarly, oxidation of recombinant parkin by hydrogen peroxide $\left(\mathrm{H}_{2} \mathrm{O}_{2}\right)$ promotes its insolubility and aggregate formation, and in exchange leads to the reduction of $\mathrm{H}_{2} \mathrm{O}_{2}$. This thiol-based redox activity is diminished by parkin point mutants, e.g., p.C431F and p.G328E. In prkn-null mice, $\mathrm{H}_{2} \mathrm{O}_{2}$ levels are increased under oxidative stress conditions, such as acutely by 1-methyl-4-phenyl-1,2,3,6-tetrahydropyridine toxin exposure or chronically due to a second, genetic hit; $\mathrm{H}_{2} \mathrm{O}_{2}$ levels are also significantly increased in parkin-deficient human brain. In dopamine toxicity studies, wild-type parkin, but not disease-linked mutants, protects human dopaminergic cells, in part through lowering $\mathrm{H}_{2} \mathrm{O}_{2}$. Parkin also neutralizes reactive, electrophilic dopamine metabolites via adduct formation, which occurs foremost at the primate-specific residue Cys95. Further, wild-type but not p.C95A-mutant parkin augments melanin formation in vitro. By probing sections of adult, human midbrain from control individuals with epitopemapped, monoclonal antibodies, we found specific and robust parkin reactivity that co-localizes with neuromelanin pigment, frequently within LAMP-3/CD $63^{+}$lysosomes. We conclude that oxidative modifications of parkin cysteines are associated with protective outcomes, which include the reduction of $\mathrm{H}_{2} \mathrm{O}_{2}$, conjugation of reactive dopamine metabolites, sequestration of radicals within insoluble aggregates, and increased melanin formation. The loss of these complementary redox effects may augment oxidative stress during ageing in dopamine-producing cells of mutant $P R K N$ allele carriers, thereby enhancing the risk of Parkinson's-linked neurodegeneration.
\end{abstract}

Dedication: This work is dedicated to the memories of $\mathrm{Mr}$. Bruce Hayter (1962-2019), a tireless advocate for persons with young-onset parkinsonism, and our co-author, Dr. Arne Holmgren (1940-2020), a pioneer in redox biology. We are grateful to Dr. Oleh Hornykiewicz (1927-2020), a leader in the pursuit of biochemical investigations of the human brain, for his encouragement.

Jacqueline M. Tokarew and Daniel N. El-Kodsi have contributed equally to this work.

Arne Holmgren: Deceased.

Extended author information available on the last page of the article 
Keywords Young-onset Parkinson disease $\cdot$ Parkinsonism $\cdot$ Parkin $\cdot$ PRKN/PARK2 gene $\cdot$ Redox chemistry $\cdot$ Dopamine metabolism $\cdot$ Neuromelanin $\cdot$ Anti-oxidant

\section{Introduction}

Bi-allelic mutations in $P R K N$, which encodes parkin, lead to a young-onset, recessive form of Parkinson disease (PD) $[39,42]$. Pathology studies of parkin-deficient brains have demonstrated that neuronal loss is largely restricted to the $S$. nigra and L. coeruleus, two brainstem nuclei that synthesize dopamine (reviewed in Doherty et al. [15]).

Parkin is a principally cytosolic protein. It has been associated with diverse cellular functions, foremost related to its ubiquitin ligase (E3) activity, the control of inflammation signalling, and maintenance of mitochondrial integrity, as mediated through participation in mitophagy and mitochondrial antigen presentation (MITAP) [5, 57-59, 63, 65, 67, 88] (reviewed in Barodia et al. [4]). Although mitophagy has recently been shown to be co-regulated by parkin in the developing heart of mice [26], the diverse roles ascribed to parkin function have not yet explained its selective neuroprotection. For example, vertebrate models of genomic prkn deletion do not reproduce dopamine cell loss; one exception is the parkin-deficient Polg mouse, where mitochondrial DNA mutagenic stress had been added as a second, genetic hit [75]. The general lack of dopamine cell loss in genomic parkin deficiency-based models of vertebrates could be due to compensatory mechanisms [86], a shorter life span of non-human mammals, and possibly, unique aspects of dopamine metabolism in humans. The latter is exemplified by the generation of cytoplasmic neuromelanin in dopamine synthesizing neurons beginning after childhood [110]. Nevertheless, genomic prkn-null models have revealed biochemical and structural changes in high energy-producing cells of flies and murine tissues $[4,21,102]$, which suggested the presence of elevated oxidative stress [34, 70,74]. These observations pointed at a contribution of parkin to redox homeostasis in vivo.

Redox equilibrium invariably involves cysteine-based chemistry. There, thiols are subjected to oxidative modifications by reactive oxygen-, reactive nitrogen- and reactive electrophilic species (ROS, RNS, RES) [2, 52], some of which are reversible. Proteins irreversibly conjugated by RES, including by electrophilic dopamine radicals, are either degraded or sequestered within inclusions. It is thought that the latter process occurs via lysosomal functions and underlies neuromelanin formation throughout adulthood [83].

Human parkin contains 35 cysteines [42], its murine homologue 34 . Of these, 28 cysteines are involved in the chelation of eight zinc ions within four RING domains [31]. Although Cys431 has been identified as critical in catalyzing human parkin's E3 ligase activity, 6 other cysteines are structurally unaccounted for, including Cys95 located within parkin's 'linker' domain. Several reports have demonstrated the unique sensitivity of parkin to ROS and RES in cells [50, $60,103]$. Further, RNS and sulfhydration can also modify its cysteines, and $\mathrm{NO}-/ \mathrm{NO}_{2}$-modified parkin variants have been described in cells and brain tissue [6-8, 97, 107]. Oxidation of parkin has been linked to both activating ('gain-of-function') and detrimental ('loss-of-function') outcomes when tested in the context of parkin's E3 ligase activity in vitro $[8,51,60,107]$.

We found that wild-type parkin is highly oxidized and insoluble in adult human midbrain, leading us to explore non-E3 ligase-mediated, protective functions. Owing to its large number of cysteine-based thiols, we hypothesized: one, that parkin confers neuroprotection by acting as an antioxidant molecule in vivo and thereby contributes to redox balance; two, specifically, that parkin directly lowers ROSas well as RNS-linked stressors and promotes the conjugation of dopamine radicals (RES); and three, we posited that selective neurodegeneration in $P R K N$-linked, autosomalrecessive PD (ARPD) could be partially explained by the absence of parkin-mediated sequestration of toxic metabolites during decades of human ageing.

\section{Materials and methods}

\section{Tissue collection}

All tissues were collected in accordance with Institutional Review Board-approved guidelines. Fresh frozen samples of the cortical human brain from subjects under 50 years of age were acquired through the University of Alabama and the Autism Tissue Program. Post mortem, frozen brain samples from frontal cortices were also obtained from the NICHD Brain and Tissue Bank at the University of Maryland. Brain tissues, including midbrain specimens, with short post mortem interval (PMI) were obtained from patients diagnosed clinically and neuropathologically with multiple sclerosis (MS) according to the revised 2010 McDonald's criteria [76]. There, tissue samples were collected from MS patients, as approved by the Montreal-based CRCHUM research ethics committee. Autopsy samples were preserved and lesions classified using Luxol Fast Blue/Haematoxylin and Eosin staining and Oil Red-O staining, as previously published $[14,48]$. No inflamed tissue areas were used in the current study. Additional, fresh-frozen and paraffin-embedded human samples were obtained from the Neuropathology Service at Brigham and Women's Hospital in Boston, MA 
and from archived autopsy specimens in the Department of Pathology and Laboratory Medicine of The Ottawa Hospital, Ottawa, ON. Human spinal cord and muscle tissues were collected post mortem from organ donors at The Ottawa Hospital with approval from the Ottawa Health Science Network Research Ethics Board.

\section{Animal tissues}

All animal protocols were approved by the review board of the Animal Care and Veterinary Services at the University of Ottawa. Brains were collected from wild-type C57B1/6J mice from Jackson laboratories (Bar Harbor, ME); prkn-null mice were from Dr. Brice's laboratory [34] and back-crossed onto a pure C57B1/6J background; Sod $2 \pm$ mice were from Jackson laboratories (pure C57Bl/6J background), and the bi-genic mouse ( $\left.\mathrm{rrkn}^{-/-} / / \operatorname{Sod}^{ \pm}\right)$was created by crossing prkn-null mice with Sod2-haploinsufficient mice, and the interbreeding of heterozygous offspring. These bi-genic mice have been characterized elsewhere (El-Kodsi et al. in preparation [17]). Following euthanasia by Euthanyl (65 mg/ $\mathrm{mL}$ ) intraperitoneal injection, mouse brains were collected and processed on ice in a Dounce glass homogenizer by 20 passes in Tris salt buffer with vs. without the addition of $1 \%$ hydrogen peroxide $\left(\mathrm{H}_{2} \mathrm{O}_{2}-\right.$ Sigma), or 0.1-1 M dithiothreitol (DTT-Sigma), transferred to ultracentrifuge tubes and spun during $30 \mathrm{~min}$ at $163,202.1 \times \mathrm{g}$ and $4{ }^{\circ} \mathrm{C}$ to extract the soluble fraction. The resulting pellets were further homogenized in the tris-salt buffer with the addition of 2-10\% SDS, transferred to ultracentrifuge tubes and spun at $163,202.1 \times g$ and $10{ }^{\circ} \mathrm{C}$ for $30 \mathrm{~min}$ to extract the insoluble fraction. Wildtype mice (of C57Bl/6J or mixed background, as indicated) were used for the analysis of the effects of PMI on murine parkin distribution in the brain. Mice ranging from 4 to 22 months in age were perfused with PBS, their brains collected and processed, as above. Wild-type SAS Sprague Dawley rats were obtained from Charles River Laboratories; frozen frontal lobe specimens of a cynomolgus monkey were provided by the New England Primate Research Center.

\section{Sequential extraction of parkin from neural tissue}

Approximately $1 \mathrm{~cm}^{3}$ of the human frontal cortex and midbrain specimens (age range, 5-85 years) were weighed and placed in $3 \times$ volume/weight of Tris-salt buffer (TS; $5 \mathrm{mM}$ Tris, $140 \mathrm{mM} \mathrm{NaCl}, \mathrm{pH}$ 7.5) containing complete EDTAfree protease inhibitor cocktail, and $10 \mathrm{mM}$ iodoacetamide (IAA, Bio-Rad). The samples were homogenized on ice in a Dounce glass homogenizer by 50 passes, transferred to ultracentrifuge tubes and spun at $163,202.1 \times g$ and $4{ }^{\circ} \mathrm{C}$ for $30 \mathrm{~min}$. The TS supernatant was transferred to a fresh tube and the pellet was extracted further with the addition of $3 \times$ volume/weight of Triton X-100 buffer (TX, TS $+2 \%$
Triton X-100). The samples were mixed by vortexing, incubated on ice for $10 \mathrm{~min}$ and centrifuged again using the same setting. The TX supernatant was transferred to a fresh tube and the pellet was extracted further with the addition of $3 \times$ volume/weight of SDS buffer (SDS, TS $+2 \%$ SDS). The samples were mixed by vortexing, incubated at room temperature for $10 \mathrm{~min}$ and centrifuged again at $163,202.1 \times \mathrm{g}$ and $12{ }^{\circ} \mathrm{C}$ for $30 \mathrm{~min}$. The SDS supernatant was transferred to a fresh tube and the pellet was either stored at $-80{ }^{\circ} \mathrm{C}$ or extracted further with the addition of $3 \times$ volume/weight of $6 \times$ non-reducing Laemmli buffer (LB, 30\% SDS, $60 \%$ glycerol, $375 \mathrm{mM}$ Tris; $\mathrm{pH}$ 6.8;), mixed by vortex and incubated at room temperature for $10 \mathrm{~min}$. Samples were centrifuged again at $163,202.1 \times g$ and $12{ }^{\circ} \mathrm{C}$ for $30 \mathrm{~min}$ and the LB supernatant was transferred to a fresh tube. Extracted proteins from TS, TXS and SDS buffers including pellet $(20-30 \mu \mathrm{g})$ and $10-20 \mu \mathrm{L}$ of LB extracts were run on SDSPAGE using reducing (100 mM DTT) and/or non-reducing (0 mM DTT) LB. Following transfer to membranes, Ponceaus S staining (Sigma) was used to probe for equal loading; following washing, membranes were immunoblotted for the detection of parkin (Biolegend 808503, 1: 5000), DJ-1 (Ab18257, 1: 2000), $\alpha$-synuclein (syn-1, 1:1000 or MJFR-1, 1:2000), LC3B (3868, 1:2000), VDAC (MSA03, 1:5000), MnSOD and GLO1 (each at 1:1000), calnexin (MAB3126, 1:1000), cathepsin D (sc-6486, 1:1000), GRP75 (sc-1058, 1:1000). ImageJ software (version $1.52 \mathrm{k}$; National Institutes of Health, USA) was used for signal quantification purposes.

\section{mRNA analyses}

PRKN mRNA isolated from individual S. nigra dopamine neurons, cortical pyramidal neurons and non-neuronal, mononuclear cells from venous blood were processed, as described [16] and annotated in the Human BRAINcode database (www.humanbraincode.org).

\section{1-methyl-4-phenyl-1,2,3,6-tetrahydropyridine (MPTP) treatment}

Eight to 12 months-old wild-type and prkn-null mice were injected intraperitoneally with $40 \mathrm{mg} / \mathrm{kg}$ of saline or MPTP and sacrificed an hour later [3]. Brains were harvested for ROS measurement, protein analysis by Western blotting and immunoprecipitation of parkin followed by MS analysis. For LC-MS/MS, murine brains were first incubated in IAA prior to homogenization and fractionation, as described above. Brain homogenates were then incubated with anti-parkin conjugated to magnetic beads (Dynabeads Coupling Kit; Invitrogen), as below. A magnet was used to enrich mouse parkin bound to Prk8 conjugated to beads, and several washes were used to remove non-specific proteins. Eluted fractions (IP elute) along with controls (input, unbound, 
wash and recombinant parkin protein standards) were run on SDS/PAGE under reducing conditions and blotted with anti-parkin. A sister gel was stained with Coomassie, as described above, and gel slices corresponding to band sizes at $50-75 \mathrm{kDa}$ were excised and analyzed by LC-MS/MS, as described below.

\section{Recombinant protein expression using a pET-SUMO vector}

Plasmid cDNA encoding for wild-type and truncated (amino acid 321-465) human parkin proteins were expressed as 6His-Smt3 fusion proteins in Escherichia coli BL21 (DE3) Codon-Plus RIL-competent cells (C2527, New England Biolabs), as previously described $[1,49,91]$. Plasmids encoding for human parkin with p. C95A, p.G328E and p.C431F substitutions were generated with the use of a restrictionfree cloning strategy [96] using the following primers: for p.C95A PRKN forward: CAGAAACGCGGCGGGAGG CgcTGAGCGGGAGCCCCAGAGCT and $P R K N$ reverse: CATCCCAGCAAGATGGACCC; for p.G328E $P R K N$ forward: TCCAAACCGGATGAGTGGTG and $P R K N$ reverse: CGGGGGCATAACACGCCCCCCATCTGCAGGACAC ACTC; for p.C431F PRKN forward: CTACTCCCTGCC TTGTGTGG and $P R K N$ reverse: GCGGACACTTCATGT GCATaaaGCCTCCATTTTTTTCCACTGG.

$D J-1$ and SNCA coding regions were cloned from pcDNA3.1 into the pET-SUMO vector using PCR and restriction enzymes. A new restriction site for NotI was inserted between SUMO cleavage site and protein start codon in pET-SUMO using the following primers: $p E T$ $S U M O$ forward: GTGATGCCGGCCACGATGCGTCCG GC and $p E T$-SUMO reverse: TTTTAAGCTTCCgcggccgcCACCACCAATCTGTTC. The inserts containing wildtype DJ-1 and SNCA sequences with 5' NotI and 3' HindIII restriction sites were generated using the following primers and inserted into pET-SUMO using standard conditions: for $D J-1$ forward: agggeggecgcATGGCTTCCAAA and $D J-1$ reverse: cctaagcttCTAGTCTTTAAGAACAAGTGGAGC CTTC; for $S N C A$ forward: agggcggecgcATGGATGTATTC ATGAAAGG and $S N C A$ reverse: ctTTAAGCTTCAGGTTC GTAGTCTTGATACCCTTCAGA.

Quality control steps were performed at the Sequencing Core Facility of the Ottawa Hospital Research Institute (OHRI) to confirm the correct sequences.

Transformed bacteria were grown at $37{ }^{\circ} \mathrm{C}$ in $2 \%$ Luria Broth containing $30 \mathrm{mg} / \mathrm{L}$ kanamycin. All parkin proteinexpressing cultures were supplemented with $0.5 \mathrm{mM}$ $\mathrm{ZnCl}_{2}$. Protein expression was induced at $16^{\circ} \mathrm{C}$ with isopropyl $\beta$-D-1-thiogalactopyranoside (Sigma) using $25 \mu \mathrm{M}$ for wild-type parkin, and $0.75 \mathrm{mM}$ for truncated parkin, DJ-1, $\alpha$-synuclein and ulp1 protease. Bacteria were harvested after $16-20 \mathrm{~h}$ by centrifugation and resuspended in isolation buffer, T500i $(50 \mathrm{mM}$ Tris, $500 \mathrm{mM} \mathrm{NaCl}$, $250 \mu \mathrm{M}$ TCEP, $25 \mathrm{mM}$ imidazole, $\mathrm{pH}$ 7.5). Lysozyme $(0.1 \mathrm{mg} / \mathrm{mL}$, except for ulp1 protease $)$ treatment and sonication steps (Sonics Vibra Cell) were used to lyse cells. Proteins were collected after $1 \mathrm{~h}$ incubation at $4{ }^{\circ} \mathrm{C}$ with Ni-NTA agarose and washed several times with buffers T500i and T200i (50 mM Tris, $200 \mathrm{mM} \mathrm{NaCl}, 250 \mu \mathrm{M}$ TCEP, $25 \mathrm{mM}$ imidazole, $\mathrm{pH}$ 7.5). Fractions of elution buffer T200e (50 mM Tris, $200 \mathrm{mM} \mathrm{NaCl}, 250 \mu \mathrm{M}$ TCEP, $250 \mathrm{mM}$ imidazole, $\mathrm{pH} 7.5$ ) were combined with 2-2.5 mg of $6 x$ His-tagged ulp1 protease and subsequently dialyzed (6-8 kDa cut-off,) against T200 (50 mM Tris, $200 \mathrm{mM}$ $\mathrm{NaCl}, 250 \mu \mathrm{M}$ TCEP, $\mathrm{pH}$ 7.5) for $24 \mathrm{~h}$ at $4{ }^{\circ} \mathrm{C}$. Remaining proteins were incubated with Ni-NTA agarose for $1 \mathrm{~h}$ at $4{ }^{\circ} \mathrm{C}$. Fractions were collected until no protein was detectable, pooled and concentrated to $1 \mathrm{mg} / \mathrm{mL}$ using $10 \mathrm{kDa}$ cut-off centrifugation filters (Millipore). The purity and correct masses of isolated proteins were assessed using electron spray ionization mass spectrometry (Agilent 6538 Q-TOF).

\section{Protein staining methods}

All proteins were separated on pre-cast $4-12 \%$ Bis-Tris SDS-PAGE gels (NPO321BOX, NPO322BOX, NPO336BOX) from Invitrogen using MES running buffer (50 mM MES, $50 \mathrm{mM}$ Tris, $1 \mathrm{mM}$ EDTA and $0.1 \%$ SDS, pH 7.3) and Laemmli loading buffer (10\% SDS, $20 \%$ glycerol, $0.1 \%$ bromophenol blue, $0.125 \mathrm{M}$ Tris $\mathrm{HCl}, 200 \mathrm{mM}$ DTT or $\beta$-mercaptoethanol). Proteins were stained in gel using SilverQuest ${ }^{\mathrm{TM}}$ Silver Staining Kit (LC6070) from Invitrogen or Coomassie brilliant blue R-250 dye $(20,278)$ from Thermo Scientific using the following protocol: The gel was transferred to a plastic container and rocked for 30 min in Fix Solution (10\% acetic acid, 50\% methanol), followed by staining for $2-24 \mathrm{~h}(0.25 \%$ Coomassie R250) until the gel turned a uniform blue. The stain was replaced with Destain Solution (7.5\% acetic acid and 5\% methanol) and the gel was rocked until crisp blue bands appeared. Following a wash with water, the gel was stored in $7 \%$ acetic acid. Proteins transferred to PVDF (Bio-Rad) membranes were stained with Ponceau S solution (Sigma) for $20 \mathrm{~min}$, washed three times with water, imaged and then destained with $0.1 \mathrm{M} \mathrm{NaOH}$ prior to Western blotting.

\section{Dynamic light scattering assay}

For each recombinant protein preparation tested, the buffer (50 mM Tris, $200 \mathrm{mM} \mathrm{NaCl}$ and $250 \mu \mathrm{M}$ TCEP, pH 7.5) was exchanged for a $20 \mathrm{mM}$ phosphate buffer with $10 \mathrm{mM}$ $\mathrm{NaCl}$ (pH 7.4). $20 \mu \mathrm{M}$ full-length wild-type recombinant parkin was centrifuged at $21,000 \times g$ for $60 \mathrm{~min}$ at $4{ }^{\circ} \mathrm{C}$ and 
light scattering intensity of the supernatant was collected 30 times at an angle of $90^{\circ}$ using a $10 \mathrm{~s}$ acquisition time. Measurements were taken at $37{ }^{\circ} \mathrm{C}$ using a Malvern Zetasizer Nano ZS instrument equipped with a thermostat cell. The correlation data were exported and analyzed using the nanoDTS software (Malvern Instruments). The samples were measured at $0,1,3$ and $5 \mathrm{~h}$. Following $24 \mathrm{~h}$ incubation, $2 \mathrm{mM}$ DTT was added to the sample and the light scattering intensity of the supernatant was measured again.

\section{Far UV circular dichroism spectroscopy}

Fifteen $\mu \mathrm{M}$ of reduced and partially oxidized full-length wild-type, recombinant ( $\mathrm{r}-$ ) parkin was measured at $t=0$ and $t=5$ days of incubation under native conditions in $20 \mathrm{mM}$ phosphate, $10 \mathrm{mM} \mathrm{NaCl}$ buffer. The aggregate-rich phase and the monomer-rich phase in the samples were separated with ultracentrifugation $(100,000 \times g$ for $2 \mathrm{~h})$. Far UV circular dichroism (CD) spectra were recorded for the monomer- and aggregate-rich phase of protein samples using a JASCO J-720 spectrometer. The final spectrum was taken as a background-corrected average of 5 scans carried out under the following conditions: wavelength range $250-190 \mathrm{~nm}$ at $25^{\circ} \mathrm{C}$; bandwidth was $1 \mathrm{~nm}$; acquisition time was $1 \mathrm{~s}$ and intervals was $0.2 \mathrm{~nm}$. Measurements were performed in a $0.01 \mathrm{~cm}$ cell. CD spectra were plotted in mean residue molar ellipticity units ( $\mathrm{deg} \mathrm{cm}^{2} \mathrm{dmol}^{-1}$ ) calculated by the following equation: $[\Theta]=\Theta_{\text {obs }} /(10 n c l)$, where $[\Theta]$ is the mean residue molar ellipticity as a function of wavelength, $\Theta_{\text {obs }}$ is the measured ellipticity as a function of wavelength $(\mathrm{nm}), n$ is the number of residues in the protein, $c$ is the concentration of the protein $(\mathrm{M})$, and $l$ is the optical path length $(\mathrm{cm})$. Secondary structure analysis of proteins using CD spectroscopic data was carried out using the BeStSel (Beta Structure Selection) software $[41,61,62,90]$.

\section{Cysteine labeling for mass spectrometry}

Recombinant protein samples were first prepared by exchanging the T200 buffer for PBS. The protein concentrations were measured and adjusted to $10 \mu \mathrm{M}$ using PBS. Stock solutions of $500 \mathrm{mM}$ DTT, $100 \mathrm{mM}$ IAA, $100 \mathrm{mM}$ $\mathrm{H}_{2} \mathrm{O}_{2}$ and $250 \mathrm{mM}$ EDTA were prepared in PBS. A stock of $500 \mathrm{mM}$ NEM was prepared in ethanol immediately before use. The stepwise Cys labeling procedure was as follows: A $10 \mu \mathrm{L}$ aliquot of protein (at $10 \mu \mathrm{M}$ ) was reacted with hydrogen peroxide at various concentrations, as indicated (Supplementary Table 2 , online resource) for $30 \mathrm{~min}$ at $37{ }^{\circ} \mathrm{C}$ as indicated. Any unreacted cysteines were alkylated with incubation with $5 \mathrm{mM}$ IAA (either with or, in some runs, without $10 \mathrm{mM}$ EDTA) for $2 \mathrm{~h}$ at $37^{\circ} \mathrm{C}$. Previously oxidized cysteines were then reduced by treatment with $40 \mathrm{mM}$ DTT for $30 \mathrm{~min}$ at $37^{\circ} \mathrm{C}$. Newly reduced cysteines were alkylated by incubation with $85 \mathrm{mM} \mathrm{N}$-ethyl maleimide (NEM) for $2 \mathrm{~h}$ at $37^{\circ} \mathrm{C}$. The samples were separated on SDS-PAGE using Laemmli buffer containing $100 \mathrm{mM}$ DTT and proteins visualized using Coomassie staining. Appropriate bands were excised and analyzed by liquid chromatography mass spectrometry (LC-MS/MS).

\section{Protein identification by LC-MS/MS}

Proteomic analyses were performed at the OHRI Proteomics Core Facility (Ottawa, Canada). Proteins were digested in-gel using trypsin (Promega) according to the method of Shevchenko [84]. Peptide extracts were concentrated by Vacufuge (Eppendorf). LC-MS/MS was performed using a Dionex Ultimate 3000 RLSC nano HPLC (Thermo Scientific) and Orbitrap Fusion Lumos mass spectrometer (Thermo Scientific). MASCOT software version 2.6.2 (Matrix Science, UK) was used to infer peptide and protein identities from the mass spectra. For detection of dopamine metabolites on parkin, the following variable modifications were included: 5,6-indolequinone $\left(+\mathrm{C}_{8} \mathrm{O}_{2} \mathrm{NH}_{3}, \mathrm{~m} / \mathrm{z}\right.$ shift +145$)$, aminochrome $\left(+\mathrm{C}_{8} \mathrm{O}_{2} \mathrm{NH}_{5},+147\right)$, aminochrome $+2 \mathrm{H}\left(+\mathrm{C}_{8} \mathrm{O}_{2} \mathrm{NH}_{7},+149\right)$, and dopamine quinone $\left(+\mathrm{C}_{8} \mathrm{O}_{2} \mathrm{NH}_{9},+151\right)$. These samples were prepared for analysis without any use of DTT or IAA. The observed spectra were matched against human sequences from SwissProt (version 2018-05) and also against an in-house database of common contaminants. The results were exported to Scaffold (Proteome Software, USA) for further validation and viewing.

Analysis of the r-parkin holoprotein and of three runs of $\mathrm{H}_{2} \mathrm{O}_{2}$-exposed r-parkin (Supplementary Table 2, online resource) was also performed at the University of Western Ontario. There, samples were run on a QToF Ultima mass spectrometer (Waters) equipped with a Z-spray source and run in positive ion mode with an Agilent 1100 HPLC used for LC gradient delivery (University of Western Proteomics Facility).

\section{MaxQuant analysis of mass spectrometry data}

For select experiments, the raw MS data files were further processed with MaxQuant software version 1.6.5 and searched with the Andromeda search engine [10]. The reference fastas were set to uniprot-human (version 2019-0212 ) and uniprot-ecoli. The $E$. coli proteome was included to account for bacterial proteins present in the recombinant protein samples. The 'second peptides' and 'match between runs' settings were enabled. All other settings were left as default. Selected variable modifications included oxidation (Met), acetylation (protein N-terminus), and carbamidomethyl (Cys), as well as custom modifications for pyro-carbamidomethyl (N-terminal Cys), N-ethylmaleimide (Cys), and 
$\mathrm{NEM}+$ water (Cys). For data analyses, site-level intensity values were obtained from the MaxQuant-generated "CarbamidomethylSites" table which combines the intensity of MS1 signals from all peptides covering a particular cysteine residue.

\section{Immunoprecipitation (IP) of brain parkin}

Conjugation of anti-parkin antibody (Prk8, 808503, lot B209868) and clone A15165-B (this report: Suppl. Figure $8 \mathrm{c}$ ) to magnetic beads at a final concentration of $10 \mathrm{mg}$ of antibody $/ \mathrm{mL}$ of beads was carried out following the Magnetic Dynabeads Antibody Coupling Kit from Invitrogen (14311D). Human tissue lysates were also prepared using the sequential extraction of proteins from neural tissue protocol, as described above, with the addition of $10 \mathrm{mM}$ IAA prior to homogenization. Equal amounts of protein from TS tissue extracts $(n=4)$ and SDS tissue extracts $(n=8)$ were diluted in TS buffer, resulting in final SDS concentrations of $0.0175-0.05 \%$ in the SDS extracts. For the IP, anti-parkin primary antibody-conjugated agarose beads were first prepared by multiple washes with $1 \mathrm{~mL}$ of TS buffer using centrifugation $\left(1000 \times g\right.$ at $4{ }^{\circ} \mathrm{C}$ for $\left.3 \mathrm{~min}\right)$ and adhesion to a strong magnet. The amount of Prk 8 conjugated agarose beads used for each experiment were approximated based on the amount of parkin $(\mu \mathrm{g}) / \mathrm{sample}$ calculated by densitometry when the sample was compared to recombinant parkin protein standards using Western blotting with Prk8 as a primary antibody. The mixture was incubated for $16 \mathrm{~h}$ at $4{ }^{\circ} \mathrm{C}$ with slow rotation. Unbound proteins, were separated from the beads by centrifugation $\left(1000 \times g\right.$ at $4{ }^{\circ} \mathrm{C}$ for $\left.3 \mathrm{~min}\right)$ followed by adhesion to a strong magnet and saved as the IP "unbound" fraction.

Beads were washed three times with $1 \mathrm{~mL}$ of ice-cold RIPA buffer (1\% nonionic polyoxyethylene-40, 0.1\% SDS, $50 \mathrm{mM}$ Tris, $150 \mathrm{mM} \mathrm{NaCl}, 0.5 \%$ sodium deoxycholate, $1 \mathrm{mM}$ EDTA) using centrifugation $\left(1000 \times g\right.$ at $4{ }^{\circ} \mathrm{C}$ for $\left.3 \mathrm{~min}\right)$ and adhesion to a strong magnet. Approximately $5-10 \mu \mathrm{L}$ of each wash was combined and saved as the IP "wash" fraction. To elute antibody-bound proteins, $35 \mu \mathrm{L}$ of $6 \mathrm{X}$ reducing Laemmli buffer (30\% SDS, $60 \%$ glycerol, $0.3 \%$ bromophenol blue, $0.375 \mathrm{M}$ Tris, $100 \mathrm{mM}$ DTT, $\mathrm{pH}$ 6.8) was added to the beads and the samples were boiled for $5 \mathrm{~min}$. Following centrifugation $\left(1000 \times g\right.$ at $4{ }^{\circ} \mathrm{C}$ for $\left.3 \mathrm{~min}\right)$, the supernatant was transferred to a fresh tube labeled "IP elute" and the beads were discarded. To assess IP efficiency, eluted fractions (IP elute), along with controls (input, unbound, wash and recombinant parkin protein standards) were run on SDS/PAGE and blotted with anti-parkin antibody (Prk8, MAB5512 Millipore or 2132S Cell Signalling). Human IP elutes used for mass spectrometry (MS) analysis were incubated with $500 \mathrm{mM}$ NEM (as indicated for select runs) for $16 \mathrm{~h}$ at $4{ }^{\circ} \mathrm{C}$ prior to SDS-PAGE and further processed for MS, as described above. Gel slices corresponding to band sizes at 50-53 kDa were excised and analyzed by LC-MS/MS.

\section{Reactive oxygen species $\left(\mathrm{H}_{2} \mathrm{O}_{2}\right)$ measurements in recombinant protein preparations, cell lysates and tissue homogenates}

An Amplex ${ }^{\circledR}$ Red hydrogen peroxide/peroxidase assay kit (Invitrogen A22188) was used to monitor endogenous levels of $\mathrm{H}_{2} \mathrm{O}_{2}$ in aliquots of tissues and cells, and in test tubes following either exposure to increasing concentrations of $\mathrm{H}_{2} \mathrm{O}_{2}, n$-ethylmaleidmide (NEM), and ethylenediaminetetraacetic acid (EDTA), or after incubation with either select, recombinant parkin proteins, or DJ-1, $\alpha$-synuclein, bovine serum albumin (Thermo Scientific), ring finger protein 43 (RNF43-BioLegend, MA.), HOIL-1-interacting protein (HOIP-Boston Biochem, MA.), glutathione (Sigma), or catalase (Sigma) for $30 \mathrm{~min}$ at room temperature. Preweighed cortex pieces from the human brain and pelleted cells were homogenized on ice in the $1 \times$ reaction buffer provided (Invitrogen A22188) using a Dounce homogenizer ( $3 \times$ volume to weight ratio). Homogenates were diluted in the same $1 \times$ reaction buffer (fivefold to tenfold). A serial dilution of the $\mathrm{H}_{2} \mathrm{O}_{2}$ standard provided was prepared (20, 10,2 and $0 \mu \mathrm{M}$ ). Fifty $\mu \mathrm{L}$ of standards and samples were plated in a 96-well black plate with a clear flat bottom (Thermo Fisher Scientific). The reaction was started by the addition of $50 \mu \mathrm{L}$ reaction buffer, Amplex ${ }^{\circledR}$ Red and horseradish peroxidase (HRP) (10 mM Amplex ${ }^{\circledR}$ Red and $10 \mathrm{U} /$ $\mathrm{mL}$ HRP). Plates were incubated at room temperature for $30 \mathrm{~min}$ protected from light. A microplate reader was used to measure either fluorescence with excitation at $560 \mathrm{~nm}$ and emission at $590 \mathrm{~nm}$, or absorbance at $560 \mathrm{~nm}$. The obtained $\mathrm{H}_{2} \mathrm{O}_{2}$ levels $(\mu \mathrm{M})$ were normalized to the tissue weight $(\mathrm{g})$ or protein concentration $(\mu \mathrm{g} / \mu \mathrm{L})$. The same assay was also used to measure parkin and glutathione's peroxidase activity compared to horseradish peroxidase.

\section{Chemiluminescence-based, direct reactive oxygen species assay}

The assay was modified from Muller et al. [64] to measure the ROS-quenching ability of parkin proteins, DJ-1, GSH, and catalase. Protein concentrations were quantified using Bradford assay and adjusted to 5, 10, 15 and $30 \mu \mathrm{M}$ in buffer not containing TCEP. Bovine serum albumin (BSA; 10 and $20 \mu \mathrm{M}$; Thermo Scientific), glutathione (15, 20, 200, 400, 800 and $2000 \mu \mathrm{M}$; Sigma), and catalase (15 $\mu \mathrm{M}$, Sigma) were prepared. Stock solutions of $\mathrm{H}_{2} \mathrm{O}_{2}$ for standard curve were prepared at $5,10,20,40$ and $50 \mathrm{mM}$ in $0.1 \mathrm{M}$ Tris $\mathrm{HCl}$ pH 8.0 using $30 \% \mathrm{H}_{2} \mathrm{O}_{2}$. Stock solutions of $300 \mathrm{mM}$ luminol and $40 \mathrm{mM} 4$-iodophenol were prepared in DMSO and protected from light. Signal reagent, containing $1.94 \mathrm{mM}$ 
luminol (Sigma) and $0.026 \mathrm{mM}$ 4-iodophenol (Sigma), was prepared in $0.1 \mathrm{M}$ Tris $\mathrm{HCl} \mathrm{pH} 8.0$ and protected from light. A $0.4 \%$ horseradish peroxidase solution was prepared using HRP-linked anti-rabbit secondary antibody diluted in Stabilizyme solution (SurModics SZ02). Each read was set up in triplicate on a white polystyrene 96-well plate (Thermo Scientific 236,105) and to each well was added $80 \mu \mathrm{L}$ Stabilizyme, $15 \mu \mathrm{L}$ of $0.4 \%$ horseradish peroxidase (HRP) and 25 $\mu \mathrm{L}$ of sample or controls. One of the injectors in a Synergy H1Multi-Mode Plate Reader (Bio Tek) was primed and set to inject $15 \mu \mathrm{L}$ of signal reagent and $15 \mu \mathrm{L}$ of each $\mathrm{H}_{2} \mathrm{O}_{2}$ stock solution was manually added to corresponding controls and samples just prior to reading. Final concentrations of reagents were $0.04 \% \mathrm{HRP}, 500,1000,2000,4000$ and $5000 \mu \mathrm{M} \mathrm{H}_{2} \mathrm{O}_{2}, 194 \mu \mathrm{M}$ luminol, $2.6 \mu \mathrm{M}$ 4-iodophenol and $0.8,1.7,2.5$ or $5 \mu \mathrm{M}$ of protein. The plate reader was set to measure luminescence every $1 \mathrm{~min}$ for a total of $10 \mathrm{~min}$.

The resulting kinetic data were converted to the area under the curve (AUC) using Prism software version 6. For samples pre-incubated with $20 \mathrm{mM}$ iodoacetamide, a stock solution of $1 \mathrm{M}$ iodoacetamide was prepared. To each well containing $25 \mu \mathrm{L}$ of the sample, $0.52 \mu \mathrm{L}$ of $1 \mathrm{M}$ iodoacetamide and $0.48 \mu \mathrm{L}$ of buffer not containing TCEP was added and the samples were incubated for $2 \mathrm{~h}$ at $37^{\circ} \mathrm{C}$. Following incubation, the reagents for chemiluminescence were added as above except $79 \mu \mathrm{L}$ of Stabilizyme was used instead of 80 $\mu \mathrm{L}$ and the samples were analyzed as above.

\section{Thiol quantification in recombinant proteins}

Recombinant protein samples were first prepared by exchanging the T200e protein buffer $(50 \mathrm{mM}$ Tris, $200 \mathrm{mM}$ $\mathrm{NaCl}$ and $250 \mu \mathrm{M}$ TCEP, $\mathrm{pH} 7.5)$ for T200 using repeat centrifugations ( 8 times $4000 \times g$ at $4{ }^{\circ} \mathrm{C}$ for $10 \mathrm{~min}$ ) in Amicon Ultra $10 \mathrm{kDa}$ MWCO filters (Millipore). The protein concentrations were measured and recorded. A glutathione stock solution of 32,539 $\mu \mathrm{M}$ was prepared by dissolving $1 \mathrm{mg}$ glutathione (GSH) in $1 \mathrm{~mL}$ of T200 and the standards $0,50,101,203,406,813$ and $1000 \mu \mathrm{M}$ were prepared by serial dilution in T200. The reaction buffer $(0.1 \mathrm{M}$ sodium phosphate, $\mathrm{pH}$ 8.0) was prepared by adding $93.2 \mathrm{~mL} 1 \mathrm{M}$ $\mathrm{Na}_{2} \mathrm{HPO}_{4}$ and $6.8 \mathrm{~mL}$ of $\mathrm{NaH}_{2} \mathrm{PO}_{4}$ in $1 \mathrm{~L}$ of water. Thiol detecting reagent (Ellman's reagent) was prepared by dissolving $2 \mathrm{mg}$ of 5,5'-dithio-bis-[2-nitrobenzoic acid] (DNTB; Sigma) in $1 \mathrm{~mL}$ of reaction buffer. The assay was performed in 96-well clear round-bottom plates (Corning) by adding $50 \mu \mathrm{L}$ of thiol detecting reagent to $50 \mu \mathrm{L}$ of sample or standard and incubating for $15 \mathrm{~min}$ at room temperature.

The resulting 5-thio-2-nitrobenzoic-acid (TNB) produced was measured by absorbance at $412 \mathrm{~nm}$ using a Synergy H1Multi-Mode Plate Reader (Bio Tek). The amount of free thiols detected in each sample was calculated using the regression curve obtained from the glutathione standards and dividing by the concentration of the sample.

\section{Zinc ion release assay}

A zinc quantification kit (Abcam-ab102507) was used to assay zinc ion $\left(\mathrm{Zn}^{2+}\right)$ release from proteins. Recombinant human proteins (wild-type r-parkin and r-DJ-1) were spun in 10 or $30 \mathrm{kDa}$ cut-off centrifugation filters (Millipore) to remove residual TCEP. Increasing concentrations of protein ( 0 to $2.5 \mu \mathrm{M}$ ) were incubated under basal conditions or with the addition of $\mathrm{H}_{2} \mathrm{O}_{2}(2 \mathrm{mM})$ or DTT $(100 \mathrm{mM})$ for $30 \mathrm{~min}$ at $37^{\circ} \mathrm{C}$. A standard curve was prepared using a zinc standard (stock, $50 \mathrm{mM}$ ) provided by the manufacturer. Two hundred $\mu \mathrm{L}$ of the reaction mixture was added to $50 \mu \mathrm{L}$ standards and samples on 96 well plates (Thermo Fisher Scientific) followed by incubation at room temperature for $10 \mathrm{~min}$. A microplate reader was used to measure the absorbance at OD560 $\mathrm{nm}$. The background was corrected by subtracting the value derived from wells of zero zinc standard from all readings.

\section{Cell cytotoxicity assay}

Human neuroblastoma cell lines (M17) without transduction (controls), or transduced by vector-only plasmid (Myc-tag), or those with low levels of stable expression of Myc-parkin cDNA (P5) and high levels of stable expression of Myc-parkin (P17), or sister lines transiently overexpressing flag-parkin (wild-type), flag-vector and flagparkin carrying one of three-point mutations (p.C431F; p.G3289E; p.C95A) were grown in 6-well culture plates at $0.3 \times 10^{6}$ cell density ( $80 \%$ confluence). There, Opti-MEM media (Gibco 11,052-021) contained heat-inactivated fetal bovine serum (Gibco 10,082-147), Pen/strep/Neo (5 mg/5 mg/10 mg; Gibco 15,640-055), MEM-non-essential amino acids (10 mM; Gibco 11,140-050) and sodium pyruvate $(100 \mathrm{mM})$. For rescue experiments, M17 cells transiently expressing cDNA for flag-vector, flag-parkin wild-type, and variants carrying p.G328E, p.C431F, or p.C95A-encoding parkin protein were used. There, $4 \mu \mathrm{g}$ of cDNA was transfected using a 1:1 ratio of cDNA to Lipofectamine 2000 (52,887, Invitrogen) in OPTI-MEM transfection medium. Lipofectamine 2000 and cDNA were first incubated for $20 \mathrm{~min}$ at room temperature before being applied directly to the cells for $1 \mathrm{~h}$ at $37{ }^{\circ} \mathrm{C}$ with $5 \%$ $\mathrm{CO}_{2}$ followed by direct addition of fresh growth medium. The cells were incubated another $20-24 \mathrm{~h}$ at $37^{\circ} \mathrm{C}$ with $5 \% \mathrm{CO}_{2}$.

Dopamine hydrochloride (Sigma) $200 \mathrm{mM}$ stock was prepared. Cells were washed with fresh media once and then incubated with media alone or supplemented with dopamine at final concentrations of $20 \mu \mathrm{M}$ and $200 \mu \mathrm{M}$ 
for $18-20 \mathrm{~h}$. Post dopamine exposure, conditioned media were collected for cytotoxicity assays and cells were harvested for lysis in TS buffer, vortexed and centrifuged. Supernatants were collected and saved for Western blot analyses and to be assessed for cytotoxicity. Cell pellets were suspended in 2-10\% SDS buffer and centrifuged to collect the 'insoluble fraction'.

Vybrant TM cytotoxicity assay kit (Molecular Probes V-23111) was used to monitor cell death through the release of the cytosolic enzyme glucose 6-phosphate dehydrogenase (G6PD) by damaged cells into the surrounding medium. Fifty $\mu 1$ of fresh media (without any exposure to cells) as well as conditioned media from control and stressed cells, in addition to lysates of M17 cells (as a positive control for maximum G6PD), were added to a 96-well microplate. Fifty $\mu \mathrm{l}$ of reaction mixture containing buffer (as per manufacturer) and resazurin, which reacts with G6PD generating fluorescently detectable resorufin, were added to each well, and the mircroplate was incubated at $37{ }^{\circ} \mathrm{C}$ for $30 \mathrm{~min}$. A microplate reader was used to measure either fluorescence with excitation at $560 \mathrm{~nm}$ and emission at $590 \mathrm{~nm}$, where the rise in fluoresence indicates a rise in G6PD levels as a surrogate marker of cell death.

\section{Aminochrome synthesis}

A solution of $0.1 \mathrm{M}$ sodium phosphate buffer $\mathrm{pH} 6.0$ was prepared from a mixture of $12 \mathrm{~mL}$ of $1 \mathrm{M} \mathrm{NaH}_{2} \mathrm{PO}_{4}$ and $88.0 \mathrm{~mL}$ of $1 \mathrm{M} \mathrm{Na}_{2} \mathrm{HPO}_{4}$. The reaction buffer $(0.067 \mathrm{M}$ sodium phosphate, $\mathrm{pH} 6.0$ ) was prepared by adding $33 \mathrm{~mL}$ of $0.1 \mathrm{M}$ sodium phosphate buffer to $17 \mathrm{~mL}$ water. A solution of $10 \mathrm{mM}$ dopamine in reaction buffer was prepared by adding $19 \mathrm{mg}$ of dopamine hydrochloride (Sigma) to $1 \mathrm{~mL}$ of reaction buffer. Oxidation was activated by adding $5 \mu \mathrm{L}$ of tyrosinase $(25,000 \mathrm{U} / \mathrm{mL}$; Sigma) and the mixture was incubated at room temperature for $5 \mathrm{~min}$. Tyrosinase was separated from the oxidized dopamine using a $50 \mathrm{kDa}$ cut-off Amicon Ultra centrifugation filter (Millipore) by centrifuging at $21,000 \times g$ for $10 \mathrm{~min}$. The absorbance of the filtrate was measured at a wavelength of $475 \mathrm{~nm}$ (Ultrospec 2100 pro spectrophotometer, Biochrom) and the concentration of aminochrome was determined using the Beer-Lambert equation and extinction coefficient of $3058 \mathrm{~L} \times \mathrm{mol}^{-1} \times \mathrm{cm}^{-1}$.

\section{Redox chemistry reactions including oxidation of cysteine-containing proteins in vitro}

Purified, recombinant proteins were prepared by removing excess TCEP, present in the elution buffer, by using repeat centrifugations ( 8 times $4000 \times g$ at $4{ }^{\circ} \mathrm{C}$ for $10 \mathrm{~min}$ ) in Amicon Ultra $10 \mathrm{kDa}$ MWCO filters (Millipore). Protein concentrations were measured and adjusted to $20 \mu \mathrm{M}$. Stock solutions of hydrogen peroxide $\left(\mathrm{H}_{2} \mathrm{O}_{2}, 9.8 \mathrm{mM}\right)$ and aminochrome (as described above) and used at concentrations of 0-200 $\mu \mathrm{M}$, were prepared. An aliquot of $10 \mu \mathrm{L}$ of each protein sample (at $20 \mu \mathrm{M}$ ) was reacted with oxidants at the following concentrations: $0,20,200,500,750,1000,2000 \mu \mathrm{M}$ for $\mathrm{H}_{2} \mathrm{O}_{2}$, and $0,10 \mu \mathrm{M}, 100 \mu \mathrm{M}, 1 \mathrm{mM}, 10 \mathrm{mM}, 100 \mathrm{mM}$, $1000 \mathrm{mM}$ for DTT. Samples were treated for $30 \mathrm{~min}$ at $37^{\circ} \mathrm{C}$ and centrifuged at $21,000 \times g$ for $15 \mathrm{~min}$. The supernatant was transferred to a fresh tube and the remaining pellet was extracted with $10 \mu \mathrm{L}$ of T200 containing either $10 \%$ SDS or $100 \mathrm{mM}$ DTT. The pellets were incubated again for $30 \mathrm{~min}$ at $37^{\circ} \mathrm{C}$ and centrifuged at $21,000 \times g$ for $15 \mathrm{~min}$. Laemmli buffer $(10 \mu \mathrm{L}$, containing $100 \mathrm{mM}$ mercaptoethanol) was added to both the pellet and supernatant fractions and samples were separated by SDS-PAGE and visualized by silver staining. Specific bands of aminochrome-treated wild-type, full-length r-parkin were excised and analyzed by LC-MS/ MS, as described above.

\section{In vitro melanin formation assay}

Recombinant protein samples were first prepared by exchanging the T200e protein buffer $(50 \mathrm{mM}$ Tris, $200 \mathrm{mM}$ $\mathrm{NaCl}$ and $250 \mu \mathrm{M}$ TCEP, $\mathrm{pH} 7.5)$ for T200 (50 mM Tris and $200 \mathrm{mM} \mathrm{NaCl}, \mathrm{pH} 7.5)$ using repeat centrifugations (8 times $4000 \times g$ at $4{ }^{\circ} \mathrm{C}$ for $10 \mathrm{~min}$ ) in Amicon Ultra $10 \mathrm{kDa}$ MWCO filters (Millipore). The protein concentrations were measured and adjusted to $20 \mu \mathrm{M}$ using T200. A $0.067 \mathrm{M}$ sodium phosphate buffer, $\mathrm{pH}$ 6.0, was prepared by adding $33 \mathrm{~mL}$ of $0.1 \mathrm{M}$ sodium phosphate buffer to $17 \mathrm{~mL}$ water and adjusting the $\mathrm{pH}$ using $\mathrm{HCl}$. A stock solution of $100 \mathrm{mM}$ dopamine hydrochloride was prepared in $0.067 \mathrm{M}$ sodium phosphate buffer and stock solutions of $100 \mathrm{mM}$ reduced glutathione and $\mathrm{H}_{2} \mathrm{O}_{2}$ were prepared in T200.

Samples and controls were prepared in $100 \mu \mathrm{L}$ total volume that contained $10 \mu \mathrm{L}$ of protein sample or T200, $10 \mu \mathrm{L}$ of $100 \mathrm{mM}$ dopamine or $0.067 \mathrm{M}$ sodium phosphate buffer, $10 \mu \mathrm{L}$ of $100 \mathrm{mM}$ glutathione or T200 buffer, and $70 \mu \mathrm{L}$ T200. Unless otherwise indicated, the final concentration of protein was $2 \mu \mathrm{M}$ and the final concentration of reagents was $10 \mathrm{mM}$. The samples and controls were plated in triplicate, and absorbance read at 405 and $475 \mathrm{~nm}$ every $90 \mathrm{~s}$ for $1 \mathrm{~h}$ and up to $4 \mathrm{~h}$ (Synergy H1Multi-Mode Plate Reader; Bio Tek).

\section{Immunohistochemistry}

Immunohistochemistry (IHC) was performed on paraffinembedded sections, as previously described [81, 82, 87]. Briefly, prior to antibody incubation, sections were deparaffinized in xylene and successively rehydrated through a series of decreasing ethanol concentration solutions. Endogenous 
peroxidase activity was quenched with $3 \%$ hydrogen peroxide in methanol, followed by a standard citric acid-based antigen retrieval protocol (CitriSolv, Decon Labs) to unmask epitopes. Sections were blocked in $10-20 \%$ goat serum in PBS-Tween (Tween $200.075 \%$ ) to reduce non-specific signal. Sections were incubated overnight at $4{ }^{\circ} \mathrm{C}$ in primary antibodies diluted in 1-5\% goat serum in PBS-T according to the following concentrations: novel anti-parkin $\mathrm{mAbs}$ from Biolegend clones D (BioLegend, A15165-D; 1:250), clone $\mathrm{E}$ (BioLegend, A15165E; 1:2,000), and clone G (1:250), Prk8 (BioLegend, MAB5512; 1:500) as well as anti-LAMP-3/CD63 (Santa Cruz, SC5275; 1:100), antiLC3B (Sigma, L7543-200uL; 1:100), anti-VDAC (MitoScience, MSA03; 1:100). Biotinylated, secondary antibodies (anti-mouse $\operatorname{IgG}(\mathrm{H}+\mathrm{L})$, Vector Labs, BA-9200, and biotinylated anti-rabbit $\operatorname{IgG}(\mathrm{H}+\mathrm{L})$, both made in goat; Vector Labs, BA-1,000) were diluted to 1:225, and sections were incubated for $2 \mathrm{~h}$ at room temperature. The signal was amplified with VECTASTAIN $®$ Elite ${ }^{\circledR}$ ABC HRP Kit (Vector Labs, PK-6100), and visualized via standard diaminobenzidine solution (DAB, $55 \mathrm{mM}$ ), or Vina green (Biocare Medical, BRR807AH), or most frequently by using 'metal enhanced DAB' (Sigma, SIGMAFAST TM DAB with Metal Enhancer D0426). Samples were counterstained with Harris Modified Hematoxylin stain and dehydrated through a series of increasing ethanol concentration solutions and xylene. Permount (Fisher Scientific, SP15-100) was used for mounting and slides processed for IHC were visualized and processed using a Quorum Slide Scanner at the OHRI Imaging Core Facility.

\section{Immunofluorescence and confocal microscopy}

Paraffin-embedded human midbrain sections were stained by routine indirect immunofluorescence (IIF) with the following details. Antigen retrieval was performed in Tris-EDTA buffer $\mathrm{pH} 9.0$ for $10 \mathrm{~min}$. Primary antibodies were incubated overnight at $4{ }^{\circ} \mathrm{C}$. Details for primary antibodies anti-parkin clone E (1:500), anti-LAMP-3 (1:250) are described above. Fourty min-long incubations with the following secondary antibodies were performed: goat anti-mouse alexa fluor 488 (1:200), goat anti-rabbit alexa fluor 594 (1:500). Slides were mounted with fluorescence mounting medium using DAPI. Sections stained for IIF were imaged using a Zeiss LSM 880 AxioObserver Z1 with an Airyscan Confocal Microscope and then processed for further analysis using Zeiss Zen and Fiji software.

\section{Statistical analyses}

Statistical analyses were performed using GraphPad Prism version 6 (GraphPad Software, San Diego, CA, USA, www. graphpad.com). Differences between two groups were assessed using an unpaired $t$-test. Differences among 3 or more groups were assessed using a one-way or two-way ANOVA followed by Tukey's post hoc corrections to identify statistical significance. Select post hoc tests are depicted graphically to visualize significance. For all statistical analyses, a cut-off for significance was set at 0.05 . Data are displayed with $p$ values represented as $* p<0.05, * * p<0.01$, $* * * p<0.001$, and $* * * * p<0.0001$. Linear regression (for the continuous dependent variable, e.g., \% soluble parkin and $\mathrm{H}_{2} \mathrm{O}_{2}$ concentration) was performed using $\mathrm{R}$ version 3.6.0. Furthermore, to address the effect of age on parkin solubility (defined as a dichotomous variable using criteria below), logistic regression and receiver operating characteristic (ROC) curves and area under the ROC curve (AUC) values were calculated using $\mathrm{R}$, as reported [87].

\section{Results}

\section{Parkin solubility declines in the ageing human brain including in the Substantia nigra}

Parkin's biochemistry in the human brainstem vs. other regions of the neuroaxis has remained largely unexplored [73]. We serially fractionated 20 midbrain specimens (ages, 26-82 years) and $>40$ cortices (ages, 5-85 years) from human subjects, which had been collected post mortem (Fig. 1, Supplementary Fig. 1; Supplementary Table 1, online resource). In control brain, we found that before the age of 20 years, nearly $50 \%$ of cortical parkin was found in soluble fractions generated by salt [Tris- $\mathrm{NaCl}$; TS]- and non-ionic detergent [Triton X-100; TX]-containing buffers (Fig. 1a, b; Supplementary Fig. 1a, online resource). In contrast, after age 50 years, parkin was predominantly (>90\%) found in the $2 \%$ SDS-soluble (SDS) fraction and the $30 \%$ SDS extract of the final fractionation pellet (P). The same distribution was seen in adult midbrain (e.g., S. nigra; red nucleus), the pons (e.g., L. coeruleus), and the striatum (Fig. 1a, b; Supplementary Fig. 1a-c, online resource).

Intriguingly, in older individuals (ages, $\geq 50$ years) approximately half of the detectable parkin remained soluble in the human spinal cord and skeletal muscle specimens, which had also been collected post mortem (Fig. 1c, d). We used univariate linear regression analysis to explore a correlation between soluble parkin (of TS- and TX-fractions relative to the total signal for parkin, plotted as \%) and age in human control cortices (Fig. 1e). The regression coefficient of age was -0.54 (at a $95 \%$ confidence interval (CI) of -0.79 to $-0.29, P=7.7 \mathrm{e}^{-05}$ ), where the multiple R-squared value was 0.302 . When defining parkin solubility as a binary variable, i.e., the presence or absence of soluble parkin in TS- and TX-fractions (absent defined as less than $2 \%$ of total 

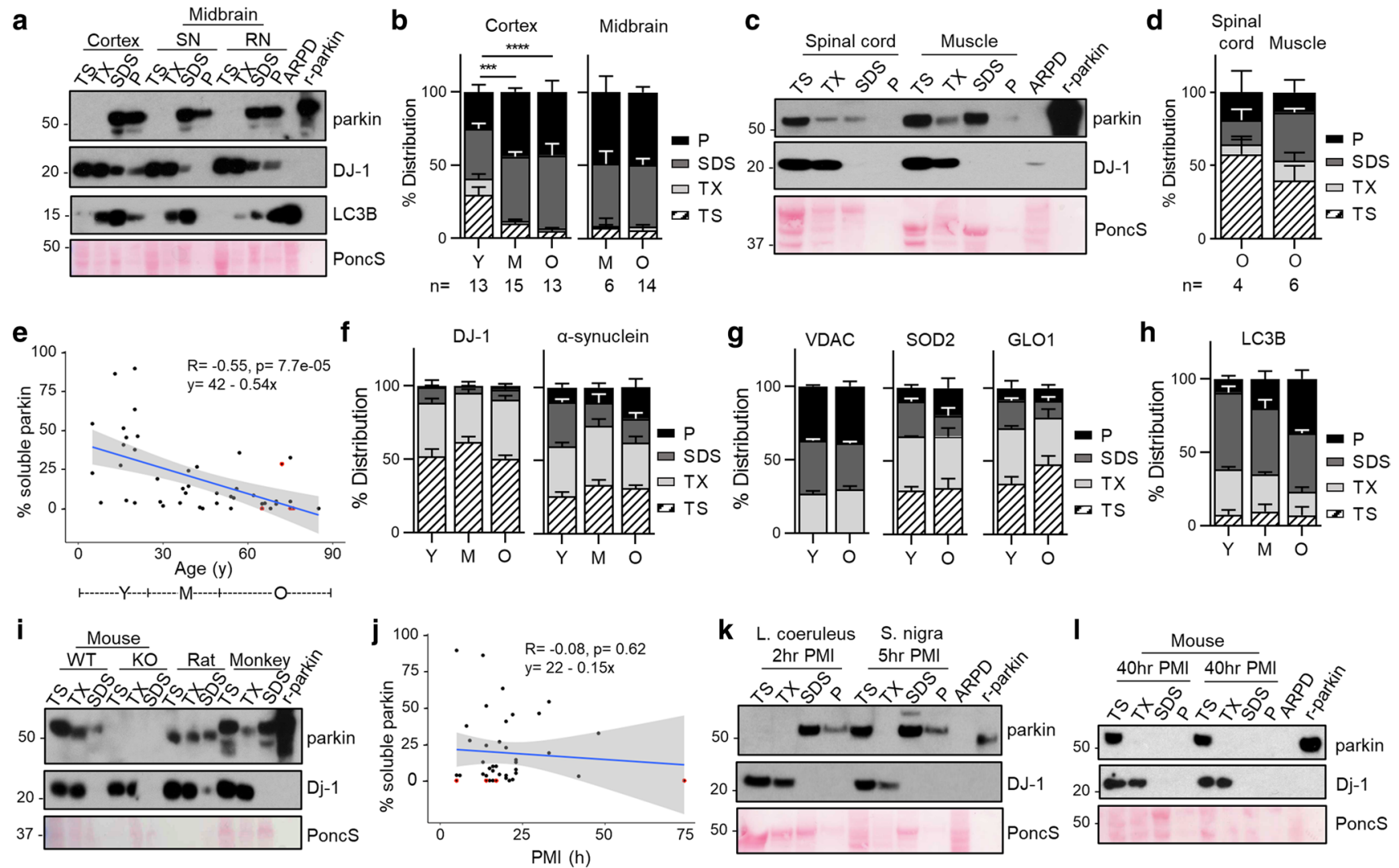

Fig. 1 Parkin's decline in solubility is specific to the adult human brain and correlates with age. a Representative Western blots of parkin, DJ-1, and LC3B distribution in human cortex, S. nigra $(\mathrm{SN})$ and red nucleus $(\mathrm{RN})$ serially fractionated into Tris- $\mathrm{NaCl}$ buffer-soluble (TS), Triton X-100-soluble (TX), 2\% SDS-soluble (SDS) extracts and the pellet $(\mathrm{P})$ lysed in $30 \%$ SDS-containing buffer. SDS extracts from $P R K N$-linked Parkinson disease (ARPD) brain and recombinant, human parkin (r-parkin) are included. Ponceau $\mathrm{S}$ is shown as loading control. b Relative distribution of parkin signal within each fraction for cortex and midbrain grouped by age ranges: young ( $\mathrm{Y} \leq 20$ years; $n=13)$; mid ( $>20$ years but $<50$ years; $n=15$ for cortex, and $n=6$ for midbrain); older $(\mathrm{O} \geq 50$ years; $n=13$ for cortex and $n=14$ for midbrain). Data shown as mean \pm SEM. The significance in protein distribution between soluble (TS + TX) and insoluble (SDS + pellet) fractions was determined using 2-way ANOVA $[F(2,76)=26.21$, $p<0.001]$ with Tukey's post hoc test $(* * * p<0.001$; ****p $<0.0001)$. Additional Western blots are shown in Supplementary Fig. 1a-c, online resource. Midbrains include both control and neurological disease cases, as listed in Supplementary Table 1, online resource. c Western blots of parkin and DJ-1 as well as Ponceau S staining of serial fractions from the representative human spinal cord and skeletal muscle tissues from individuals $\geq 50$ years. d Relative distribution of parkin as in (b) for human spinal cord $(n=4)$ and skeletal muscle specimens $(n=6)$ from donors aged $50-71$ years. e Univariate linear

signal), and using logistic regression analysis, we found that the transition to insoluble parkin occurred between the ages of 28 years (with low sensitivity but high specificity values) and 42 years (with high sensitivity and low specificity values) (data not shown).

regression analysis of parkin solubility in cortices as a function of age $(n=46)$. Each brain is represented by an individual dot; red circles denote three cases of parkinsonism not linked to PRKN; the linear regression line (in blue) and 95\% confidence intervals (grey) are shown. Age ranges that correspond to $\mathrm{Y}-\mathrm{O}-\mathrm{M}$ in (b) are shown under the graph. Age coefficient was -0.54 (95\% CI: -0.79 to -0.29 , $\left.P=7.7 \mathrm{e}^{-05}\right) . \mathbf{f}-\mathbf{h}$ Relative distribution of $\mathbf{f} \mathrm{DJ}-1, \alpha$-synuclein and $\mathbf{g}$ VDAC, MnSOD, glyoxalase (GLO1) and $\mathbf{h}$ LC3B in human cortices ( $n=3-5$ per age group), as described in (b). Representative Western blots are shown in Supplementary Fig. 1b, c, online resource. i Western blots of parkin and $\mathrm{Dj}-1$ and Ponceau $\mathrm{S}$ staining of serial fractions from whole brains of wild-type (WT; 8 months of age) and prkn knock-out (KO) mice, WT rat (WT; 14 months) and from frontal cortex of a cynomolgus monkey (60 months). $\mathbf{j}$ Univariate linear regression analysis of parkin solubility in human brain as a function of length for post mortem interval (PMI; in hours); the linear regression line (in blue) and 95\% confidence intervals (grey) are shown ( $n=41$ cortices). $\mathbf{k}$ Western blots of parkin and DJ-1 distribution in two human brainstem nuclei, L. coeruleus and S. nigra, which were collected within $2-5 \mathrm{~h}$ after death prior to freezing and processed as in (a, c). 1 Immunoblots for endogenous parkin and $\mathrm{Dj}-1$ as well as Ponceau S staining from serially extracted WT mouse brains $(n=3)$ dissected after a $40 \mathrm{~h}$ post mortem interval. Note, Western blots shown in this figure followed SDS/PAGE under reducing conditions

This age-dependent partitioning of parkin was not seen for any other protein examined, including two other PD-linked proteins, i.e., DJ-1 and $\alpha$-synuclein (Fig. 1a, f), or for organelle-associated markers, e.g., cytosolic glyoxalase-1, peroxiredoxin-1 and -3; and endoplasmic reticulum-associated calnexin. Notably, mitochondrial 
markers, e.g., voltage-dependent anion channel (VDAC) and $\mathrm{Mn}^{2+}$-superoxide dismutase (MnSOD), also did not partition with parkin (Fig. 1g; Supplementary Fig. 1b, c, online resource; and data not shown). In contrast, parkin did co-distribute with LC3B, a marker of protein aggregation, foremost in brain specimens from older individuals (Fig. 1a, h; Supplementary Fig. 1c, online resource).

The age-associated loss in parkin solubility appeared unique to the human brain in that it remained predominantly soluble in the adult nervous system of other species, e.g., mice and rats as well as cynomolgus monkey, which were processed in the same way (Fig. 1i). Specifically, in brain lysates of two different wild-type strains of mice (C57Bl/6J, and a mixed 129S//FVB/N//C57B1/6J background) aged to 18 and 22 months respectively, parkin remained present in the soluble fraction throughout their lifespan (Supplementary Fig. 1d, online resource; and data not shown).

In soluble fractions from older humans, we did not detect any truncated species of parkin using several, specific antibodies (data not shown). Despite the loss of parkin solubility with progression in age, $P R K N$ mRNA was detectable in individual neurons isolated from the $S$. nigra and cortex throughout all age groups; there, transcript levels in neurons did not correlate with the subject's age (Supplementary Fig. 1e, f, online resource).

Our analysis comprised samples with post mortem intervals (PMI) that spanned from 2 to $74 \mathrm{~h}$ (Supplementary Table 1, online resource). Using univariate linear regression analysis, we detected no correlation between parkin solubility in human control cortices $(n=41)$ and PMI length, where the regression coefficient for PMI measured -0.15 (95\% CI: -0.76 to $0.46, P=0.62$ ), and the multiple R-squared value was 0.0064 (Fig. 1j). As expected, PMI did not correlate with the age of the deceased person (not shown). Likewise, wild-type parkin was found to be largely insoluble in striatal, midbrain and pontine samples isolated from aged subjects with PMIs as short as 2 to 6 h (Fig. 1k; Supplementary Fig. 2a, b, online resource). We further explored a possible contribution of PMI to parkin solubility by mimicking conditions of some of the human autopsy cases, using adult mice. This included a PMI length of up to $40 \mathrm{~h}$, where animals were kept at room temperature for the first $14 \mathrm{~h}$, followed by storage over $26 \mathrm{~h}$ at $4{ }^{\circ} \mathrm{C}$ before removal of their brain; in these cases, parkin remained in the soluble compartments (Fig. 11 and data not shown). While we cannot exclude that PMI length could affect parkin's solubility in some cases, the age-dependent loss of parkin solubility observed in human brain samples of our cohort was not due to the PMI.

Further, we determined that the decline in detectable parkin solubility in the aged human brain did not differ based on the sex of the deceased person, such as when examined by univariate linear regression analysis or by multivariate analysis (data not shown); it was also not caused by either tissue freezing prior to protein extraction or the $\mathrm{pH}$ value of the buffer (Supplementary Fig. 2c-f, online resource). Moreover, employing the commonly used 'RIPA buffer' instead of our serial extraction buffers resulted in the release of parkin into the supernatant with some reactivity left in the pellet, as expected (Supplementary Fig. 2g, online resource).

\section{Decline in parkin solubility correlates with rising hydrogen peroxide levels in the mammalian brain}

We next explored a possible association between parkin distribution, age and oxidative changes. Using sister aliquots from the brain specimens examined above, we found that hydrogen peroxide $\left(\mathrm{H}_{2} \mathrm{O}_{2}\right)$ concentrations positively correlated with age (Fig. 2a, b; see also Supplementary Table 1, online resource), as expected from the literature [54]. Using univariate linear regression analysis, we determined that the coefficient of age was 0.067 (95\% CI: 0.035 to 0.098 , $P=3 \mathrm{e}^{-04}$; multiple R-squared value, 0.4877).

In three brains from subjects with non- $P R K N$-linked parkinsonism, the levels of $\mathrm{H}_{2} \mathrm{O}_{2}$ were similar to those measured in age-matched controls (Fig. 2b). When analyzing parkin distribution vs. $\mathrm{H}_{2} \mathrm{O}_{2}$ concentrations in human cortices, we found that parkin solubility in human brain negatively correlated with $\mathrm{H}_{2} \mathrm{O}_{2}$, where the coefficient of the latter was -4.2 (95\% CI: -7.92 to $-0.48, P=0.029$; multiple R-squared value, 0.2174) (Fig. 2c).

We next sought to dynamically model the observed correlation between higher ROS levels in the nervous system and reduced parkin solubility. We first used an ex vivo approach, whereby wild-type mouse brains were exposed to either saline or $\mathrm{H}_{2} \mathrm{O}_{2}$ during tissue homogenization. There, we saw a significant reduction in soluble parkin and an increase in insoluble parkin in the $\mathrm{H}_{2} \mathrm{O}_{2}$-exposed lysates (Fig. 2d, e). We next examined two in vivo models. In the first, wildtype mice were intraperitoneally injected with $40 \mathrm{mg} / \mathrm{kg}$ of 1-methyl-4-phenyl-1,2,3,6-tetrahydropyridine (MPTP) toxin one hour before sacrificing them to induce acute oxidative stress, but no cell death [3]. Brains were serially fractionated, and parkin distribution was quantified across soluble and insoluble compartments. There, we measured a decrease of murine parkin in the soluble fraction and a corresponding rise in the insoluble fractions of MPTP- vs. saline-injected littermates (Fig. 2f, g).

In the second in vivo model, we observed a similar, significant shift in parkin distribution toward insolubility in adult mice that were haploinsufficient for the Sod2 gene, which encodes mitochondrial MnSOD, and which occurred in the absence of an exogenous toxin (Fig. 2h, i). Of note, in both models we confirmed the expected rise in $\mathrm{H}_{2} \mathrm{O}_{2}$ levels (see below and El-Kodsi et al. [17]). Moreover, in contrast to murine parkin, the solubility of 
a

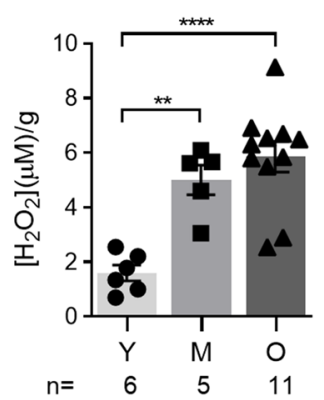

b

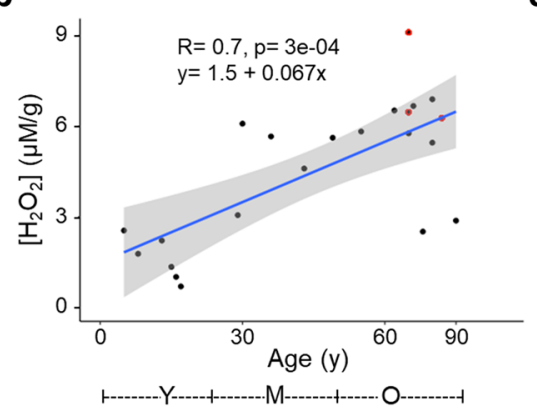

C

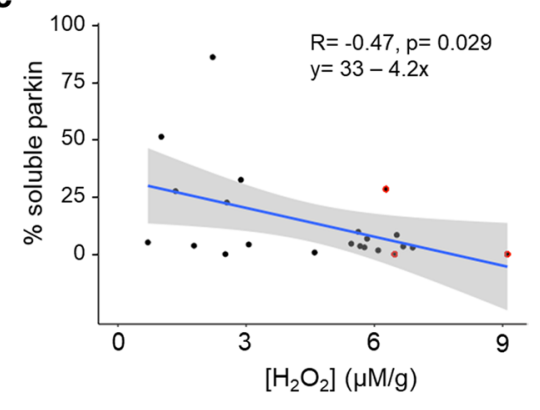

d

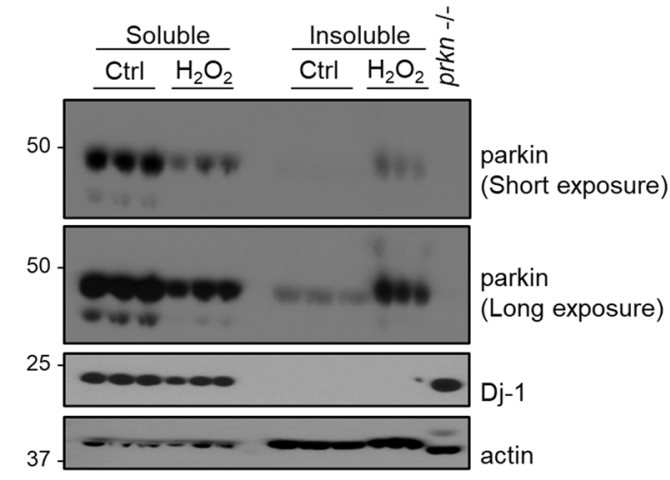

$\mathbf{f}$

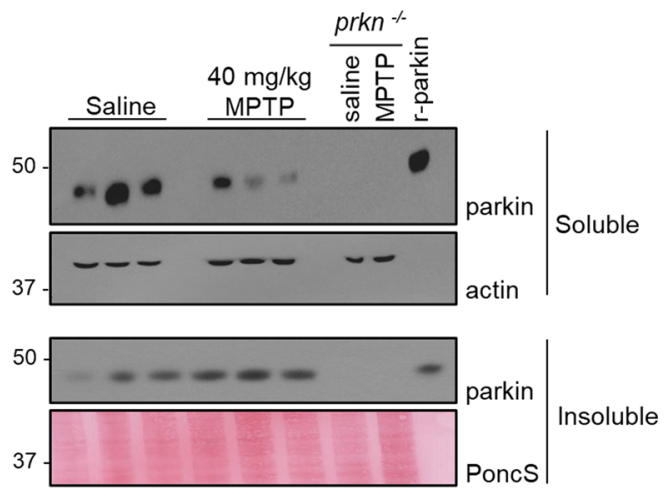

h

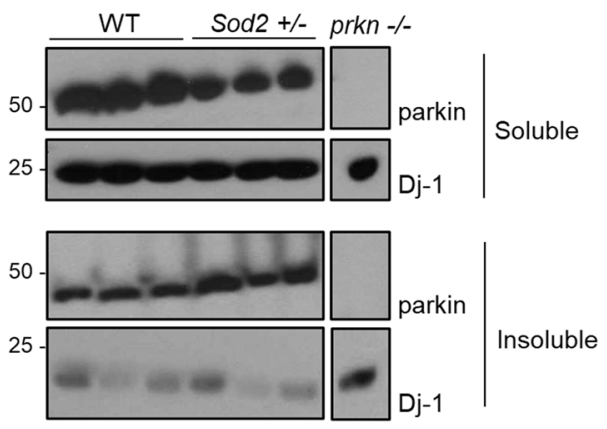

e

Soluble

Insoluble

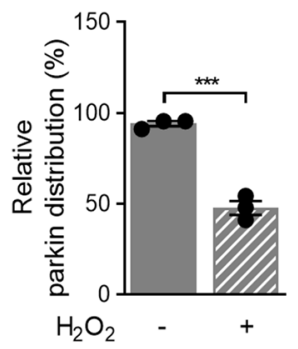

g

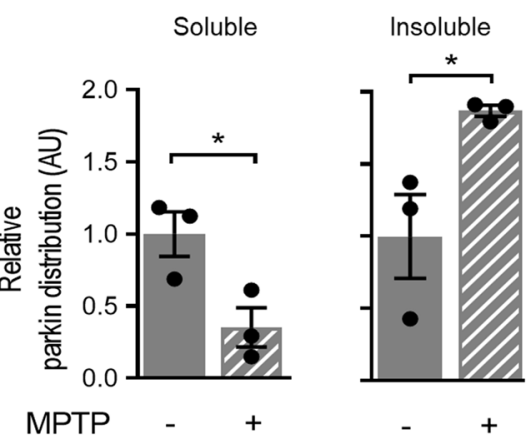

i

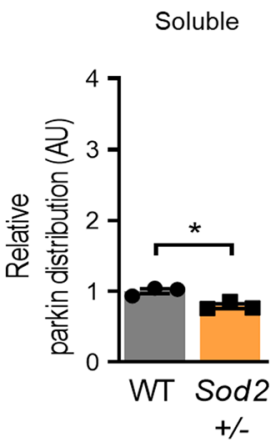

endogenous Dj-1, which is encoded by a second, ARPDlinked gene, was not visibly altered under these elevated oxidative stress conditions, as monitored by SDS/PAGE/ Western blotting (Fig. 2h).
Parkin is reversibly oxidized in the adult human brain

The correlation between parkin insolubility and $\mathrm{H}_{2} \mathrm{O}_{2}$ levels in the human brain suggested to us that the relation could be 
4Fig. 2 Decline in parkin solubility correlates with a rise of oxidative stress in mammalian brain. a Mean concentrations of $\mathrm{H}_{2} \mathrm{O}_{2}$ in human brain cortices grouped by age range, as described in Fig. 1. Individual data points represent separate brains, as reported in Supplementary Table 1, online resource. Results are plotted as mean \pm SEM; significance was determined using 2-way ANOVA $[F(2,76)=26.21$, $p<0.001$ ] with Tukey's post hoc test $(* * p<0.01$; ***p $p<0.001)$. b-c Linear regression analysis of $\mathrm{H}_{2} \mathrm{O}_{2}$ concentrations in control cortices ( $\mu \mathrm{M} / \mathrm{g}$ tissue) as a function of age (b), and $\mathbf{c}$ linear regression analysis of parkin solubility as a function of $\mathrm{H}_{2} \mathrm{O}_{2}$ levels in the same specimens $(n=22)$. Red circles denote three disease cortices (non$P R K N$-linked parkinsonism). $\mathrm{H}_{2} \mathrm{O}_{2}$ concentration coefficient (in (c)) was -4.2 (95\% CI: -7.92 to $-0.48, P=0.0287)$. d-e Western blots (d) of parkin distribution in brain lysates of 2-4 month-old wild-type $\mathrm{C} 57 \mathrm{Bl} / 6 \mathrm{~J}$ mice containing either saline or $1 \% \mathrm{H}_{2} \mathrm{O}_{2}$; e parkin signal distribution was quantified using ImageJ, as controlled for respective loading controls, in both soluble and insoluble fractions. A student $\mathrm{t}$-test was used for statistical analysis $\left({ }^{*} p<0.05\right)$. f, $\mathbf{g}$ Western blots $\mathbf{f}$ of parkin distribution in brains of wild-type C57B1/6 J mice $1 \mathrm{~h}$ following intraperitoneal administration of either saline or MPTP neurotoxin $(40 \mathrm{mg} / \mathrm{kg})$; $\mathbf{g}$ parkin signals were quantified as in (e). $\mathbf{h}-\mathbf{i}$ Western blots $\mathbf{h}$ of fractionated brain homogenates from C57B1/6 J wild-type and $\operatorname{Sod} 2^{ \pm}$mice; $\mathbf{i}$ parkin signals were quantified and statistically analyzed as in $(\mathbf{e})\left({ }^{*} p<0.05\right)$. Note, Western blots shown in this figure followed SDS/PAGE under reducing conditions

due to posttranslational, oxidative modifications. Indeed, in contrast to SDS-containing brain fractions analyzed under reducing conditions (+DTT), when gel electrophoresis was performed under non-reducing (-DTT) conditions, we detected parkin proteins ranging in $M_{r}$ from $>52$ to $270 \mathrm{kDa}$, invariably in the form of redox-sensitive, high molecular weight (HMW) smears (right vs. left panel; Fig. 3a). We saw the same pattern in fractions prepared from control midbrains; no such reactivity was seen in SDS-extracts of parkin-deficient ARPD brains, thus demonstrating the specificity of protein detection.

We confirmed that reversible oxidation of brain parkin was also present in soluble (TS-, TX-) fractions, albeit at lesser intensities (Fig. 3b; data not shown). Of note, the formation of high $M_{r}$ parkin was not due to secondary oxidation in vitro, because specimens had been processed and fractionated in the presence of iodoacetamide (IAA) prior to SDS/ PAGE in order to protect unmodified thiols. These HMW parkin smears also did not arise from covalent ubiquitinconjugation, such as due to auto-ubiquitylation of parkin, owing to the fact that such adducts cannot be reversed by reducing agents (e.g., DTT) (data not shown).

Because we predicted that the loss of parkin solubility was due to thiol-based, posttranslational oxidation events [50], we first sought to test this in vitro using purified, tag-less, full-length, recombinant (r-) parkin. There, we observed the $\mathrm{H}_{2} \mathrm{O}_{2}$ dose-dependent formation of $\mathrm{HMW}$ smears and loss of parkin solubility; however, r-parkin protein solubility was greatly recovered by adding DTT (Fig. 3c; Supplementary Fig. 3a, online resource) or $\beta$-mercaptoethanol (not shown). Demonstrating its sensitivity to bi-directional redox forces, the exposure of native r-parkin to excess DTT also rendered it increasingly insoluble (Supplementary Fig. 3b, online resource), likely due to loss of zinc-sulfur chelation in its four RING domains [31, 47]. Unlike r-parkin, the addition of up to 1 M DTT in the extraction buffer did not induce parkin's extraction into a soluble phase (i.e., TS- or TX-fractions) in aged human brain tissue (Supplementary Fig. 3c, online resource).

We confirmed by mass spectrometry (MS) of the holoprotein carried out without any trypsin digestion that all 35 cysteine-based thiol groups of human r-parkin are principally accessible to alkylation by IAA (right $v s$. left panel; Supplementary Fig. 3d, online resource). These results unequivocally demonstrated that each parkin cysteine theoretically possesses the capacity to have its thiol be modified. Nevertheless, in these in vitro experiments we consistently observed a concentration-dependent change in r-parkin solubility, thereby suggesting that some thiols were more amenable than others to modification by reactive species (see below and summary in Supplementary Table 2, online resource).

\section{Oxidative conditions alter parkin structure}

The progressive insolubility of brain parkin and r-parkin due to redox stress suggested that the protein had undergone structural changes. Indeed, when we analyzed the effects of spontaneous oxidation using native r-parkin by far-UV-circular dichroism (Fig. 3d), soluble fractions initially contained both $\alpha$-helically ordered as well as unstructured r-parkin proteins. Five days later, r-parkin preparations were separated by centrifugation and fractions re-analyzed. There, we found a marked shift to increased $\beta$-pleated sheet-positive r-parkin in insoluble fractions (Fig. 3d). Similarly, when we monitored r-parkin during spontaneous oxidization using dynamic-light scattering (Supplementary Fig. 3e, online resource), we observed a gradual shift in the hydrodynamic diameter from $5.1 \mathrm{~nm}$, representing a folded monomer, to multiple peaks with larger diameters $5 \mathrm{~h}$ later. The latter indicated spontaneous multimer formation, which was partially reversed by the addition of DTT (right panel; Supplementary Fig. 3e, online resource). Thus, these structural and solubility changes of r-parkin were congruent with our immunoblot results for human brain parkin (Fig. 3a). 
a

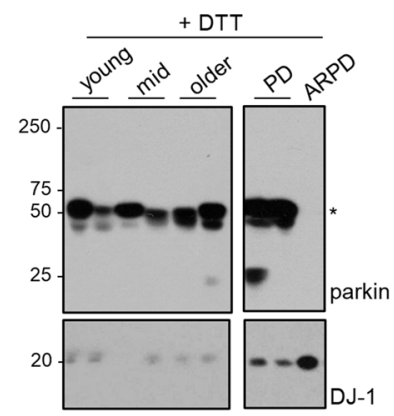

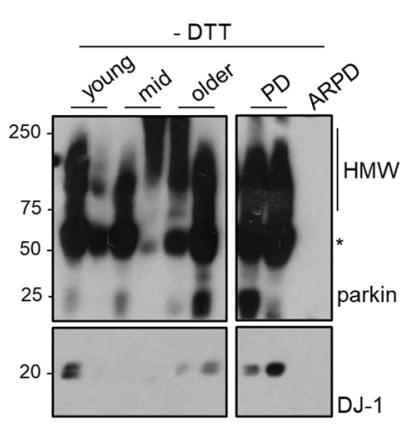

b

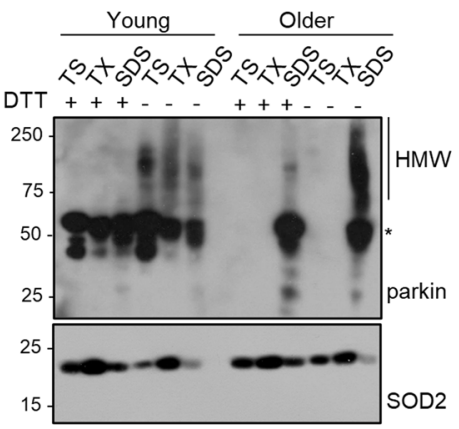

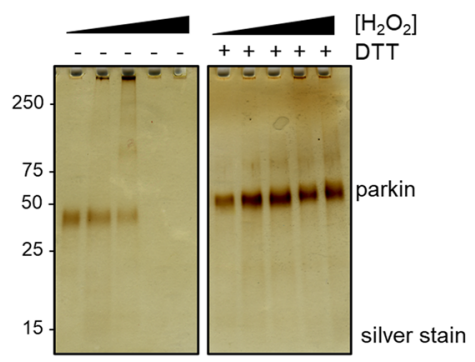

d

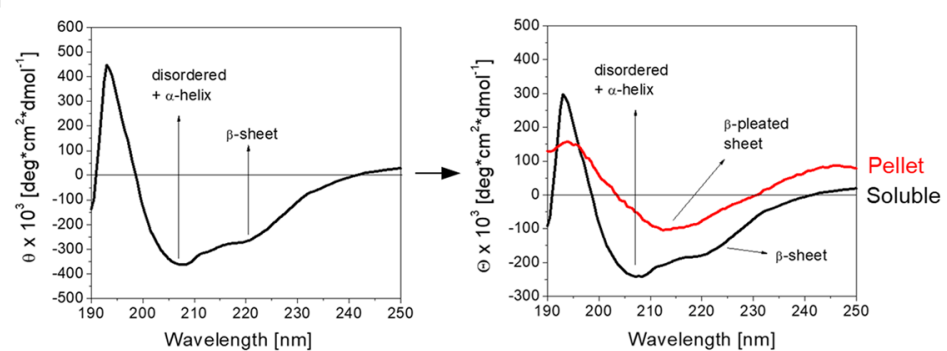

e

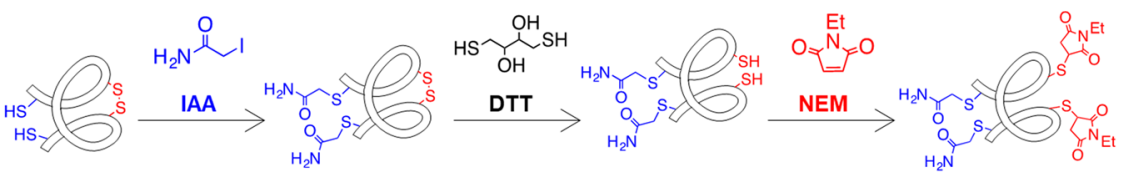

h

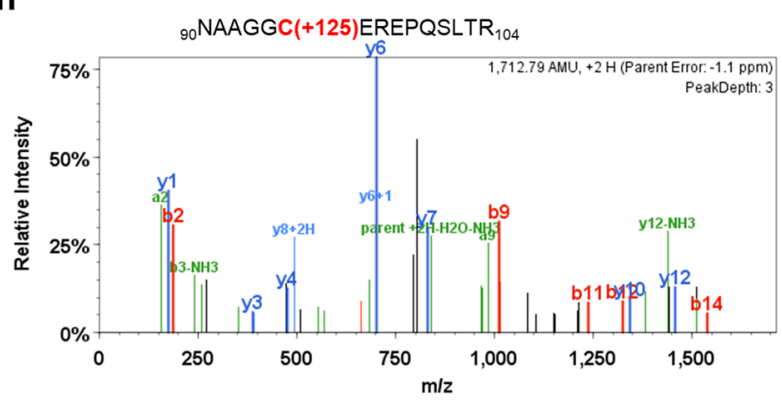

Fig. 3 Parkin's solubility and structure are altered by oxidative modifications. a Western blots of parkin and DJ-1 in SDS fractions from normal cortices ( 3 age groups are shown) and two age-matched patients, i.e., idiopathic Parkinson's (PD) and parkin-deficient ARPD. Sister aliquots of the same lysates were processed in parallel by SDSPAGE either under reducing (+DTT) or non-reducing (-DTT) conditions. b Western blots of parkin and SOD2 distribution in serially fractionated human cortices from a young individual (age, 5 years) and an adult (62 years) subject, and separated by SDS-PAGE under reducing (+DTT) and non-reducing (-DTT) conditions. c Silver staining of the supernatant of sister aliquots of r-parkin following initial exposure to increasing concentrations of $\mathrm{H}_{2} \mathrm{O}_{2}(0-2 \mathrm{mM})$ followed by the addition (or absence of) DTT $(100 \mathrm{mM})$ prior to centrifugation as indicated. d Circular dichroism spectra of soluble, untreated, wild-type r-parkin at the start of experiment $(T=0$; left panel), and spectra of soluble (black line) and aggregated (red line) states following incubation at $37{ }^{\circ} \mathrm{C}$ for $T=5$ days (right panel). e
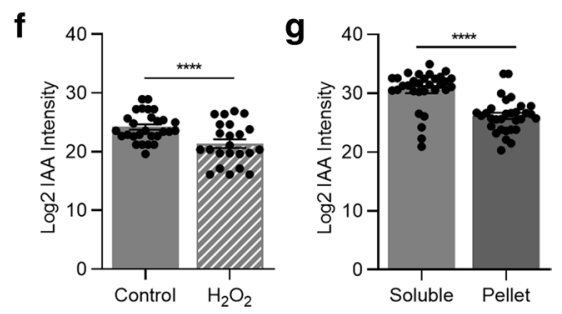

i

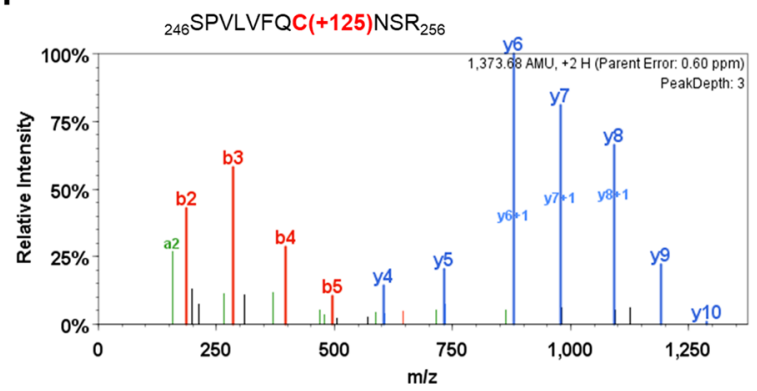

Graphic depiction of strategy for LC-MS/MS-based analysis to identify cysteine oxidation state for untreated and $\mathrm{H}_{2} \mathrm{O}_{2}$-treated, parkin species, by using IAA-DTT-NEM fingerprinting to identify reduced cysteines with an iodacetamide (IAA) tag or reversibly-oxidized residues with a $N$-ethylmaleimide (NEM) tag. f, g Quantitative analyses of IAA-modified cysteines captured by LC-MS/MS for $\mathbf{f}$ untreated vs. $\mathrm{H}_{2} \mathrm{O}_{2}$-exposed, wild-type, human r-parkin, and g soluble compared to insoluble (pellet) fractions. Each dot represents the $\log 2-$ transformed total IAA-signal intensities of individual cysteines $(n=3$ runs for each). The cysteine pool is shown with the mean $\pm S E M$; significance $* * p<0.01$, as determined using Student $T$-Test. $\mathbf{h}-\mathbf{i}$ LCMS/MS-generated spectra following trypsin digestion of labelled, oxidized r-parkin indicating NEM adducts $(+125$ mass gain) at Cys95 and Cys253; r-parkin was exposed to $\mathrm{H}_{2} \mathrm{O}_{2}$, and cysteines labelled as in (e). See Supplementary Table 2, online resource, for a complete list of modified cysteines and oxidizing conditions 


\section{Hydrogen peroxide modifies parkin at multiple cysteines}

To determine whether the oxidation of cysteines and/or methionine residues caused parkin insolubility, we analysed r-parkin that was treated with and without $\mathrm{H}_{2} \mathrm{O}_{2}$ and/or thiol-alkylating agents using liquid chromatography-based MS (LC-MS/MS). To differentiate reduced from oxidized cysteines we used a serial thiol-fingerprinting approach, which labelled reduced thiols with IAA, and tagged reversibly oxidized thiols with $N$-ethylmaleimide (NEM) after their prior reduction with DTT (Fig. 3e). The first test was to determine how progressive oxidation affected thiol accessibility. As expected, using the strong alkylating agent IAA on the nascent protein (and trypsin digestion to map individually modified peptides), we confirmed that the majority of parkin cysteines were reactive (Supplementary Fig. 3d; Supplementary Table 2, online resource). Intriguingly, when treating native r-parkin with lower $\mathrm{H}_{2} \mathrm{O}_{2}$ concentrations, we identified an average of 19 cysteines (54.3\%) to be modified; in contrast, higher $\mathrm{H}_{2} \mathrm{O}_{2}$ concentrations increased this number to 32 cysteines $(91.4 \%)$. These results suggested progressive unfolding of r-parkin with increasing oxidation (Supplementary Table 2, online resource).

Next, we sought to precisely identify the location of oxidized cysteine residues. Using Scaffold PTM-software, we found a rise in the number of oxidized residues (NEMCys, range of 3-26), which was proportional to the increase in $\mathrm{H}_{2} \mathrm{O}_{2}$ concentrations and appeared to begin in parkin's RING1 domain at three residues, i.e., Cys238, Cys241 and Cys253 (Supplementary Table 2, online resource; Fig. 3i), but also involved Cys95 in its linker domain (Fig. 3h). Furthermore, when quantifying thiol modifications by MaxQuant software [10], we found a significant drop for the number of cysteines in the reduced state (IAA-cysteines) within the $\mathrm{H}_{2} \mathrm{O}_{2}$-treated samples $(P=0.0016$; Fig. $3 \mathrm{f})$, as expected.

In accordance, when comparing cysteine oxidation events in soluble and insoluble fractions of untreated $v s$. oxidized r-parkin preparations, the number of IAA-Cys was significantly decreased in the pellets $(P<0.0001$; Fig. $3 \mathrm{~g})$. Of note, modifications at methionine residues did not correlate with r-parkin solubility. These collective results unequivocally demonstrated that $\mathrm{H}_{2} \mathrm{O}_{2}$-induced oxidation events at cysteine-based thiols are linked to both progressive, structural change and lesser solubility of human r-parkin.

\section{Parkin is also irreversibly oxidized in adult human and mouse brains}

We next sought to identify oxidation events at parkin cysteines in vivo by LC-MS/MS. To this end, we examined both cortex-derived, human parkin and brain parkin isolated from intraperitoneally, MPTP toxin- (vs. saline-) treated mice (Fig. 4). Specimens were processed with IAA during homogenization and fractionation to prevent any oxidation artefacts in vitro. Following immunoprecipitation and gel excision of endogenous parkin at the $50-53 \mathrm{kDa}$ range (an example is shown in Supplementary Fig. 4a, b, online resource), we focused on cysteine mapping and the identification of thiol redox states (Fig. 4a). A graphic representation of theoretically possible, thiol-based redox modifications is provided in Supplementary Fig. 4c, online resource).

In human control cortices $(n=12$ runs; summarized in Fig. 4a), we mapped a mean of 46.8 and $19.4 \%$ of parkin's wild-type sequence in the soluble and insoluble fractions, respectively. There, we found cysteines in either a redox reduced state (IAA-alkylated Cys +57 ; examples shown in Fig. 4b, d) or in oxidized states (e.g., to sulfonic acid Cys + 48). Irreversible oxidation events in human cortices occurred, for example, at Cys95 (Fig. 4c) and Cys253 (Fig. 4e). The relative frequencies of detection for parkin thiols that were found in a reduced state in vivo (and thus, were alkylated by IAA in vitro) in the soluble $v s$. insoluble fractions of the human brain were 67.3 vs. $38.1 \%$, respectively (Fig. 4a).

Likewise, in saline- and MPTP-treated mouse brains ( $n=6$ runs), we mapped 25.0 and $51.5 \%$ of wild-type parkin, respectively (summarized in Fig. 4a). Interestingly, akin to the findings in the human brain, we identified the murine sequence-corresponding residue Cys 252 in either a reduced or in irreversibly oxidized states (Fig. 4f, g). As mentioned, mice do not carry a cysteine at residue 95 (for sequence comparison, see below). The relative frequencies of detection for thiols that were in a reduced state in vivo (and thus, alkylated by IAA in vitro) in parkin from saline- vs. MPTP toxin-treated mouse brains were 92.9 vs. $68.2 \%$, respectively (Fig. 4a). These collective results demonstrate that parkin cysteines are variably oxidized in adult mammalian brain.

\section{Parkin thiols reduce hydrogen peroxide in vitro}

A typical redox reaction involves the reduction of an oxidized molecule in exchange for the oxidation of the reducing agent (examples are shown in Supplementary Fig. 4c, online resource). We, therefore, asked whether parkin oxidation resulted in a reciprocal reduction of its environment (Fig. 5; Supplementary Fig. 5, online resource). Using r-parkin, we established that parkin could reduce $\mathrm{H}_{2} \mathrm{O}_{2}$ levels in a concentration-dependent manner in vitro (Fig. 5a; Supplementary Fig. 5h, online resource). This reducing activity was not enzymatic, in that it did not mirror the dynamics of catalase, and r-parkin did not possess peroxidase activity (Fig. 5a; Supplementary Fig. 5a, online resource). Rather, the reaction was dependent on parkin's thiol integrity, because pre-treatment with NEM (or IAA) and pre-oxidation of the protein 
a

\begin{tabular}{ccccc}
\hline & \multicolumn{2}{c}{ Human Brain } & \multicolumn{2}{c}{ Mouse Brain } \\
\hline & TSS-extractable & SDS-extractable & Saline & MPTP \\
Mean (range) & (IP, $\mathbf{n = 4 )}$ & (IP, $\mathbf{n = 8})$ & (IP, $\mathbf{n = 3})$ & (IP, $\mathbf{n}=3)$ \\
\% Parkin protein coverage & $46.8(35-72)$ & $19.4(2-58)$ & $25.0(23-27)$ & $51.5(33-70)$ \\
\# Peptides identified & $15.0(10-23)$ & $6.4(1-17)$ & 11.0 & $22.5(18-27)$ \\
\# Cysteines identified & $17.5(13-26)$ & $6.1(1-16)$ & $6.5(6-7)$ & $18.0(10-26)$ \\
\# Reduced residues (=IAA-Cys) & $17.5(13-26)$ & $6.1(1-16)$ & $6.5(6-7)$ & $15.0(8-22)$ \\
IAA / total \# Cys identified & $17.5 / 26$ & $6.1 / 16$ & $6.5 / 7$ & $15.0 / 22$ \\
\% of above & 67.3 & 38.1 & 92.9 & 68.2 \\
\hline
\end{tabular}

b

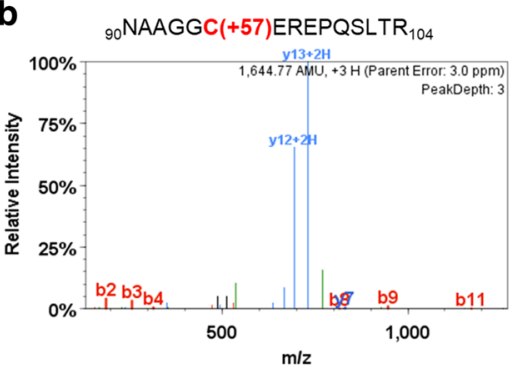

C

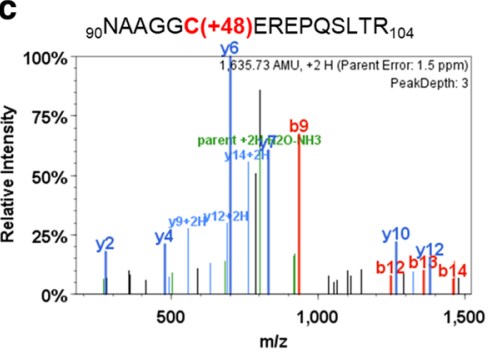

d

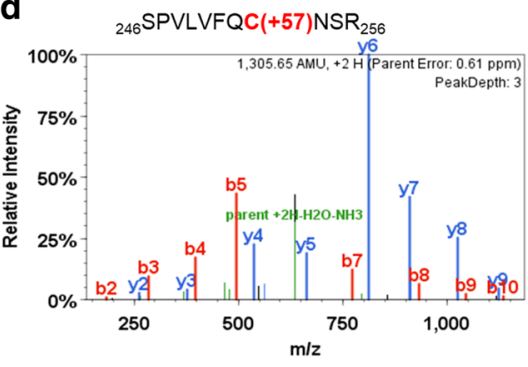

e

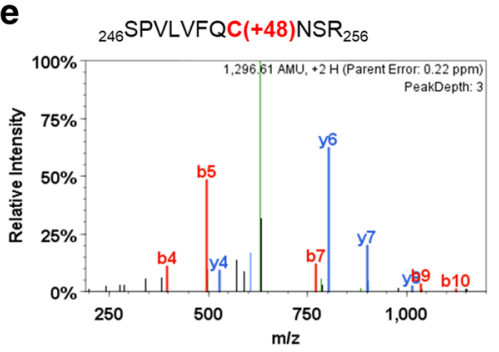

f ${ }_{245} \mathrm{SPVLVFQC}(+57) \mathrm{NHR}_{255}$

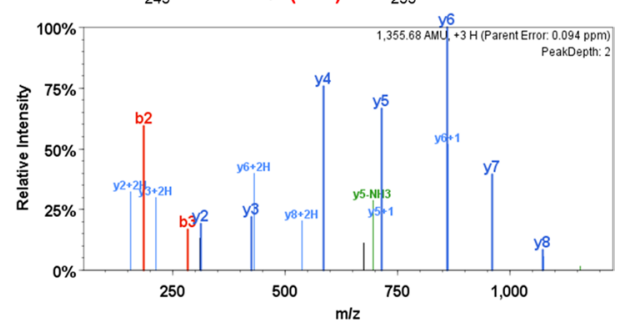

g

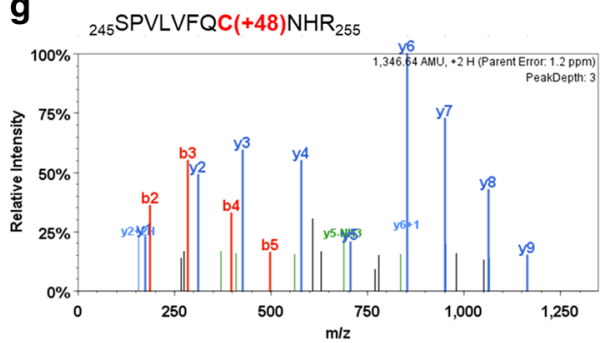

Fig. 4 Select parkin cysteine residues are oxidized in human and mouse brain. a Summary of results for 12 immunoprecipitation (IP) runs (TS extracts; $n=4$; SDS extracts, $n=8$ ) from human cortices and either saline- or acute $(1 \mathrm{~h})$ MPTP toxin-treated murine brain (as described in Fig. 2d, e) for endogenous parkin enrichment to identify the redox state of its cysteine residues (see also $\mathbf{b}-\mathbf{g}$ ). All specimens were fractionated in the presence of IAA. b-g Among the redox active residues identified Cys95 and Cys 253 in human brain parkin were found in either a reduced redox state (b, d) (i.e., IAAlabelled; +57 mass gain) or (c, e) in irreversibly oxidized states, e.g., to sulfonic acid (trioxidation; +48 mass). In mouse brain parkin (f, g), Cys252 was found either reduced or oxidized as well with $\mathrm{H}_{2} \mathrm{O}_{2}$ abrogated the ROS-reducing activity of r-parkin (Fig. 5b; Supplementary Fig. 5b, g, online resource). It thus appeared similar to the effect of glutathione (Fig. 5a; Supplementary Fig. 5a, e, f, online resource).

The anti-oxidant effect by r-parkin was also dependent on its intact $\mathrm{Zn}^{2+}$ coordination, because increasing concentrations of the divalent ion chelator, EDTA, abrogated the activity; the latter could be ameliorated by supplementing the reaction buffer with zinc (Supplementary Fig. 5c, online resource). As expected, the exposure of r-parkin to excess $\mathrm{H}_{2} \mathrm{O}_{2}$ (or excess DTT) led to the release of zinc ions from the nascent recombinant protein, as measured in vitro (Supplementary Fig. 5d, online resource).

Interestingly, RNF43 (a distinct E3 ligase that contains a zinc-finger domain), HOIP (an E3 ligase containing a RING domain) and bovine serum albumin (BSA, which akin to parkin has 35 cysteines), did not show any $\mathrm{H}_{2} \mathrm{O}_{2}$-lowering capacity (Fig. 5c, d; Supplementary Fig. 5e, online resource). Further, Parkinson's-linked $\alpha$-synuclein, which has no cysteines, also had no reducing effect (Fig. 5c, d). These results suggested that the cysteine-rich, primary sequence and the tertiary structure of r-parkin conferred anti-oxidant activity.

We next examined an additional, cysteine-containing, ARPD-linked protein, e.g., r-DJ-1 and two disease-linked variants of full-length r-parkin, p.G328E and p.C431F, as well as a C-terminal RING2-peptide of parkin (r-parkin $_{321 \mathrm{C}}$ ). We also used a second ROS quantification assay for further validation and to expand our dose-dependency studies (Fig. 5e, Supplementary Fig. 5f-m, online resource). There, r-DJ-1 and r-parkin ${ }_{321 \mathrm{C}}$ showed negligible $\mathrm{H}_{2} \mathrm{O}_{2}$-lowering capacity, and the two point-mutants conferred less activity than did wild-type, human r-parkin (Fig. 5e). As expected from typical redox reactions (Supplementary Fig. 4c, online resource), the lowering of ROS in vitro correlated with reciprocal r-parkin oxidation, as revealed by SDS/PAGE, which was performed under 


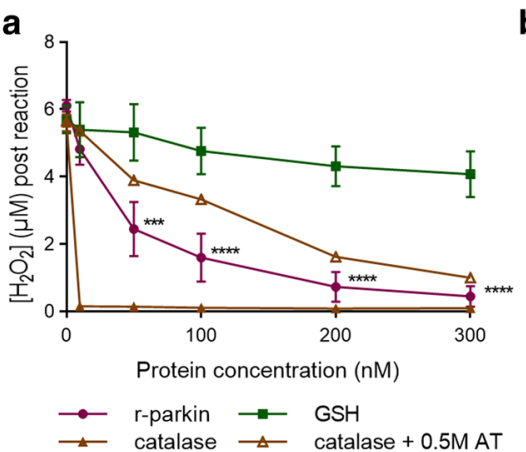

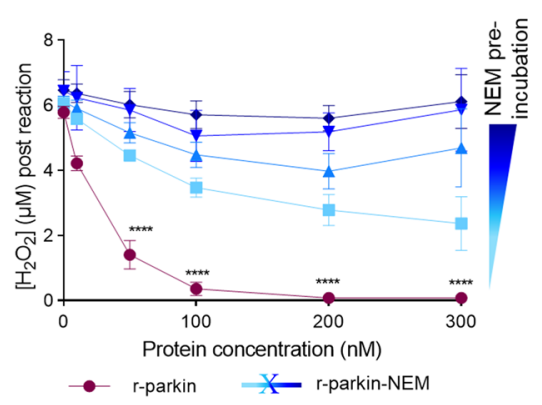

C

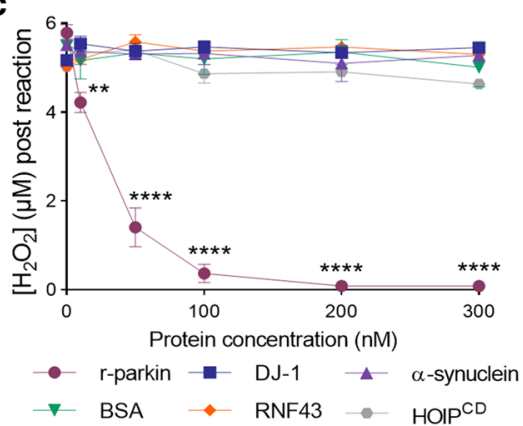

d

\begin{tabular}{ccccc}
\hline Protein & $\begin{array}{c}\text { Total } \\
\text { aa }\end{array}$ & Cys & $\begin{array}{c}\text { Cys } \\
\%\end{array}$ & $\begin{array}{c}\text { Met } \\
\%\end{array}$ \\
\hline parkin & 465 & 35 & 7.5 & 1.5 \\
a-synuclein & 140 & 0 & 0.0 & 2.9 \\
DJ-1 & 189 & 3 & 1.6 & 2.6 \\
BSA & 607 & 35 & 5.8 & 0.8 \\
RNF43 & 783 & 26 & 3.3 & 1.3 \\
HOIP $^{C D}$ & 373 & 27 & 7.2 & 1.9 \\
\hline
\end{tabular}

h

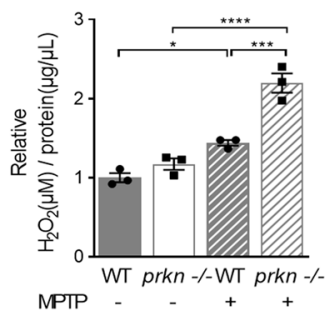

e

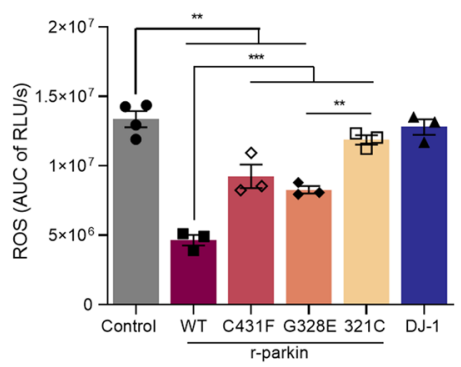

i

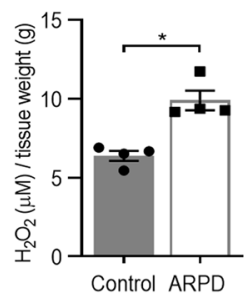

j
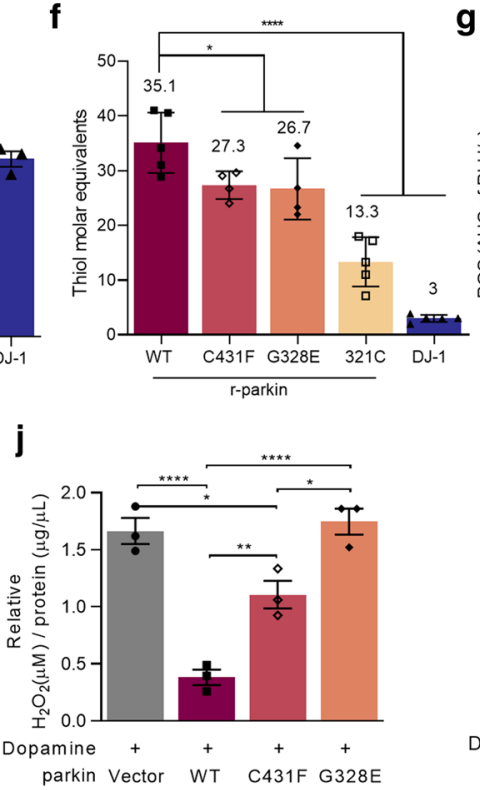

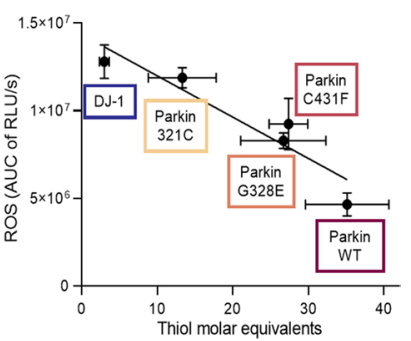

k

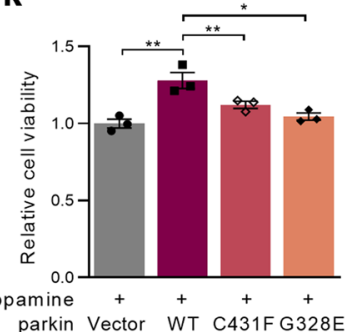

Fig. 5 Wild-type parkin lowers hydrogen peroxide in vitro, in cells and the brain. a-c Quantification of $\mathrm{H}_{2} \mathrm{O}_{2}$ concentration using AmplexRed, demonstrating (a) full-length, human, recombinant (r-) parkin when incubated with $\mathrm{H}_{2} \mathrm{O}_{2}$ is able to reduce it in a r-parkin concentration-dependent manner. Effects of r-Parkin were compared to catalase and GSH at equimolar concentrations as well as following partial inhibition of catalase by amino-triazole (AT), as indicated. b Pre-incubation of r-parkin with a thiol-conjugating compound (NEM) inhibits parkin-dependent $\mathrm{H}_{2} \mathrm{O}_{2}$ reduction in a NEM-concentration-dependent manner. c Reducing capacity of wild-type r-parkin compared to two other, PD-linked proteins (DJ$1 ; \alpha$-synuclein), bovine serum albumin (BSA) and two RING-carrying ubiquitin ligases (RNF43; HOIP ${ }^{\mathrm{cd}}$; $\mathrm{cd}=$ catalytic domain). Their respective cysteine and methionine contents are summarized in (d). Two-way ANOVA with Tukey's post hoc test $(* * p<0.01$, $* * * p<0.001$, and $* * * * p<0.0001)$ was used for statistical analysis a $[F(15,48)=5.069, p<0.0001] ; \mathbf{b}[F(20,60)=3.966, p<0.0001]$; and $\mathbf{c}[F(25,72)=22.91, p<0.0001]$. e Area under the curve (AUC) plots for results from in vitro colorimetric assays, where AUC integrates total $\mathrm{H}_{2} \mathrm{O}_{2}$ levels measured over the time course of the assay (see also Supplementary Fig. 5f, online resource). Comparison of WT r-parkin with DJ-1, two r-parkin point mutants, and r-parkin $321-465$ (321C). Results represent $n=3 \pm \mathrm{SD}$ using one-way ANOVA [ $F$ $(7,17)=99.87, p<0.0001]$ with Tukey's post hoc test $* p<0.05$,
$* * p<0.01, * * * p<0.001$, and $* * * * p<0.0001$. f Quantification of reactive thiol content (in molar equivalents) for r-parkin (WT; two point mutants; 321C) and full-length r-DJ-1 using the Ellman's reagent assay. Results analyzed by one-way ANOVA $[F(4,18)=45.11$, $p<0.0001]$. g Correlation curve between number of free thiols (f) vs. the $\mathrm{H}_{2} \mathrm{O}_{2}$-reducing capacity (e) for indicated proteins with $R^{2}=0.8789$. h-i Quantification of $\mathrm{H}_{2} \mathrm{O}_{2}$ levels in (h) saline vs. MPTP toxin-treated prkn wild-type (WT) and $\mathrm{prkn}^{-1-}$ mouse brain $(n=3 /$ genotype/condition), and $\mathbf{i}$ in human brain from parkin-deficient ARPD cortices compared to age- and post-mortem interval-matched controls ( $n=4 /$ group) collected at the same institution. Results are represented as the mean concentration of $\mathrm{H}_{2} \mathrm{O}_{2}(\mu \mathrm{M})$ per total protein concentration $(\mu \mathrm{g} / \mu \mathrm{L})$ or tissue weight $(\mathbf{g})$ analyzed $\pm \mathrm{SEM}$; ${ }^{*} p<0.05, * * * p<0.001$, and $* * * * p<0.0001$ determined using a Student $T$-test or one-way ANOVA with Tukey's post hoc test; $[F$ (3, $8)=45.41, p<0.0001]$. j, $\mathbf{k ~} \mathrm{H}_{2} \mathrm{O}_{2}$ quantification (j) and cell viability assay (k) for dopamine-treated, human M17 cells expressing either WT or two ARPD-linked parkin point mutants, as indicated relative to treatment with vehicle alone. Cells were exposed to $200 \mu \mathrm{M}$ dopamine or vehicle for $20 \mathrm{~h}$, as indicated. Data points represent the mean of duplicates \pm SEM ( $n=3$ experiments); $* p<0.05$ and $* * p<0.01$, and $* * * * p<0.0001$ by one-way ANOVA with Tukey's post hoc test: $\mathbf{j}[F(3,8)=35.34, p<0.0001] ;$ and $\mathbf{k}[F(3,8)=12.92, p=0.0020]$ 
non-reducing conditions immediately after the reaction with $\mathrm{H}_{2} \mathrm{O}_{2}$ (Supplementary Fig. 5n, online resource).

These results suggested that the anti-oxidant activity by r-parkin was dependent on its reactive thiol content, which we examined next using the Ellman's reagent. There, fulllength r-parkin, r-parkin ${ }_{321 \mathrm{C}}$ and r-DJ-1 showed the predicted number of reactive thiols, whereas the single point-mutant variants of r-parkin revealed fewer accessible thiols (Fig. 5f). From these results, we observed a linear correlation between thiol equivalencies and the degree of ROS reduction in vitro, demonstrating that a greater number of readily reactive and/ or a greater number of accessible thiols in human parkin proteins corresponded with a more effective lowering of $\mathrm{H}_{2} \mathrm{O}_{2}$ (Fig. 5g).

\section{Hydrogen peroxide levels are increased in parkin-deficient brain}

To explore whether parkin oxidation conferred ROS reduction in vivo, we first quantified $\mathrm{H}_{2} \mathrm{O}_{2}$ concentrations in the brains of wild-type and $\mathrm{prkn}^{-1-}$ mice. A trend, but no significant difference, was measured under normal redox equilibrium conditions. However, when analyzing brain homogenates from mice treated with MPTP-toxin $v s$. saline, carried out as above (Fig. 2), we found significantly higher $\mathrm{H}_{2} \mathrm{O}_{2}$ levels in the brains of adult $\mathrm{prkn}^{-/-}$mice compared to wild-type littermates $(P<0.001$; Fig. 5 h). Similarly, in adult humans $\mathrm{H}_{2} \mathrm{O}_{2}$ levels were significantly increased in the cortex of $P R K N$-linked ARPD patients $v s$. age-, PMI-, ethnicity- and brain region-matched controls [42] $(P<0.05$; Fig. 5i). Specimens of three non- $P R K N$-linked patients with parkinsonism showed $\mathrm{H}_{2} \mathrm{O}_{2}$ levels comparable to those from age-matched normal cortices (Fig. 2b, red circles). We concluded that the expression of wild-type PRKN alleles contributes to the lowering of ROS concentrations in adult, mammalian brain.

\section{Parkin prevents dopamine toxicity in cells in part by lowering hydrogen peroxide}

To address the question of selective neuroprotection, we revisited the role of parkin in cellular dopamine toxicity studies [51, 104]. We first tested parkin's effect on ROS concentrations in dopamine-synthesizing, human M17 neuroblastoma cells. There, dopamine exposure of up to $24 \mathrm{~h}$ caused a significant rise in endogenous $\mathrm{H}_{2} \mathrm{O}_{2}(P<0.05$; Fig. 5j), as expected. Wild-type $P R K N$ cDNA expression effectively protected M17 cells against the dopamine stress-related rise in $\mathrm{H}_{2} \mathrm{O}_{2}$ levels $(P<0.0001$; Fig. 5j). By comparing sister cultures that expressed similar amounts of exogenous parkin proteins, the E3 ligase-inactive p.C431F mutant had a partial rescue effect, whereas p.G328E, which we confirmed to retain its E3 ligase activity in vitro, showed no $\mathrm{H}_{2} \mathrm{O}_{2}$-lowering capacity in these cells (Fig. 5j; and data not shown).

Moreover, only wild-type parkin, but none of the mutant variants tested, increased the viability of M17 cells under rising dopamine stress conditions $(P<0.01$; Fig. $5 \mathrm{k}$; and data not shown). This protective effect also correlated with parkin insolubility and its HMW smear formation, as expected from previous studies [51]. These posttranslational changes in M17-expressed parkin were not reversible by DTT or SDS (Supplementary Fig. 6a, b, online resource), thereby suggesting irreversible dopamine-adduct formation. Notably, the protection from dopamine toxicity positively correlated with the level of PRKN cDNA transcribed, as confirmed in sister lines of M17 cells that stably express human, wild-type parkin. There, we estimated that $\sim 4 \mathrm{ng}$ of parkin protein expressed in healthy, neural cultures neutralized each $\mu \mathrm{M}$ of dopamine added during up to $24 \mathrm{~h}$ (Supplementary Fig. 6c, d, online resource).

\section{Parkin binds dopamine radicals predominantly at primate-specific cysteine 95}

We next explored which thiols of parkin were involved in the neutralization of dopamine radicals. Covalent conjugation of RES metabolites at parkin residues had been previously suggested [51, 104], but not yet mapped by LC-MS/ MS examining the whole protein. Aliquots of r-parkin were exposed to increasing levels of the relatively stable dopamine metabolite aminochrome. As expected, this led to the loss of protein solubility and HMW species formation at the highest dose tested (Fig. 6a, b). These reaction products were then used to map modified residues by LC-MS/ MS. Specifically, proteins corresponding to r-parkin monomer (51-53 kDa) and two HMW bands, one at $\sim 100 \mathrm{kDa}$, the other near the loading well, were gel-excised (Fig. 6a), trypsin digested and analyzed.

There, we made the following four related observations: (i) Increasing aminochrome concentrations led to a significant decline in the total number of spectra readily identified by LC-MS/MS as parkin-derived peptides, both in the monomeric and HMW bands $(P<0.001$ and $P<0.0001)$, respectively (Fig. 6c). This indicated to us either a marked loss in solubility (and thus, lesser accessibility by trypsin) or a rise in heterogenous, complex modifications, which rendered the analyte undetectable by LC-MS/MS, or both; (ii) Despite fewer spectra recorded, we identified a significant increase in the number of oxidized cysteines (such as irreversibly modified to sulfonic acid) following aminochrome exposure, in particular within the HMW bands of r-parkin $(P<0.0001$; Fig. 6d); (iii) Under these conditions, four distinct forms of dopamine metabolites were found conjugated to parkin cysteines. Mass shifts of $+145,+147,+149$ and +151 were identified, which represented covalent 

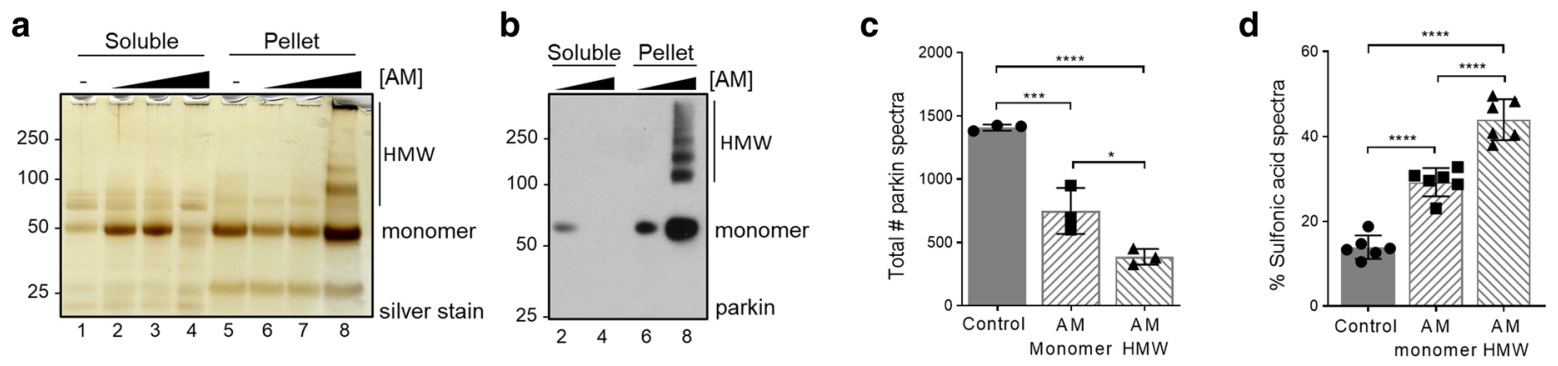

e

\begin{tabular}{|c|c|c|c|c|c|c|c|c|}
\hline Peptide Sequence & Variable Modifications & $\begin{array}{c}\text { Observed } \\
\mathrm{m} / \mathrm{z}\end{array}$ & $\begin{array}{c}\text { Spectrum } \\
\text { Charge }\end{array}$ & $\begin{array}{c}\text { Actual } \\
\text { Peptide Mass } \\
\text { (AMU) }\end{array}$ & $\begin{array}{c}\text { Peptide } \\
\text { Identification } \\
\text { Probability } \\
\end{array}$ & $\begin{array}{c}\text { Mascot } \\
\text { lon } \\
\text { Score }\end{array}$ & $\begin{array}{l}\text { Scaffold } \\
\text { Peptide } \\
\text { Score }\end{array}$ & Quantity \\
\hline 76 KGQEmNATGGDDPRNAAGGcEREPQSLTR 104 & M80 Oxidation (+16), C95 Indolequinone (+145) & 802.3541 & 4 & $3,205.39$ & $99.40 \%$ & 28.2 & 29.55 & 1 \\
\hline 76 KGQEmNATGGDDPRNAAGGcEREPQSLTR 104 & M80 Oxidation (+16), C95 Aminochrome (+147) & 802.8554 & 4 & $3,207.39$ & $99.70 \%$ & 33.3 & 41.69 & 5 \\
\hline 76 KGQEmNATGGDDPRNAAGGcEREPQSLTR 104 & M80 Oxidation (+16), C95 Aminochrome (+149) & 642.8917 & 5 & $3,209.42$ & $97.40 \%$ & 27.7 & 18.71 & 1 \\
\hline 76 KGQEmNATGGDDPRNAAGGcEREPQSLTR 104 & M80 Oxidation (+16), C95 Dopamine Quinone (+151) & 803.8625 & 4 & $3,211.42$ & $97.80 \%$ & 28.4 & 64.11 & 1 \\
\hline 90 NAAGGCEREPQSLTR 104 & C95 Indolequinone (+145) & 867.388 & 2 & $1,732.76$ & $99.70 \%$ & 59.5 & 130.03 & 57 \\
\hline 90 NAAGGCEREPQSLTR 104 & C95 Aminochrome (+147) & 579.2650 & 3 & $1,734.77$ & $99.70 \%$ & 37.3 & 87.17 & 29 \\
\hline 90 NAAGGCEREPQSLTR 104 & C95 Dopamine Quinone (+151) & 580.6098 & 3 & $1,738.81$ & $99.50 \%$ & 27.7 & 72.14 & 4 \\
\hline 162 LRVQcSTCRQATLTLTQGPSCWDDVLIPNR 191 & C166 Aminochrome (+149), C169 Cys->Dha (-34) & 1164.2490 & 3 & $3,489.73$ & $99.30 \%$ & 83.9 & 42.91 & 3 \\
\hline 162 LRVQcSTcRQATLTLTQGPScWDDVLIPNR 191 & C166 Aminochrome (+149), C169 Dopamine Quinone (+151), C182 Cys->Dha (-34) & 1214.6033 & 3 & $3,640.79$ & $99.20 \%$ & 31.4 & 25.73 & 1 \\
\hline 164 VQcSTcRQATLTLTQGPScWDDVLIPNR 191 & $\begin{array}{l}\text { C166 Aminochrome (+149), C169 Dopamine Quinone (+151), C182 Indolequinone } \\
\qquad(+145)\end{array}$ & 888.4120 & 4 & $3,549.62$ & $99.50 \%$ & 32 & 11.71 & 1 \\
\hline 212 cGAHPTSDKETSVALHLIATNSRNITCITCTDVR 245 & C212 Dopamine Quinone (+151), C238 Dopamine Quinone (+151) & 1310.9731 & 3 & $3,929.90$ & $99.10 \%$ & 27.8 & 19.84 & 2 \\
\hline 235 NITCITCTDVRSPVLVFQCNSR 256 & C238 Indolequinone (+145), C241 Cys $>$ Dha (-34), C253 Trioxidation (+48) & 1314.6143 & 2 & 2,627.21 & $99.20 \%$ & 26.3 & 38.93 & 1 \\
\hline 276 QFVHDPQLGYSLPcVAGcPNSLIK 299 & C289 Cys->Dha $(-34)$, C293 Indolequinone $(+145)$ & 899.7746 & 3 & $2,696.30$ & $99.70 \%$ & 38.1 & 45.87 & 1 \\
\hline $\begin{array}{l}350 \text { VTcEGGNGLGcGFAFcREcKEAYHEGECSAVFEA } \\
\text { SGTTQAYR } 392\end{array}$ & $\begin{array}{c}\text { C352 Cys->Dha (-34), C360 Aminochrome (+147), C365 Cys->Dha }(-34), \text { C } 368 \\
\text { Trioxidation (+48), C377 Trioxidation (+48) }\end{array}$ & 1179.4941 & 4 & $4,713.95$ & $98.40 \%$ & 27.2 & 14.08 & 1 \\
\hline $\begin{array}{l}350 \text { VTcEGGNGLGcGFAFcREcKEAYHEGECSAVFEA } \\
\text { SGTTQAYR } 392\end{array}$ & $\begin{array}{c}352 \text { Cys }->\text { Dha }(-34), \text { C } 360 \text { Cys }->\text { Dha }(-34), \text { C } 365 \text { Indolequinone }(+145), \text { C } 368 \\
\text { Trioxidation }(+48), \text { C377 Trioxidation }(+48)\end{array}$ & 1178.9937 & 4 & $4,711.95$ & $96.10 \%$ & 29.3 & 11.1 & 1 \\
\hline
\end{tabular}

f

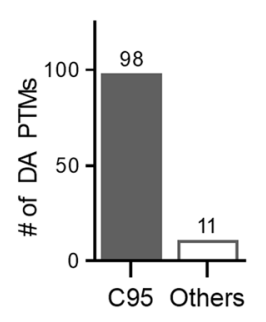

g

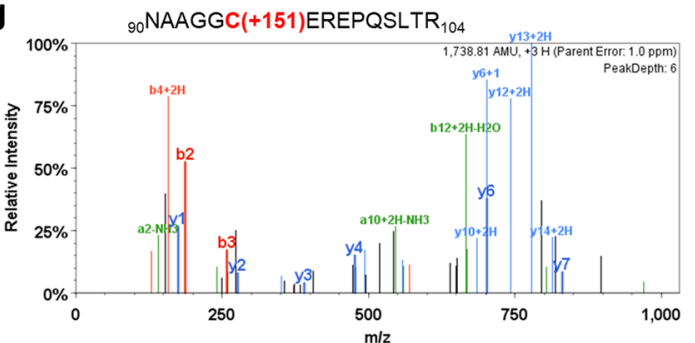

h

Human 90 NAAG G CEREPQSLTR 104 Chimpanzee 90 NAAG G CREPQSLTR 104 Gorilla 90 NAAG G CERPQSLTR 104 Macaque 90 NAAGGCEREPQSLTR 104 Rat 90 S TPEG S I WEPR S LTR 104 Mouse 90 STSEG S I WESRSLTR 104 Fruit fly 120 P S LS D EASKP L . - 130
Fig. 6 Human parkin conjugates dopamine radicals foremost at residue Cys95. a, b Silver staining (a) and Western blot (b) of r-parkin in soluble (supernatant) and insoluble (pellet) phases following exposure to increasing concentrations of aminochrome (AM; 0-200 $\mu \mathrm{M}$ ) and analyzed under non-reducing conditions. See lane number for corresponding samples. c Mean total number of parkin spectra, as identified by LC-MS/MS following trypsin digestion, of control vs. monomeric vs. high molecular weight (HMW), AM-modified r-parkin. Data represent the mean of $n=3$ runs \pm SEM. $* p<0.05$; $* * * p<0.001 ; * * * * p<0.0001$ by one-way ANOVA with Tukey's post-hoc test $[F(2,6)=64.73, p<0.0001]$. d Percentage of peptides carrying a sulfonic acid modification in control vs. monomeric and HMW, AM-modified r-parkin. Each point represents one gel specimen submitted to MS. The percentage was calculated using only the subset of peptides that were ever detected as carrying a sulfonic acid modification. Statistics were done as in (c) $[\mathbf{F}(2,15)=96.87$,

attachment by indole-5,6-quinone, two variants of aminochrome $(\mathrm{O}=; \mathrm{HO}-)$, and dopamine quinone itself, respectively (Fig. 6e; Supplementary Fig. 7a, online resource); and (iv) Unexpectedly, we identified in Cys95 the most $p<0.0001]$. e Table summarizing LC-MS/MS-based detection of adducts representing dopamine metabolites conjugated to cysteines identified in human r-parkin following exposure to aminochrome in vitro. Chemical structures for identified cysteine-conjugated adducts are shown in Supplementary Fig. 7b, online resource. Individual quantification of each peptide with adduct listed is shown on the right side of the table. f Frequency of occurrences for dopaminemetabolite adducts being detected on Cys95 vs. all other cysteine residues, as detected by LC-MS/MS and individually shown in (e). $\mathbf{g}$ LC-MS/MS-generated spectrum following trypsin digestion of AMexposed r-parkin highlighting a dopamine $(+151$ mass gain) adduct covalently bound to Cys 95 . See also Supplementary Fig. 7c-p, online resource, for additional spectra. $\mathbf{h}$ Species comparison for wild-type parkin proteins covering sequence alignment of aa90-104, with primate-specific residue Cys95 highlighted in red

frequently dopamine-conjugated parkin residue $(P<0.0001$; $n=98$ spectra; Fig. 6e-g; Supplementary Fig. $7 \mathrm{~b}-\mathrm{g}$, online resource). Other residues of r-parkin, which we identified to carry any one of the dopamine metabolites we tracked, 
included Cys166, Cys169, Cys182, Cys212, Cys238, Cys293, Cys360 and Cys365, but at a much lesser frequency (Fig. 6e, f; Supplementary Fig. 7h-o, online resource). No dopamine metabolite-related mass shifts were detected in the control samples that had not been exposed to aminochrome, as expected. We noted with interest that residue Cys95 of wild-type parkin, as the most frequently catalogued one to be modified by dopamine metabolites, is also primate sequence-specific (Fig. 6g, h).

\section{Parkin augments melanin formation in vitro, which involves residue cysteine 95}

The oxidation of dopamine in the presence of cysteine-containing proteins, which generates covalent adduct-carrying proteins, underlies structural characteristics during the formation of neuromelanin pigment in the human midbrain (and pons), of which biochemical aspects have been modeled ex vivo [18, 19]. Given the observed relations between r-parkin, dopamine radical conjugation, aggregate formation and protein insolubility, we next examined whether melanin formation was altered by the presence of parkin. Indeed, wild-type r-parkin augmented total melanin formation in a protein concentration- and timedependent manner in vitro (Fig. 7a). Like the wild-type protein, two ARPD-linked, full-length r-parkin variants, p.C431F and p.G328E, also augmented melanin formation in vitro, when monitored over $60 \mathrm{~min}$, whereas r-DJ-1 and BSA showed no effect under these conditions (Fig. 7b). a

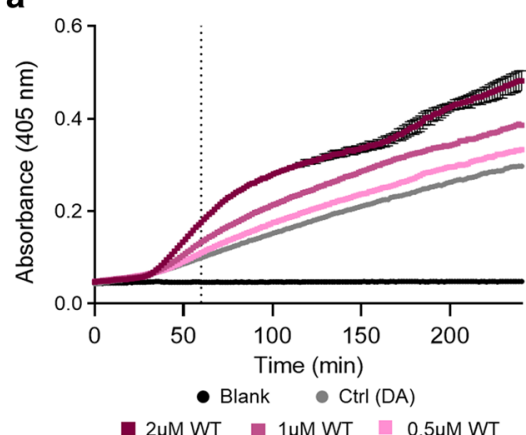

b

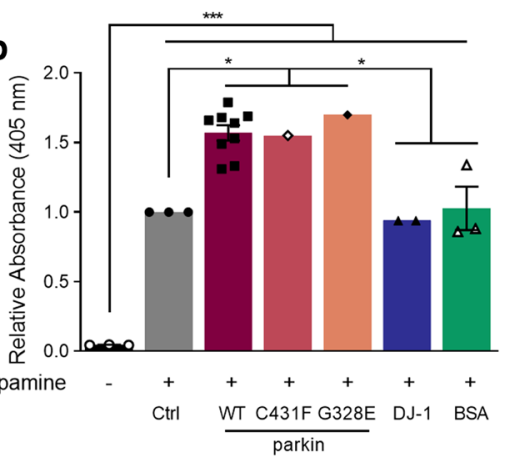

C

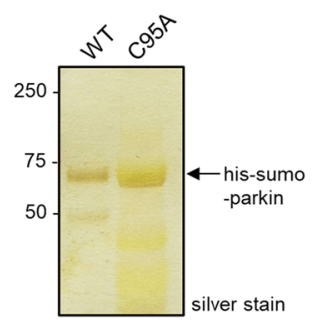

d

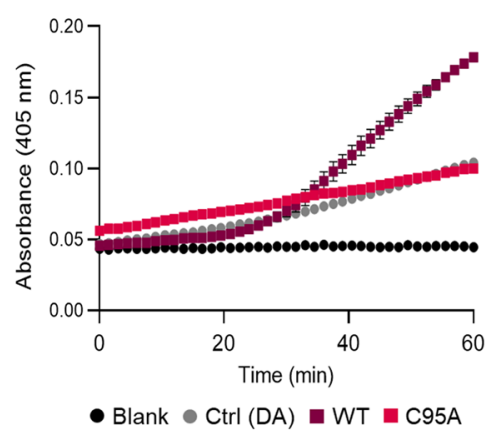

e

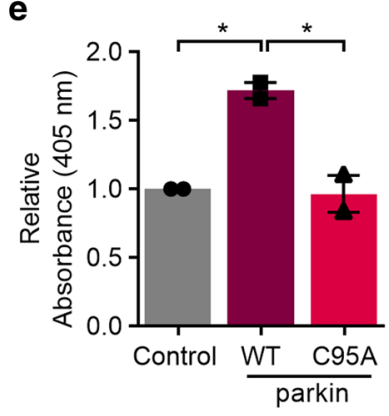

f

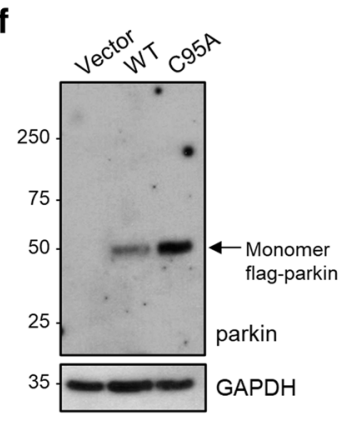

g

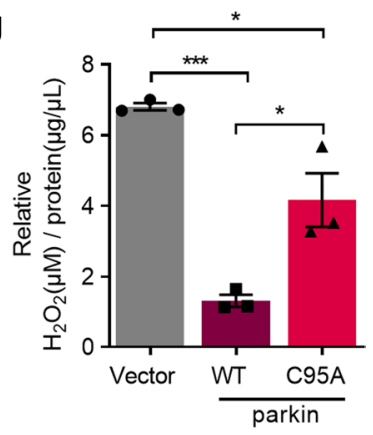

Fig. 7 Parkin-dependent increase in melanin formation involves residue cysteine 95. a Kinetic curve of melanin production (read at absorbance $405 \mathrm{~nm}$ ) over time in the absence of exogenous protein (dopamine (DA Ctrl) alone) vs. increasing molar concentrations of wild-type (WT), full-length human r-parkin shown for three concentrations $(0.5,1,2 \mu \mathrm{m})$. Each condition was performed in triplicate. b Total melanin formation for indicated recombinant proteins at $60 \mathrm{~min}$, as expressed relative to its production under dopamine only control (Ctrl) condition. Data represent the mean of triplicates \pm SEM. $* * * p<0.05$ by 1 -way ANOVA with Tukey's post-hoc test $[F(6,15)=40.05, p<0.0001]$. c Silver gel for the analysis of HisSUMO-tagged, full-length, human r-parkin proteins of wild-type sequence and its variant carrying a p.C95A mutation. SDS/PAGE was performed under reducing conditions. d, e Representative kinetic curve for melanin production (d) and relative total melanin formation at $60 \mathrm{~min}(\mathbf{e})$, where production in the presence of wild-type (WT) or p.C95A mutant r-parkin (each, $2 \mu \mathrm{M}$ ) is shown relative to dopamine (DA) (Ctrl) alone. Data represent mean of $n=2$, each performed in triplicate \pm SEM. $* * * p<0.05$ by 1 -way ANOVA with Tukey's post-hoc test $[F(2,3)=24.96, p=0.0135]$. f, $\mathbf{g}$ Protein expression, as shown by Western blotting (f), and fold change in $\mathrm{H}_{2} \mathrm{O}_{2}$ levels (g) for dopamine-treated M17 cells -relative to vehicle-treated sister wellsthat transiently express either flag-control, or WT vs. p.C95A-mutant human parkin-encoding cDNA plasmids. Results are shown as mean \pm SEM $(n=3)$ and all dopamine-treated samples (200 $\mu \mathrm{m}$ dopamine) were normalized to their respective untreated samples. AntiGAPDH immunoblotting served as a loading control (in f). A oneway ANOVA with Tukey's post hoc test $(* p<0.05$ and $* * * p<0.001)$ was used for statistical analysis; $[F(2,6)=36.86, p=0.0004]$ 
Interestingly, mutagenesis of residue Cys95 to alanine (p.C95A; Fig. 7c), which was confirmed by nucleotide- and protein sequencing (by LC-MS/MS), completely abrogated the enhancing effect by r-parkin on the polymerization rate of dopamine to melanin (Fig. 7d, e). Of note, in our study all the recombinant proteins heretofore analyzed were used after their N-terminal His-SUMO-tag had been removed; however, the p.C95A-mutant was resistant to enzymatic digestion of the tag from the parkin holoprotein. Therefore, both His-SUMO-r-parkin and His-SUMO-p.C95A were utilized (Fig. 7c-e). Importantly, in parallel experiments we saw no difference in the kinetics of melanin formation between wild-type r-parkin proteins that either carried a His-SUMOtag or were tag-less (not shown). We concluded that under these in vitro conditions, residue Cys95 was highly relevant to enhanced melanin polymerization by human parkin.

Furthermore, when the p.C95A-variant of parkin was expressed in M17 cells and examined in our dopamine toxicity assay, the mutant protein showed only a partial effect in $\mathrm{H}_{2} \mathrm{O}_{2}$ lowering capacity when compared to wild-type parkin, even when p.C95A was expressed at much higher levels (Fig. 7f, g). These results were consistent with our collective LC-MS/MS results of oxidative modifications of parkin at Cys95 (shown in: Figs. 3h, 4c; Supplementary Table 2, online resource). We reasoned from these complementary ex vivo results that wild-type parkin could be associated with the synthesis of neuromelanin in vivo. Therefore, we sought to explore this further in dopamine neurons of human midbrain.

\section{Anti-parkin reactivity localizes to neuromelanin in the Substantia nigra of adult control brain}

Subcellular localization studies of parkin in human brains had previously been hindered by the lack of renewable antibodies (Abs) that reliably detect the protein in situ $[73,77$, 81, 85]. We, therefore, developed and extensively characterized several, monoclonal Abs of the $\operatorname{IgG}_{2}$ b-subtype using preparations of untagged, full-length, human r-parkin as immunogen. To this end, we generated four stable, epitope-

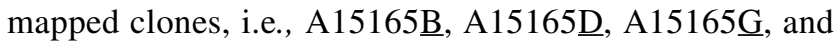
A15165E. The performance and specificity of these clones had been confirmed by ELISA, dot blot analyses, SDS/ PAGE/Western blotting under reducing conditions, which included the usage of ARPD brain extracts, immunoprecipitation from the human brain and indirect immunofluorescence in cellular studies (Supplementary Fig. 8a-c, online resource; Tokarew et al., manuscript in preparation). Impor-

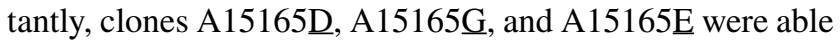
to specifically detect human parkin in human brain sections by immunohistological methods (see below).

Serial sections of adult, human midbrain from control subjects were developed by traditional immunohistochemistry (IHC) using metal-enhanced 3-3'-diaminobenzadine (eDAB), which generates a black signal for positive immunoreactivity. There, anti-parkin clones A15165ㅁ, A15165G and A15165E revealed dark, granular staining throughout the cytoplasm of pigmented cells (ages, $\geq 55$ years) (Fig. 8a, b, d). Using sections of anterior midbrains from nine adult control subjects, $\geq 83 \%$ of the anti-tyrosine hydroxylase (TH)-positive neurons were also positive for parkin, as quantified by double labelling (Fig. 8c). Under these conditions and Ab concentrations, no anti-parkin signal was generated by clone A15165․ㅡ, which had been successfully used in IP experiments above (Fig. 4a). Further, in brainstem nuclei outside the S. nigra, for example in neurons of cranial nerve III (CNIII) and the periaquaductal grey, as well as in sections of control cortices anti-parkin clones A15165므, - $\underline{G}$ and - $\underline{E}$ also stained vesicular structures adjacent to the nucleus, albeit at a much lesser intensity than pigmented neurons (Tokarew et al., manuscript in preparation).

Intriguingly, sections from younger control subjects (ages, $\leq 33$ years) that were processed in parallel revealed less intense, anti-parkin reactivity in S. nigra neurons, which matched the paucity of their intracellular pigment (Fig. 8e); of note, mature neuromelanin consistently generates a brown color in sections developed without any primary Ab. The different immunoreactivities seen between younger $v s$. older midbrains suggested that the three anti-parkin clones (A15165므, - $\underline{G}$ and $-\underline{E}$ ) likely reacted with an age-related, modified form of parkin in situ, because the PRKN gene is already expressed in dopamine cells at a young age (Fig. 1b; Supplementary Fig. 1a-d, online resource).

To confirm the specificity of the new anti-parkin clones, we serially stained midbrain sections from a 71 year-old, male ARPD patient, who was entirely deficient in parkin protein due to compound heterozygous deletions of $P R K N$ exons 2 and 3 (Fig. 8f; Supplementary Fig. 9a-c, online resource) [38]. Development of serial sections with antiparkin clones A15165 $\underline{\mathrm{E}}, \underline{-\underline{D}}$ and $-\underline{G}$ revealed no immunoreactivity in surviving midbrain neurons of the $S$. nigra from this ARPD subject. In the absence of parkin, there was no signal overlap between eDAB reactivity (black color) and either intracellular neuromelanin granules in surviving dopamine cells or with extracellular pigment (brown; Fig. 8f; Supplementary Fig. 9c, online resource). In parallel, development of midbrain sections from individuals with the diagnoses of dementia with Lewy bodies, of non-PRKN-linked, sporadic $P D$ as well as of cases with incidental Lewy bodies readily demonstrated eDAB reactivity overlapping with neuromelanin for all three anti-parkin clones (Supplementary Fig. 9d-g, online resource; and data not shown). These results demonstrated that the staining by the three anti-parkin clones in our microscopy studies of post mortem human brain appeared specific. 

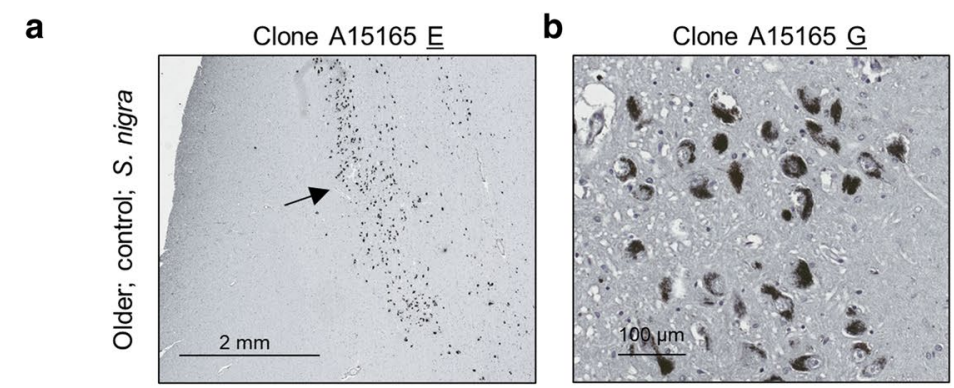

d

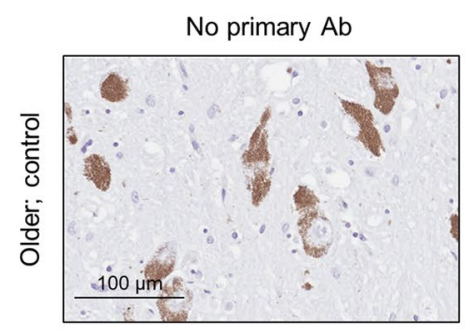

e
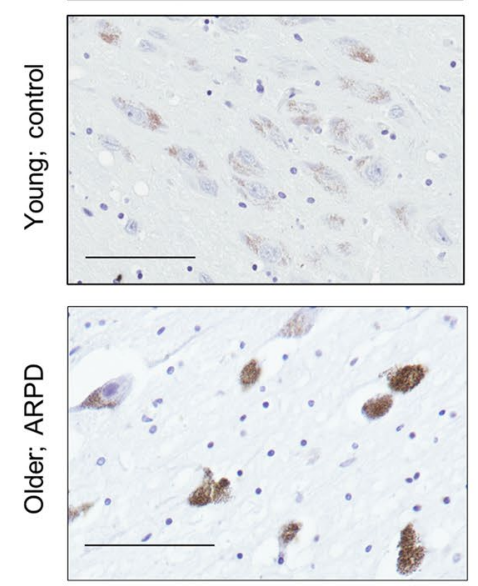

g
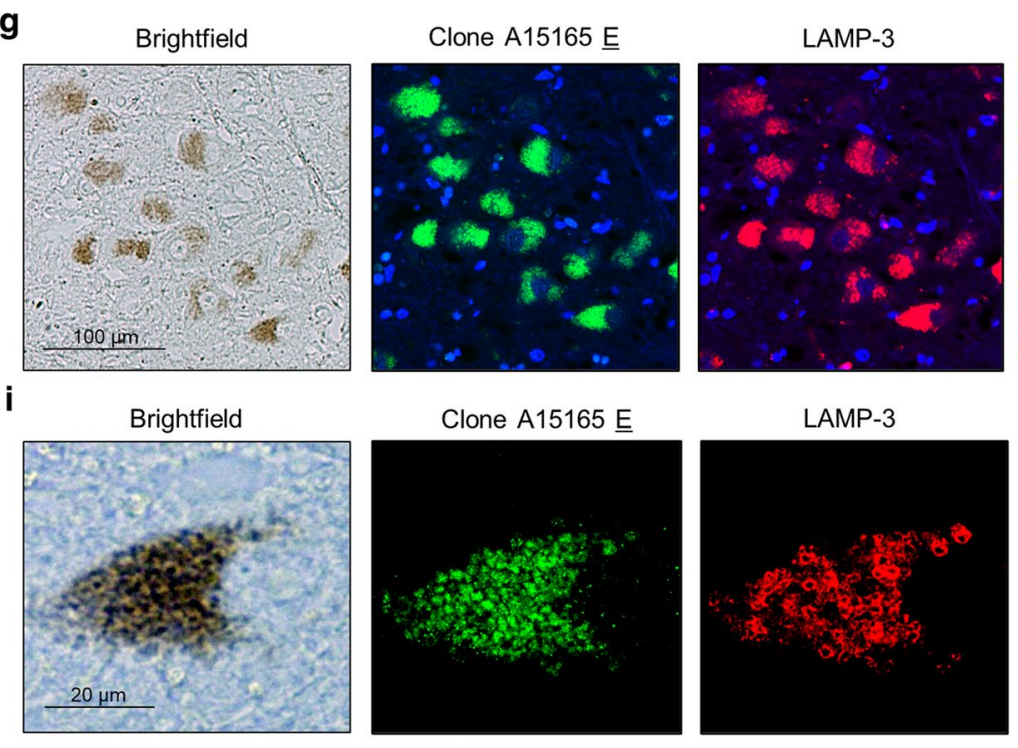
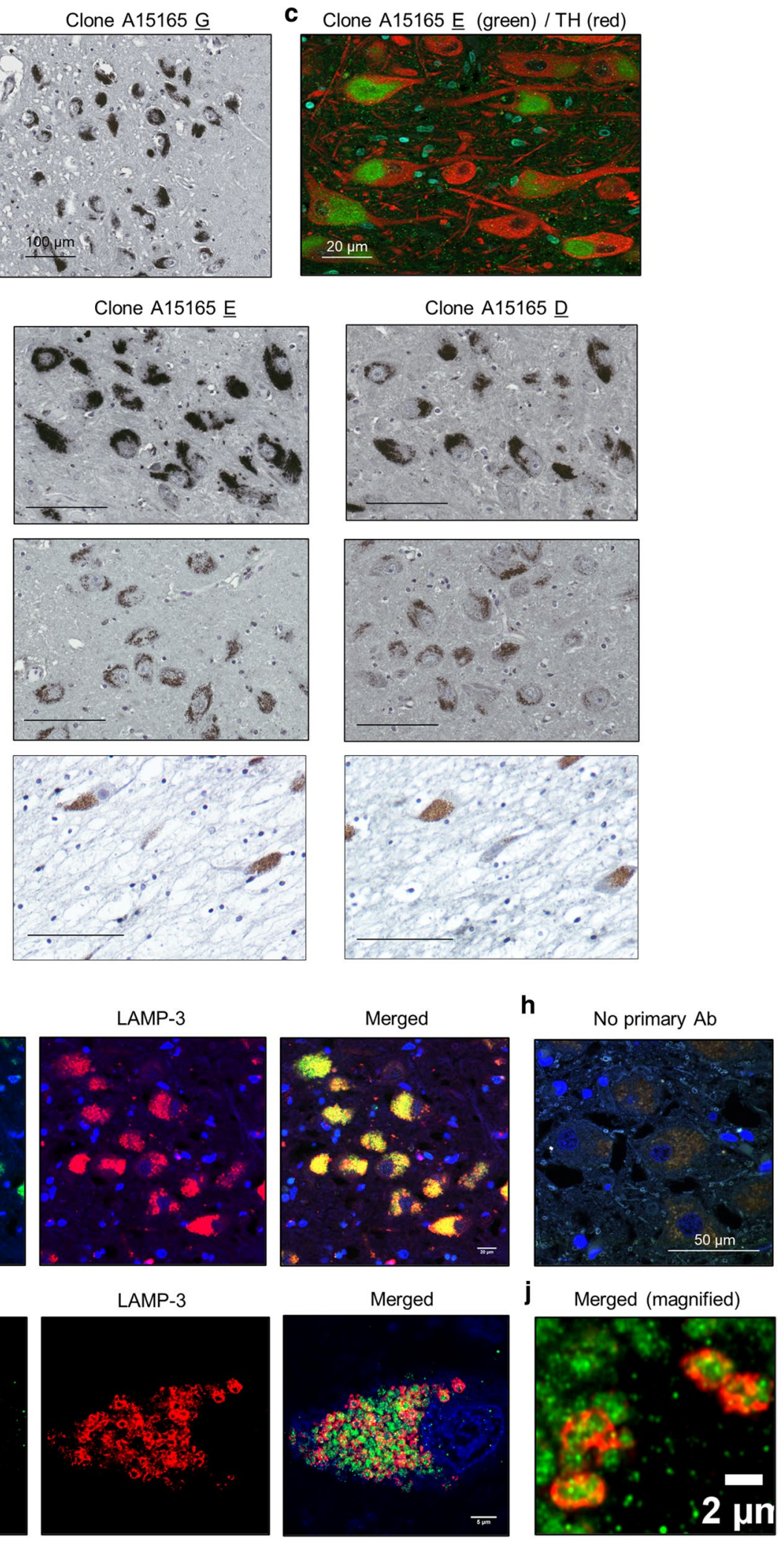
4Fig. 8 Parkin localizes to neuromelanin pigment in S. nigra neurons of normal human midbrain. a, b Immunohistochemical detection of parkin in the adult human brain including dopamine neurons of the $S$. nigra using anti-parkin monoclonal antibody clones A15165E (a) and -G (b). c Double labelling for tyrosine hydroxylase (TH) and parkin (clone A15165E) in the S. nigra from an adult control subject using indirect immunofluorescence microscopy. d-f Immunohistochemical reactivities generated by no primary antibody vs. two anti-parkin (Clones A15165E, -D) antibodies on sections of the S. nigra from two control subjects, aged (d) 66 years and (e) 24 years, as well as (f) from a parkin-deficient ARPD case, aged 71 years. In the indicated panels, immunoreactivity was detected by metal-enhanced DAB (eDAB; generating black colour) and hematoxyline as a counterstain (blue). No primary antibody added generates a pigment-induced signal for neuromelanin (brown). Scale bars represent $100 \mu \mathrm{m}$, or as indicated. g-j Immunofluorescent signals, as generated by doublelabelling of human $S$. nigra sections containing dopamine neurons, using anti-parkin (clone A15165E; green colour) and anti-LAMP-3/ CD63 (red colour) antibodies; (blue colour, Hoechst stain). Brightfield microscopy image in the same field (neuromelanin pigment is visible; left panel) and a no primary antibody (h) run in parallel are shown. i Higher magnification of a single dopamine neuron and (j) further magnification for visualization of subcellular signals within a neighbouring dopamine neuron is shown, as indicated

\section{Parkin frequently localizes to LAMP- $3^{+}$-lysosomes within Substantia nigra neurons}

Neuromelanin granules have been shown to occur in specialized autolysosomes [111]. When screening for colocalization of parkin reactivity with a variety of markers for subcellular organelles in sections of adult control brain, we detected that immunofluorescent signals by anti-parkin (green) and anti-CD63/LAMP-3 (red) antibodies strongly overlapped with pigmented granules of nigral neurons (Fig. 8g-i; see also Supplementary Fig. 9h, online resource).

Using confocal microscopy, we demonstrated that in adult midbrain anti-parkin signals, as generated by clone A15165E, and neuromelanin granules were frequently surrounded by circular, $\sim 2 \mu \mathrm{M}$ (in diameter)-sized rings of antiLAMP-3 reactivity (Fig. 8i, j). A z-stack video for the parkin and LAMP-3 co-labelling studies is appended (Supplemental Information_video, online resource). We concluded that in the adult, human midbrain from neurologically healthy controls and in surviving neurons of subjects, who suffer from parkinsonism that is not linked to bi-allelic PRKN deletion, a pool of parkin appears physically associated with neuromelanin pigment in close association with juxtanuclear, lysosomal structures.

\section{Discussion}

Here, we demonstrate that posttranslational modifications of parkin contribute to its age-related decline in solubility, and in exchange, to redox homeostasis in the human brain. Our study also provides insights into the native processing of the PD-linked parkin protein in the adult midbrain. Parkin's progressive insolubility in the ageing human brain is relatively unique when compared to other PD-linked proteins and several other cellular constituents, which include mitochondrial proteins. It is also tissue and species-specific. Unlike in the brain, approximately $50 \%$ of detectable parkin remain soluble in the spinal cord and in skeletal muscle from aged human subjects, and a comparable loss of parkin solubility is not observed in aged rodent brain and adult monkey cortex (Fig. 1a-d, i; Supplementary Fig. 1d, online resource).

In human control brain, the loss of parkin solubility in post mortem tissue correlates with a rise in $\mathrm{H}_{2} \mathrm{O}_{2}$ concentrations and with age, but not with the subject's sex or the length of PMI (Figs. 1e, j, 2a-c). Although we have analyzed autopsy material with a PMI as short as $2 \mathrm{~h}$ (Supplementary Table 1, online resource), in future work we will also extend our efforts to the analysis of specimens removed from living subjects during neurosurgical procedures. Using our cohort of specimens, we found that the transition to parkin insolubility in frontal lobe cortices occurs between the ages of 28 and 42 years (Fig. 1b; Supplementary Fig. 1a-b; Supplementary Table 1, online resource). The age at which parkin transitions in the $S$. nigra will require a larger number of midbrain specimens from young, neurologically normal subjects. While we were unable to assess its solubility in midbrains from subjects younger than 20 years, parkin's relative distribution in adult midbrain specimens matched the results of control cortices (Fig. 1b). Of note, in the brainstem nuclei that we examined (i.e., S. nigra; L. coeruleus; red nucleus; CN III nucleus; periaqueductal grey), we found that parkin's distribution was not visibly affected by disease state per se (11 control cases vs. 9 neuropathological cases; Fig. 1b; Supplementary Table 1, online resource). However, parkin's total abundance was lower in the $S$. nigra of cases from subjects with various forms of neurodegenerative illnesses, as expected (not shown). In mice, brain parkin showed partial partitioning when oxidative stress had been induced systemically, either acutely or chronically (Fig. 2c-i). In future work, we will examine parkin distribution in larger numbers of brainstem specimens of autopsy material with different neuropathological diagnoses.

In accordance, we demonstrate that a key contributor to parkin insolubility is thiol-oxidation and that the resulting, posttranslational modifications are linked to three protective outcomes: (i) the neutralization of a range of potentially toxic, pro-oxidant radicals (ROS, RES); (ii) the effective lowering of $\mathrm{H}_{2} \mathrm{O}_{2}$ concentrations, including its direct reduction in vitro; and (iii) the apparent effect that parkin has on dopamine metabolism through Cys95-mediated conjugation of its radicals and enhanced melanin formation. We have modeled parkin's redox chemistry-based function in vitro, in cells and in mice, and provide evidence that these 
outcomes are physiologically relevant to the human brain. From these observations, we propose that insoluble parkin represents a functionally important protein of the ageing human brain including the $S$. nigra. Further, our findings integrate the early literature related to parkin mutations and stress-induced modifications vis a vis its insolubility, which included a wide range of complementary investigations [6, $9,28,29,60,92,98,99,103,104]$, such as findings from induced pluripotent stem cell-derived, human dopamine neurons [32, 35, 68]. Our discovery of a function for parkin in redox homeostasis also helps explain seemingly disparate evidence of previous observations made in studies of flies, mice [70, 74] and humans [73].

The reactivity of cysteine thiols is governed by their own redox state as well as by the surrounding electrostatic environment, which includes the charges of neighbouring residues [105]. Unlike parkin, 34 out of 35 cysteines found in BSA are engaged in disulphide bonds [37, 72]. BSA was not able to reduce $\mathrm{H}_{2} \mathrm{O}_{2}$, nor did it enhance the formation of insoluble melanin polymers in vitro under these conditions. Two other $\mathrm{Zn}^{2+}$-coordinating, cysteine-containing proteins that we tested, RNF43 and HOIP ${ }^{\mathrm{CD}}$ (Fig. 5c), also did not lower $\mathrm{H}_{2} \mathrm{O}_{2}$, thus suggesting that select cysteines in parkin have a high affinity for ROS and, as discussed below, RES molecules. When mapping the redox state of parkin cysteines under progressively pro-oxidant conditions in vitro, we found that $\mathrm{Zn}^{2+}$-coordinating residues at its RING domains are not protected from modifications by ROS [56] (Supplementary Table 2, online resource). This observation suggests that oxidative changes of parkin in vivo could occur continuously in the form of a gradient, rather than representing a binary event.

Based on our results, we also estimated the levels of provs. anti-oxidant forces. There, the ratio of $\mathrm{H}_{2} \mathrm{O}_{2}$-to-r-parkin (0.1-1.0 $\mathrm{mM}$ of $\mathrm{H}_{2} \mathrm{O}_{2}$ per $1 \mathrm{ng}$ of r-parkin) was within the physiological range of what we had measured for human control brain extracts (i.e., $0.4-6.0 \mathrm{mM}$ of $\mathrm{H}_{2} \mathrm{O}_{2}$ per $1 \mathrm{ng}$ of parkin). In the latter, $\mathrm{H}_{2} \mathrm{O}_{2}$ concentrations were calculated to lie between 0.7 and $9.1 \mathrm{mM} / \mathrm{mg}$ of tissue (see Supplementary Table 1, online resource). Using semiquantitative Western blotting with aliquots of the same Ab lot (Prk8), parkin concentrations were estimated to be $\sim 1.42 \mathrm{ng} / \mathrm{mg}$ brain tissue using r-parkin dilutions as standards; these had been run in parallel with brain lysates of ARPD cortices to demonstrate specificity for the detection of the $\sim 51-53 \mathrm{kDa}$ holoprotein. These estimates represent a first approximation of the concentration of wild-type parkin in the adult human brain; these numbers may need to be revised in the future based on controlling for potentially confounding variables, such as the presence of truncated species and modified forms (not detected by our antibodies), and/or due to marked variability in parkin's turnover rate in different regions of the cortex and between subjects.
As was observed for r-parkin, we also found cysteine residues that were oxidized in parkin proteins after their affinity isolation from human control cortices and mouse brains, including of $\mathrm{Zn}^{2+}$-binding ones. For example, Cys253 (Cys252 in mice), which helps coordinate $\mathrm{Zn}^{2+}$ within parkin's RING1 domain, was frequently identified by us as being oxidized (Figs. 3i, 4e, g). We predict that variable modifications of non- $\mathrm{Zn}^{2+}$-coordinating residues in human parkin could induce early, conformational changes in parkin's tertiary structure, such as at Cys95, which is located in the-heretofore structurally understudied —-linker region, or Cys59, as positioned in its ubiquitin-like (UbL) domain [17] (see Figs. 6e-h, 7c-g). Such N-terminally located changes could profoundly affect both the structure and function of other domains in wild-type parkin, as has been convincingly delineated in studies of parkin's E3 ligase activity as a readout following modifications at its UbL domain [7, 8, $51,60,69,71,101,104,107]$ (and reviewed by Yi et al. [108].). Our results do not exclude the possibility that other non-thiol-based, posttranslational modifications alter parkin's solubility, such as phosphorylation at Ser65 [46], or at Ser77 [17], which we found in brains of MPTP-treated mice. Currently, ongoing experiments seek to answer the question as to how structural changes caused by select ARPD-linked parkin mutants, e.g., p.C431F and p.G328E, as determined by far-UV-circular dichroism, dynamic-light scattering and NMR techniques, could alter redox functions in vitro. Their completion will add to our understanding as to how these mutants alter solubility and half-life of nascent parkin proteins in cell-based studies $[9,92]$.

As mentioned above, $P R K N$-linked ARPD is thought to be pathologically restricted to catecholamine producing cells of the brainstem [15, 40, 45, 53, 55]. Dopamine neurons of the $S$. nigra have unique biophysical properties that lead to high bioenergetic demands and the related rise in oxidative stress [23]. Further, unlike in other animals, dopamine is not completely catabolized in the human brain, and neuromelanin is thought to be essential for the sequestration and long-term storage of its otherwise toxic metabolites [110]. We found parkin to be involved in mitigating two well-established, PD-linked stressors (i.e., ROS; dopamine radicals), which is indirectly supported by our findings in the human brain.

We show that parkin functions as a classical redox molecule that is able to lower $\mathrm{H}_{2} \mathrm{O}_{2}$ in a thiol-dependent manner. In the absence of wild-type parkin, $\mathrm{H}_{2} \mathrm{O}_{2}$ concentrations are elevated in the human brain (Fig. 5i), in dopaminergic cells (Fig. 5j, k) and in brains from mice exposed to MPTP-toxin (Fig. 5h). There, acute MPTP exposure not only correlated with a decline in parkin solubility but also with the oxidation of select cysteines (Fig. 4a). Hence, PRKN expression contributes to anti-oxidant activity in vivo through a net reduction in $\mathrm{H}_{2} \mathrm{O}_{2}$ levels, which can occur in part through its direct 
reduction, as shown by us in vitro (Fig. 5; Supplementary Fig. 5, online resource).

Because both MPTP toxin exposure and $\operatorname{Sod} 2$ gene function affect mitochondrial integrity $[12,20]$, we reason that redox homeostasis in the cytosol, as coregulated by parkin oxidation, could also indirectly influence the health of mitochondria, in addition to E3 ligase-associated mitophagy (and MITAP). Such a cross-talk between cytosol and mitochondria likely includes glutathione metabolism-linked pathways, in which we and others found parkin cysteines to be involved in as well [11, 17, 25, 34, 79, 89].

A role for $P R K N$ expression in the neutralization and sequestration of dopamine metabolites may explain why dopamine synthesizing neurons are at greater risk in humans born with parkin deficiency. Previously, parkin has been shown to be uniquely sensitive to dopamine stress leading to aggregate formation [51, 104] (Supplementary Fig. 6a, b, online resource). In both cells and mice, prkn gene expression has been indirectly implicated in the metabolism of this neurotransmitter, in particular under ex vivo conditions, such as induced by high dopamine level-induced stress [25, 34-36, 43, 51] (see also Supplementary Fig. 6c, d, online resource).

Our results, and those by others, suggest that dopaminemediated stress in neural cells is ameliorated when parkin undergoes irreversible modifications by dopamine metabolites. However, in contrast to current interpretations, which stipulate oxidation by quinones is equal to a loss of parkin activity, we posit that such oxidation is part of parkin's physiological role within post-mitotic cells of the adult brain based on two principal findings. First, we demonstrate that wild-type parkin directly interacts with highly electrophilic dopamine metabolites at specific residues, foremost Cys95 (Fig. 6e-h). This primate-specific cysteine is located within the linker region next to charged residues that impact its electrostatic properties and likely its redox reactivity $[24,105]$. In support, we found that in addition to dopamine adduct conjugation, Cys95 is vulnerable to ROS attacks (Figs. 3h, 4b, c), and in parallel studies, is S-glutathionylated when exposed to rising concentrations of oxidized glutathione [17]. Strikingly, we found that Cys95 is not only required for parkin-dependent enhanced melanin formation, but also for participation in effective $\mathrm{H}_{2} \mathrm{O}_{2}$ reduction in M17 cells during dopamine stress-mediated toxicity (Figs. 6e-g, 7f-g).

Second, our finding that parkin augments melanin formation in vitro, together with our finding that the protein is closely associated with neuromelanin granules within LAMP- $3^{+}$- lysosomes of human brain (Fig. $8 \mathrm{~g}-\mathrm{j}$; Supplementary Fig. 9h, online resource), suggest a role for parkin in dopamine metabolism-linked neuroprotection (Supplementary Fig. 10, online resource). We have noted with interest that several autopsy reports have described lesser neuromelanin content in surviving neurons of the $S$. nigra in PRKN-linked ARPD [22, 27, 30, 95, 106, 109] (Fig. 8f). Intriguingly, variants at the $L A M P 3 / C D 63$ locus, as well as of other dopamine metabolism-related genes, e.g., $G C H-1$, have been recently identified as modifiers of susceptibility to late-onset, typical PD [33, 66, 100]. However, proof of the concept that parkin plays an important, contributing role in the formation of neuromelanin in human brain awaits a suitable animal model.

To date, parkin is best known for its function as an E3 ligase and the ubiquitin ligation-dependent involvement in mitophagy. Because ubiquitin-ligating activity occurs via cysteine-mediated trans-thiolation, controlling the cellular redox state and functioning as an E3 ligase may not be mutually exclusive. For example, low concentrations of pro-oxidants, as well as sulfhydration, can activate parkin's E3 activity in vitro [71, 97, 107]. A similar duality in functions, i.e., regulating ubiquitylation and redox state in cells, has been previously described for the sensitiveto-apoptosis gene (SAG) product, also known as RBX2/ ROC2/RNF7 [93, 94]. It contains a RING finger, and similar to parkin, was found to form HMW oligomers through oxidation of its cysteines [93, 94]. SAG protein protects cells from oxidative stress in a thiol-mediated manner in addition to functioning as an E3 ligase.

From this analogy, we postulate that parkin's cytoprotective E3 function and its role in mitophagy are possibly linked to its soluble form within the cytosol, which could be most important during early developmental stages, such as during organ development [26], in dividing striated muscle cells [80], and in relatively younger, neural cells including glia [89]. In support, Yi et al. recently described a strong correlation between parkin point mutants, their impact on structure and protein stability vs. ubiquitin ligase activity and the degree of mitophagy efficiency [108]. Conversely, redox-based neutralization of radicals by wild-type parkin could be more essential to the sustained health of long-lived, postmitotic cells, e.g., S. nigra neurons.

In summary, we have shown that parkin fulfils criteria of a typical redox molecule: the sensing of oxidative (and reducing) stress via its thiols; and the direct, reciprocal redox regulation of its environment, thus conferring protective outcomes. If confirmed by future work, this redox chemistry-based expansion of parkin functions in the ageing human midbrain (Supplementary Fig. 10, online resource) may open the door to testing its anti-oxidant role in related neurodegenerative conditions, such as lateonset, non-PRKN-linked PD [13]. Most important, our findings emphasize the need for early identification of persons afflicted by bi-allelic PRKN gene mutations for the prioritization of appropriate interventions in the future, 
such as via gene therapy [44] and polyvalent, anti-oxidant therapy [78].

Supplementary Information The online version contains supplementary material available at https://doi.org/10.1007/s00401-021-02285-4.

Acknowledgements We are grateful for the commitment of patients and their families to participate in autopsy studies. We thank Dr. J. Palacino for creating stable M17 cell lines, Drs. A. Brice and E. Fon for sharing prkn-null mice, Dr. B. Madras for providing specimens of cynomolgus brain, Drs. R. Tam, L. Dong, Ms. K. Solti and Ms. H. Boston for technical support, Dr. D. Gibbings for antibodies, Dr. D. Gray for assistance with confocal imaging, Drs. M. Medina and R. R. Ratan for encouragement, Drs. S. Bennett, D. Pratt for discussions, and Drs. H. Lochmueller, M. Rousseaux and past members of the Schlossmacher lab for their suggestions.

Author contributions Study design: JMT, DNEK, PT, JJT, MGS; Writing and Figure preparation: JMT, DNEK, NAL, TKF, MJ, APN, JL, GSS, JMW, GT, PT, JJT, and MGS prepared the initial draft of the manuscript and figures. All authors reviewed and/or edited the manuscript and approved of the submitted versions. Experiments: JMT, DNEK, NAL, TKF, MJ, APN, BO, LW, JK, ACN, QJ, RS, JL, MZ, KRB, AT, XD, LP, GT, BS performed experiments; and CRS, ABW, ET, AH, AP, JAC, provided data, tissue specimens and critical comments. Analysis: JMT, DNEK, JL, TKF, GSS, LP, GT, JMW, PT, JJT, MGS performed data analyses. Study supervision: PT, JJT, MGS. Overall responsibility: MGS

Funding This work was supported by the: Parkinson Research Consortium of Ottawa (J.M.T., D.N.E.K., J.J.T.); Queen Elizabeth II Graduate Scholarship Fund (J.M.T.); Government of Canada [Natural Sciences and Engineering Research Council of Canada (J.K.); Canadian Institutes of Health Research (CIHR) MD/PhD Program (J.M.T., A.C.N.); CIHR Research Grant (G.S.S., A.P.); CIHR Canada Research Chair Program (M.G.S., A.P.)]; Michael J. Fox Foundation for Parkinson's Research (P.T., J.J.T., L.Z., M.G.S.); The Research Foundation of the Multiple Sclerosis Society of Canada; Progressive Multiple Sclerosis Alliance (A.P.); Hungarian Brain Research Program (G.T.); Uttra and Sam Bhargava Family (E.T., M.G.S.); and The Ottawa Hospital (E.T., M.G.S.).

Data and materials availability Original data associated with this study are available in the main text and supplementary figures and tables; additional data will be made available upon request.

\section{Compliance with ethical standards}

Conflict of interest Drs. B. O'Nuallain, M. Jin, L. Wang, P. Taylor are (or were) employees of BioLegend Inc. (Dedham, MA., USA). The Ottawa Hospital receives payments from BioLegend Inc. related to licensing agreements for immunological reagents related to parkin and $\alpha$-synuclein. Dr. M. Schlossmacher received travel reimbursements from the Michael J. Fox Foundation for Parkinson's Research for participation in industry summits and consulting fees as well as royalties from Genzyme-Sanofi for patents unrelated to this work. Dr. G. Toth is an employee and a shareholder of Cantabio Pharmaceuticals. Dr. A. Holmgren (deceased) served as chairman and senior scientist at IMCO Corporation Ltd AB, Stockholm, Sweden. No additional, potentially competing financial interests are declared.

Open Access This article is licensed under a Creative Commons Attribution 4.0 International License, which permits use, sharing, adaptation, distribution and reproduction in any medium or format, as long as you give appropriate credit to the original author(s) and the source, provide a link to the Creative Commons licence, and indicate if changes were made. The images or other third party material in this article are included in the article's Creative Commons licence, unless indicated otherwise in a credit line to the material. If material is not included in the article's Creative Commons licence and your intended use is not permitted by statutory regulation or exceeds the permitted use, you will need to obtain permission directly from the copyright holder. To view a copy of this licence, visit http://creativecommons .org/licenses/by/4.0/.

\section{References}

1. Aguirre JD, Dunkerley KM, Mercier P, Shaw GS (2017) Structure of phosphorylated UBL domain and insights into PINK1orchestrated parkin activation. Proc Natl Acad Sci USA 114:298 303. https://doi.org/10.1073/pnas.1613040114

2. Alcock LJ, Perkins MV, Chalker JM (2018) Chemical methods for mapping cysteine oxidation. Chem Soc Rev 47:231-268. https://doi.org/10.1039/c7cs00607a

3. Ali SF, David SN, Newport GD, Cadet JL, Slikker W Jr (1994) MPTP-induced oxidative stress and neurotoxicity are agedependent: evidence from measures of reactive oxygen species and striatal dopamine levels. Synapse 18:27-34. https://doi. org/10.1002/syn.890180105

4. Barodia SK, Creed RB, Goldberg MS (2017) Parkin and PINK1 functions in oxidative stress and neurodegeneration. Brain Res Bull 133:51-59. https://doi.org/10.1016/j.brainresbu 11.2016.12.004

5. Berger AK, Cortese GP, Amodeo KD, Weihofen A, Letai A, LaVoie MJ (2009) Parkin selectively alters the intrinsic threshold for mitochondrial cytochrome c release. Hum Mol Genet 18:4317-4328. https://doi.org/10.1093/hmg/ddp384

6. Chakraborty J, Basso V, Ziviani E (2017) Post translational modification of Parkin. Biol Direct 12:6. https://doi.org/10.1186/ s13062-017-0176-3

7. Chung KK, Dawson VL, Dawson TM (2005) S-nitrosylation in Parkinson's disease and related neurodegenerative disorders. Methods Enzymol 396:139-150. https://doi.org/10.1016/S0076 -6879(05)96014-X

8. Chung KK, Thomas B, Li X, Pletnikova O, Troncoso JC, Marsh L et al (2004) S-nitrosylation of parkin regulates ubiquitination and compromises parkin's protective function. Science 304:1328-1331. https://doi.org/10.1126/science.1093891

9. Cookson MR, Lockhart PJ, McLendon C, O'Farrell C, Schlossmacher M, Farrer MJ (2003) RING finger 1 mutations in Parkin produce altered localization of the protein. Hum Mol Genet 12:2957-2965. https://doi.org/10.1093/hmg/ddg328

10. Cox J, Mann M (2008) MaxQuant enables high peptide identification rates, individualized p.p.b.-range mass accuracies and proteome-wide protein quantification. Nat Biotechnol 26:13671372. https://doi.org/10.1038/nbt.1511

11. Damiano M, Gautier CA, Bulteau AL, Ferrando-Miguel R, Gouarne C, Paoli MG et al (2014) Tissue- and cell-specific mitochondrial defect in Parkin-deficient mice. PLoS ONE 9:e99898. https://doi.org/10.1371/journal.pone.0099898

12. Dauer W, Przedborski S (2003) Parkinson's disease: mechanisms and models. Neuron 39:889-909. https://doi.org/10.1016/s0896 $-6273(03) 00568-3$

13. Dawson TM, Dawson VL (2014) Parkin plays a role in sporadic Parkinson's disease. Neurodegener Dis 13:69-71. https://doi. org/10.1159/000354307 
14. Dhaeze T, Tremblay L, Lachance C, Peelen E, Zandee S, Grasmuck $C$ et al (2019) CD70 defines a subset of proinflammatory and CNS-pathogenic TH1/TH17 lymphocytes and is overexpressed in multiple sclerosis. Cell Mol Immunol 16:652-665. https://doi.org/10.1038/s41423-018-0198-5

15. Doherty KM, Silveira-Moriyama L, Parkkinen L, Healy DG, Farrell M, Mencacci NE et al (2013) Parkin disease: a clinicopathologic entity? JAMA Neurol 70:571-579. https://doi.org/10.1001/ jamaneurol.2013.172

16. Dong X, Liao Z, Gritsch D, Hadzhiev Y, Bai Y, Locascio JJ et al (2018) Enhancers active in dopamine neurons are a primary link between genetic variation and neuropsychiatric disease. Nat Neurosci 21:1482-1492. https://doi.org/10.1038/s41593-018-0223-0

17. El Kodsi DN, Tokarew JM, Sengupta R, Lengacher NA, Ng AC, Boston $\mathrm{H}$ et al (2020) Parkinson disease-linked parkin mediates redox reactions that lower oxidative stress in mammalian brain. bioRxiv. https://doi.org/10.1101/2020.04.26.062380

18. Ferrari E, Capucciati A, Prada I, Zucca FA, D’Arrigo G, Pontiroli D et al (2017) Synthesis, structure characterization, and evaluation in microglia cultures of neuromelanin analogues suitable for modeling Parkinson's disease. ACS Chem Neurosci 8:501-512. https://doi.org/10.1021/acschemneuro.6b00231

19. Ferrari E, Engelen M, Monzani E, Sturini M, Girotto S, Bubacco L et al (2013) Synthesis and structural characterization of soluble neuromelanin analogs provides important clues to its biosynthesis. J Biol Inorg Chem 18:81-93. https://doi.org/10.1007/s0077 5-012-0951-7

20. Flynn JM, Melov S (2013) SOD2 in mitochondrial dysfunction and neurodegeneration. Free Radic Biol Med 62:4-12. https:// doi.org/10.1016/j.freeradbiomed.2013.05.027

21. Ge P, Dawson VL, Dawson TM (2020) PINK1 and Parkin mitochondrial quality control: a source of regional vulnerability in Parkinson's disease. Mol Neurodegener 15:20. https://doi. org/10.1186/s13024-020-00367-7

22. Gibb WR, Narabayashi H, Yokochi M, Iizuka R, Lees AJ (1991) New pathologic observations in juvenile onset parkinsonism with dystonia. Neurology 41:820-822. https://doi.org/10.1212/ wnl.41.6.820

23. Giguere N, Pacelli C, Saumure C, Bourque MJ, Matheoud D, Levesque D et al (2018) Comparative analysis of Parkinson's disease-associated genes in mice reveals altered survival and bioenergetics of Parkin-deficient dopamine neurons. J Biol Chem 293:9580-9593. https://doi.org/10.1074/jbc.RA117.000499

24. Gladkova C, Maslen SL, Skehel JM, Komander D (2018) Mechanism of parkin activation by PINK1. Nature 559:410-414. https ://doi.org/10.1038/s41586-018-0224-x

25. Goldberg MS, Fleming SM, Palacino JJ, Cepeda C, Lam HA, Bhatnagar A et al (2003) Parkin-deficient mice exhibit nigrostriatal deficits but not loss of dopaminergic neurons. J Biol Chem 278:43628-43635. https://doi.org/10.1074/jbc.M308947200

26. Gong G, Song M, Csordas G, Kelly DP, Matkovich SJ, Dorn GW 2nd (2015) Parkin-mediated mitophagy directs perinatal cardiac metabolic maturation in mice. Science 350:aad2459. https://doi. org/10.1126/science.aad2459

27. Gouider-Khouja N, Larnaout A, Amouri R, Sfar S, Belal S, Ben Hamida $\mathrm{C}$ et al (2003) Autosomal recessive parkinsonism linked to parkin gene in a Tunisian family. Clinical, genetic and pathological study. Parkinsonism Relat Disord 9:247-251. https://doi. org/10.1016/s1353-8020(03)00016-6

28. Gu WJ, Corti O, Araujo F, Hampe C, Jacquier S, Lucking CB et al (2003) The C289G and C418R missense mutations cause rapid sequestration of human Parkin into insoluble aggregates. Neurobiol Dis 14:357-364

29. Hampe C, Ardila-Osorio H, Fournier M, Brice A, Corti O (2006) Biochemical analysis of Parkinson's disease-causing variants of Parkin, an E3 ubiquitin-protein ligase with monoubiquitylation capacity. Hum Mol Genet 15:2059-2075. https://doi.org/10.1093/ hmg/ddl131

30. Hayashi S, Wakabayashi K, Ishikawa A, Nagai H, Saito M, Maruyama M et al (2000) An autopsy case of autosomal-recessive juvenile parkinsonism with a homozygous exon 4 deletion in the parkin gene. Mov Disord 15:884-888

31. Hristova VA, Beasley SA, Rylett RJ, Shaw GS (2009) Identification of a novel $\mathrm{Zn} 2+$-binding domain in the autosomal recessive juvenile Parkinson-related E3 ligase parkin. J Biol Chem 284:14978-14986. https://doi.org/10.1074/jbc.M808700200

32. Hyun DH, Lee M, Hattori N, Kubo S, Mizuno Y, Halliwell B et al (2002) Effect of wild-type or mutant Parkin on oxidative damage, nitric oxide, antioxidant defenses, and the proteasome. J Biol Chem 277:28572-28577. https://doi.org/10.1074/jbc.M2006 66200

33. International Parkinson Disease Genomics C, Nalls MA, Plagnol V, Hernandez DG, Sharma M, Sheerin UM, Saad M et al (2011) Imputation of sequence variants for identification of genetic risks for Parkinson's disease: a meta-analysis of genome-wide association studies. Lancet 377:641-649. https://doi.org/10.1016/S0140 $-6736(10) 62345-8$

34. Itier JM, Ibanez P, Mena MA, Abbas N, Cohen-Salmon C, Bohme GA et al (2003) Parkin gene inactivation alters behaviour and dopamine neurotransmission in the mouse. Hum Mol Genet 12:2277-2291. https://doi.org/10.1093/hmg/ddg239

35. Jiang H, Ren Y, Yuen EY, Zhong P, Ghaedi M, Hu Z et al (2012) Parkin controls dopamine utilization in human midbrain dopaminergic neurons derived from induced pluripotent stem cells. Nat Commun 3:668. https://doi.org/10.1038/ncomms1669

36. Jiang H, Ren Y, Zhao J, Feng J (2004) Parkin protects human dopaminergic neuroblastoma cells against dopamine-induced apoptosis. Hum Mol Genet 13:1745-1754. https://doi. org/10.1093/hmg/ddh 180

37. Jordan GM, Yoshioka S, Terao T (1994) The aggregation of bovine serum albumin in solution and in the solid state. J Pharm Pharmacol 46:182-185. https://doi. org/10.1111/j.2042-7158.1994.tb03774.x

38. Kano M, Takanashi M, Oyama G, Yoritaka A, Hatano T, ShibaFukushima K et al (2020) Reduced astrocytic reactivity in human brains and midbrain organoids with PRKN mutations. NPJ Parkinsons Dis 6:33. https://doi.org/10.1038/s41531-020-00137-8

39. Kasten M, Hartmann C, Hampf J, Schaake S, Westenberger A, Vollstedt EJ et al (2018) Genotype-phenotype relations for the Parkinson's disease genes parkin, PINK1, DJ1: MDSGene systematic review. Mov Disord 33:730-741. https://doi.org/10.1002/ mds. 27352

40. Khan NL, Graham E, Critchley P, Schrag AE, Wood NW, Lees AJ et al (2003) Parkin disease: a phenotypic study of a large case series. Brain 126:1279-1292. https://doi.org/10.1093/brain lawg142

41. Kiss R, Zhu M, Jojart B, Czajlik A, Solti K, Forizs B et al (2017) Structural features of human DJ-1 in distinct Cys106 oxidative states and their relevance to its loss of function in disease. Biochim Biophys Acta Gen Subj 1861:2619-2629. https://doi. org/10.1016/j.bbagen.2017.08.017

42. Kitada T, Asakawa S, Hattori N, Matsumine H, Yamamura Y, Minoshima S et al (1998) Mutations in the parkin gene cause autosomal recessive juvenile parkinsonism. Nature 392:605-608. https://doi.org/10.1038/33416

43. Kitada T, Pisani A, Karouani M, Haburcak M, Martella G, Tscherter A et al (2009) Impaired dopamine release and synaptic plasticity in the striatum of parkin-/- mice. J Neurochem 110:613-621. https://doi.org/10.1111/j.1471-4159.2009.06152.x

44. Kitada T, Tomlinson JJ, Ao HS, Grimes DA, Schlossmacher MG (2012) Considerations regarding the etiology and future treatment of autosomal recessive versus idiopathic Parkinson disease. 
Curr Treat Options Neurol 14:230-240. https://doi.org/10.1007/ s11940-012-0175-8

45. Klein C, Lohmann K (2009) Parkinson disease(s): is "Parkin disease" a distinct clinical entity? Neurology 72:106-107. https ://doi.org/10.1212/01.wnl.0000333666.65522.8d

46. Koyano F, Okatsu K, Kosako H, Tamura Y, Go E, Kimura M, Kimura et al (2014) Ubiquitin is phosphorylated by PINK1 to activate parkin. Nature 510:162-166. https://doi.org/10.1038/ nature 13392

47. Krezel A, Maret W (2016) The biological inorganic chemistry of zinc ions. Arch Biochem Biophys 611:3-19. https://doi. org/10.1016/j.abb.2016.04.010

48. Kuhlmann T, Ludwin S, Prat A, Antel J, Bruck W, Lassmann H (2017) An updated histological classification system for multiple sclerosis lesions. Acta Neuropathol 133:13-24. https://doi. org/10.1007/s00401-016-1653-y

49. Kumar A, Aguirre JD, Condos TE, Martinez-Torres RJ, Chaugule VK, Toth R et al (2015) Disruption of the autoinhibited state primes the E3 ligase parkin for activation and catalysis. EMBO J 34:2506-2521. https://doi.org/10.15252/embj.201592337

50. LaVoie MJ, Cortese GP, Ostaszewski BL, Schlossmacher MG (2007) The effects of oxidative stress on parkin and other E3 ligases. J Neurochem 103:2354-2368. https://doi.org/10.111 1/j.1471-4159.2007.04911.x

51. LaVoie MJ, Ostaszewski BL, Weihofen A, Schlossmacher MG, Selkoe DJ (2005) Dopamine covalently modifies and functionally inactivates parkin. Nat Med 11:1214-1221. https://doi. org $/ 10.1038 / \mathrm{nm} 1314$

52. Lee SJ, Kim DG, Lee KY, Koo JS, Lee BJ (2018) Regulatory mechanisms of thiol-based redox sensors: lessons learned from structural studies on prokaryotic redox sensors. Arch Pharm Res 41:583-593. https://doi.org/10.1007/s12272-018-1036-0

53. Lesage S, Lunati A, Houot M, Romdhan SB, Clot F, Tesson C, French Parkinson Disease Genetics Study G et al (2020) Characterization of recessive Parkinson disease in a large multicenter study. Ann Neurol 88:843-850. https://doi.org/10.1002/ ana. 25787

54. Liguori I, Russo G, Curcio F, Bulli G, Aran L, Della-Morte D et al (2018) Oxidative stress, aging, and diseases. Clin Interv Aging 13:757-772. https://doi.org/10.2147/CIA.S158513

55. Lucking CB, Durr A, Bonifati V, Vaughan J, De Michele G, Gasser T et al (2000) Association between early-onset Parkinson's disease and mutations in the parkin gene. N Engl J Med 342:1560-1567. https://doi.org/10.1056/NEJM20000525342 2103

56. Maret W (2006) Zinc coordination environments in proteins as redox sensors and signal transducers. Antioxid Redox Signal 8:1419-1441. https://doi.org/10.1089/ars.2006.8.1419

57. Matheoud D, Sugiura A, Bellemare-Pelletier A, Laplante A, Rondeau C, Chemali M, Fazel A et al (2016) Parkinson's diseaserelated proteins PINK1 and parkin repress mitochondrial antigen presentation. Cell 166:314-327. https://doi.org/10.1016/j. cell.2016.05.039

58. Matsuda N, Sato S, Shiba K, Okatsu K, Saisho K, Gautier CA et al (2010) PINK1 stabilized by mitochondrial depolarization recruits Parkin to damaged mitochondria and activates latent Parkin for mitophagy. J Cell Biol 189:211-221. https://doi. org/10.1083/jcb.200910140

59. McLelland GL, Soubannier V, Chen CX, McBride HM, Fon EA (2014) Parkin and PINK1 function in a vesicular trafficking pathway regulating mitochondrial quality control. EMBO J 33:282-295. https://doi.org/10.1002/embj.201385902

60. Meng F, Yao D, Shi Y, Kabakoff J, Wu W, Reicher J et al (2011) Oxidation of the cysteine-rich regions of parkin perturbs its E3 ligase activity and contributes to protein aggregation. Mol Neurodegener 6:34. https://doi.org/10.1186/1750-1326-6-34

61. Micsonai A, Wien F, Bulyaki E, Kun J, Moussong E, Lee YH et al (2018) BeStSel: a web server for accurate protein secondary structure prediction and fold recognition from the circular dichroism spectra. Nucleic Acids Res 46:W315-W322. https:// doi.org/10.1093/nar/gky497

62. Micsonai A, Wien F, Kernya L, Lee YH, Goto Y, Refregiers M et al (2015) Accurate secondary structure prediction and fold recognition for circular dichroism spectroscopy. Proc Natl Acad Sci USA 112:E3095-3103. https://doi.org/10.1073/pnas.15008 51112

63. Mouton-Liger F, Rosazza T, Sepulveda-Diaz J, Ieang A, Hassoun SM, Claire E et al (2018) Parkin deficiency modulates NLRP3 inflammasome activation by attenuating an A20-dependent negative feedback loop. Glia 66:1736-1751. https://doi.org/10.1002/ glia. 23337

64. Muller CH, Lee TK, Montano MA (2013) Improved chemiluminescence assay for measuring antioxidant capacity of seminal plasma. Methods Mol Biol 927:363-376. https://doi. org/10.1007/978-1-62703-038-0_31

65. Muller-Rischart AK, Pilsl A, Beaudette P, Patra M, Hadian K, Funke $\mathrm{M}$ et al (2013) The E3 ligase parkin maintains mitochondrial integrity by increasing linear ubiquitination of NEMO. Mol Cell 49:908-921. https://doi.org/10.1016/j.molcel.2013.01.036

66. Nalls MA, Pankratz N, Lill CM, Do CB, Hernandez DG, Saad M, International Parkinson's Disease Genomics C, Parkinson's Study Group Parkinson's Research: The Organized GI, andMe, GenePd, NeuroGenetics Research C, Hussman Institute of Human G, Ashkenazi Jewish Dataset I, Cohorts for H, Aging Research in Genetic E, North American Brain Expression C, United Kingdom Brain Expression C, Greek Parkinson's Disease C, Alzheimer Genetic Analysis G et al (2014) Large-scale metaanalysis of genome-wide association data identifies six new risk loci for Parkinson's disease. Nat Genet 46:989-993. https://doi. org/10.1038/ng.3043

67. Narendra DP, Jin SM, Tanaka A, Suen DF, Gautier CA, Shen J et al (2010) PINK1 is selectively stabilized on impaired mitochondria to activate Parkin. PLoS Biol 8:e1000298. https://doi. org/10.1371/journal.pbio.1000298

68. Okarmus J, Bogetofte H, Schmidt SI, Ryding M, Garcia-Lopez S, Ryan BJ et al (2020) Lysosomal perturbations in human dopaminergic neurons derived from induced pluripotent stem cells with PARK2 mutation. Sci Rep 10:10278. https://doi. org/10.1038/s41598-020-67091-6

69. Ozawa K, Komatsubara AT, Nishimura Y, Sawada T, Kawafune $\mathrm{H}$, Tsumoto $\mathrm{H}$ et al (2013) S-nitrosylation regulates mitochondrial quality control via activation of parkin. Sci Rep 3:2202. https://doi.org/10.1038/srep02202

70. Palacino JJ, Sagi D, Goldberg MS, Krauss S, Motz C, Wacker $\mathrm{M}$ et al (2004) Mitochondrial dysfunction and oxidative damage in parkin-deficient mice. J Biol Chem 279:18614-18622. https ://doi.org/10.1074/jbc.M401135200

71. Panicker N, Dawson VL, Dawson TM (2017) Activation mechanisms of the E3 ubiquitin ligase parkin. Biochem J 474:30753086. https://doi.org/10.1042/BCJ20170476

72. Paris G, Kraszewski S, Ramseyer C, Enescu M (2012) About the structural role of disulfide bridges in serum albumins: evidence from protein simulated unfolding. Biopolymers 97:889-898. https://doi.org/10.1002/bip.22096

73. Pawlyk AC, Giasson BI, Sampathu DM, Perez FA, Lim KL, Dawson VL et al (2003) Novel monoclonal antibodies demonstrate biochemical variation of brain parkin with age. J Biol Chem 278:48120-48128. https://doi.org/10.1074/jbc.M3068 89200 
74. Periquet M, Corti O, Jacquier S, Brice A (2005) Proteomic analysis of parkin knockout mice: alterations in energy metabolism, protein handling and synaptic function. J Neurochem 95:12591276. https://doi.org/10.1111/j.1471-4159.2005.03442.x

75. Pickrell AM, Huang CH, Kennedy SR, Ordureau A, Sideris DP, Hoekstra JG et al (2015) Endogenous Parkin preserves dopaminergic substantia nigral neurons following mitochondrial DNA mutagenic stress. Neuron 87:371-381. https://doi.org/10.1016/j. neuron.2015.06.034

76. Polman $\mathrm{CH}$, Reingold SC, Banwell B, Clanet M, Cohen JA, Filippi M et al (2011) Diagnostic criteria for multiple sclerosis: 2010 revisions to the McDonald criteria. Ann Neurol 69:292302. https://doi.org/10.1002/ana.22366

77. Pramstaller PP, Schlossmacher MG, Jacques TS, Scaravilli F, Eskelson C, Pepivani I et al (2005) Lewy body Parkinson's disease in a large pedigree with 77 Parkin mutation carriers. Ann Neurol 58:411-422. https://doi.org/10.1002/ana.20587

78. Ratan RR (1999) Antioxidants and the treatment of neurological disease. In: Koliatsos VE, Ratan, RR (ed) Cell death and diseases of the nervous system. Humana Press, Totowa. https:// doi.org/10.1007/978-1-4612-1602-5_32

79. Rodriguez-Navarro JA, Casarejos MJ, Menendez J, Solano RM, Rodal I, Gomez A et al (2007) Mortality, oxidative stress and tau accumulation during ageing in parkin null mice. J Neurochem 103:98-114. https://doi.org/10.1111/j.1471-4159.2007.04762.x

80. Rosen KM, Veereshwarayya V, Moussa CE, Fu Q, Goldberg MS, Schlossmacher MG et al (2006) Parkin protects against mitochondrial toxins and beta-amyloid accumulation in skeletal muscle cells. J Biol Chem 281:12809-12816. https://doi.org/10.1074/ jbc.M512649200

81. Schlossmacher MG, Frosch MP, Gai WP, Medina M, Sharma N, Forno L et al (2002) Parkin localizes to the Lewy bodies of Parkinson disease and dementia with Lewy bodies. Am J Pathol 160:1655-1667. https://doi.org/10.1016/S0002-9440(10)61113 $-3$

82. Schlossmacher MG, Shimura H (2005) Parkinson's disease: assays for the ubiquitin ligase activity of neural Parkin. Methods Mol Biol 301:351-369

83. Segura-Aguilar J, Paris I, Munoz P, Ferrari E, Zecca L, Zucca FA (2014) Protective and toxic roles of dopamine in Parkinson's disease. J Neurochem 129:898-915. https://doi.org/10.1111/ jnc. 12686

84. Shevchenko A, Tomas H, Havlis J, Olsen JV, Mann M (2006) Ingel digestion for mass spectrometric characterization of proteins and proteomes. Nat Protoc 1:2856-2860. https://doi.org/10.1038/ nprot. 2006.468

85. Shimura H, Hattori N, Kubo S, Yoshikawa M, Kitada T, Matsumine $\mathrm{H}$ et al (1999) Immunohistochemical and subcellular localization of Parkin protein: absence of protein in autosomal recessive juvenile parkinsonism patients. Ann Neurol 45:668-672. https ://doi.org/10.1002/1531-8249(199905)45:5\%3c668::aid-ana19 $\% 3 \mathrm{e} 3.0 . \mathrm{co} ; 2-\mathrm{z}$

86. Shin JH, Ko HS, Kang H, Lee Y, Lee YI, Pletinkova O et al (2011) PARIS (ZNF746) repression of PGC-1alpha contributes to neurodegeneration in Parkinson's disease. Cell 144:689-702. https://doi.org/10.1016/j.cell.2011.02.010

87. Shutinoski B, Hakimi M, Harmsen IE, Lunn M, Rocha J, Lengacher $\mathrm{N}$ et al (2019) Lrrk2 alleles modulate inflammation during microbial infection of mice in a sex-dependent manner. Sci Transl Med. https://doi.org/10.1126/scitranslmed.aas9292

88. Sliter DA, Martinez J, Hao L, Chen X, Sun N, Fischer TD et al (2018) Parkin and PINK1 mitigate STING-induced inflammation. Nature 561:258-262. https://doi.org/10.1038/s4158 6-018-0448-9

89. Solano RM, Casarejos MJ, Menendez-Cuervo J, Rodriguez-Navarro JA, Garcia de Yebenes J, Mena MA (2008) Glial dysfunction in parkin null mice: effects of aging. J Neurosci 28:598-611. https://doi.org/10.1523/JNEUROSCI.4609-07.2008

90. Solti K, Kuan WL, Forizs B, Kustos G, Mihaly J, Varga Z et al (2020) DJ-1 can form beta-sheet structured aggregates that co-localize with pathological amyloid deposits. Neurobiol Dis 134:104629. https://doi.org/10.1016/j.nbd.2019.104629

91. Spratt DE, Martinez-Torres RJ, Noh YJ, Mercier P, Manczyk N, Barber KR et al (2013) A molecular explanation for the recessive nature of parkin-linked Parkinson's disease. Nat Commun 4:1983. https://doi.org/10.1038/ncomms2983

92. Sriram SR, Li X, Ko HS, Chung KK, Wong E, Lim KL et al (2005) Familial-associated mutations differentially disrupt the solubility, localization, binding and ubiquitination properties of parkin. Hum Mol Genet 14:2571-2586. https://doi.org/10.1093/ hmg/ddi292

93. Sun Y, Li H (2013) Functional characterization of SAG/RBX2/ ROC2/RNF7, an antioxidant protein and an E3 ubiquitin ligase. Protein Cell 4:103-116. https://doi.org/10.1007/s1323 8-012-2105-7

94. Sun Y, Tan M, Duan H, Swaroop M (2001) SAG/ROC/Rbx/Hrt, a zinc RING finger gene family: molecular cloning, biochemical properties, and biological functions. Antioxid Redox Signal 3:635-650. https://doi.org/10.1089/15230860152542989

95. Takahashi H, Ohama E, Suzuki S, Horikawa Y, Ishikawa A, Morita T et al (1994) Familial juvenile parkinsonism: clinical and pathologic study in a family. Neurology 44:437-441. https ://doi.org/10.1212/wnl.44.3_part_1.437

96. Unger T, Jacobovitch Y, Dantes A, Bernheim R, Peleg Y (2010) Applications of the Restriction Free (RF) cloning procedure for molecular manipulations and protein expression. J Struct Biol 172:34-44. https://doi.org/10.1016/j.jsb.2010.06.016

97. Vandiver MS, Paul BD, Xu R, Karuppagounder S, Rao F, Snowman AM et al (2013) Sulfhydration mediates neuroprotective actions of parkin. Nat Commun 4:1626. https://doi.org/10.1038/ ncomms 2623

98. Wang C, Ko HS, Thomas B, Tsang F, Chew KC, Tay SP et al (2005) Stress-induced alterations in parkin solubility promote parkin aggregation and compromise parkin's protective function. Hum Mol Genet 14:3885-3897. https://doi.org/10.1093/ $\mathrm{hmg} / \mathrm{ddi} 413$

99. Wang C, Tan JM, Ho MW, Zaiden N, Wong SH, Chew CL et al (2005) Alterations in the solubility and intracellular localization of parkin by several familial Parkinson's disease-linked point mutations. J Neurochem 93:422-431. https://doi.org/10.111 1/j.1471-4159.2005.03023.x

100. Wang YQ, Tang BS, Yu RL, Li K, Liu ZH, Xu Q et al (2014) Association analysis of STK39, MCCC1/LAMP3 and sporadic PD in the Chinese Han population. Neurosci Lett 566:206-209. https://doi.org/10.1016/j.neulet.2014.03.007

101. Wauer T, Komander D (2013) Structure of the human Parkin ligase domain in an autoinhibited state. EMBO J 32:2099-2112. https://doi.org/10.1038/emboj.2013.125

102. Whitworth AJ, Theodore DA, Greene JC, Beneš H, Wes PD, Pallanck LJ (2005) Increased glutathione S-transferase activity rescues dopaminergic neuron loss in a Drosophila model of Parkinson's disease. Proc Natl Acad Sci 102:8024-8029. https://doi. org/10.1073/pnas.0501078102

103. Winklhofer KF, Henn IH, Kay-Jackson PC, Heller U, Tatzelt J (2003) Inactivation of parkin by oxidative stress and C-terminal truncations: a protective role of molecular chaperones. J Biol Chem 278:47199-47208. https://doi.org/10.1074/jbc.M3067 69200

104. Wong ES, Tan JM, Wang C, Zhang Z, Tay SP, Zaiden $\mathrm{N}$ et al (2007) Relative sensitivity of parkin and other cysteine-containing enzymes to stress-induced solubility alterations. J Biol Chem 282:12310-12318. https://doi.org/10.1074/jbc.M609466200 
105. Xiao H, Jedrychowski MP, Schweppe DK, Huttlin EL, Yu Q, Heppner DE et al (2020) A quantitative tissue-specific landscape of protein redox regulation during aging. Cell 180(968983):e924. https://doi.org/10.1016/j.cell.2020.02.012

106. Yamamura Y, Kuzuhara S, Kondo K, Yanagi T, Uchida M, Matsumine $\mathrm{H}$ et al (1998) Clinical, pathologic and genetic studies on autosomal recessive early-onset parkinsonism with diurnal fluctuation. Parkinsonism Relat Disord 4:65-72. https://doi. org/10.1016/s1353-8020(98)00015-7

107. Yao D, Gu Z, Nakamura T, Shi ZQ, Ma Y, Gaston B et al (2004) Nitrosative stress linked to sporadic Parkinson's disease: S-nitrosylation of parkin regulates its E3 ubiquitin ligase activity. Proc Natl Acad Sci USA 101:10810-10814. https://doi. org/10.1073/pnas.0404161101

108. Yi W, MacDougall EJ, Tang MY, Krahn AI, Gan-Or Z, Trempe JF et al (2019) The landscape of Parkin variants reveals pathogenic mechanisms and therapeutic targets in Parkinson's disease. Hum Mol Genet 28:2811-2825. https://doi.org/10.1093/hmg/ ddz080
109. Yokochi M, Narabayashi H, Iizuka R, Nagatsu T (1984) Juvenile parkinsonism-some clinical, pharmacological, and neuropathological aspects. Adv Neurol 40:407-413

110. Zucca FA, Basso E, Cupaioli FA, Ferrari E, Sulzer D, Casella L et al (2014) Neuromelanin of the human substantia nigra: an update. Neurotox Res 25:13-23. https://doi.org/10.1007/s1264 0-013-9435-y

111. Zucca FA, Vanna R, Cupaioli FA, Bellei C, De Palma A, Di Silvestre D et al (2018) Neuromelanin organelles are specialized autolysosomes that accumulate undegraded proteins and lipids in aging human brain and are likely involved in Parkinson's disease. NPJ Parkinsons Dis 4:17. https://doi.org/10.1038/s4153 $1-018-0050-8$

Publisher's Note Springer Nature remains neutral with regard to jurisdictional claims in published maps and institutional affiliations.

\section{Authors and Affiliations}

Jacqueline M. Tokarew ${ }^{1,2} \cdot$ Daniel N. El-Kodsi ${ }^{1,2} \cdot$ Nathalie A. Lengacher ${ }^{1,2} \cdot$ Travis K. Fehr $^{1,2} \cdot$ Angela P. Nguyen $^{1}$. Bojan Shutinoski ${ }^{1}$ - Brian O'Nuallain ${ }^{3}$ - Ming Jin ${ }^{3}$. Jasmine M. Khan ${ }^{1}$. Andy C. H. Ng ${ }^{1}$. Juan $\mathrm{Li}^{1}$. Qiubo Jiang ${ }^{1}$. Mei Zhang ${ }^{4}$. Liqun Wang ${ }^{3}$. Rajib Sengupta ${ }^{5,6} \cdot$ Kathryn R. Barber $^{7}$ - An Tran ${ }^{7}$. Doo Soon Im $^{20,21}$. Steve Callaghan ${ }^{20}$. David S. Park ${ }^{20,21}$. Stephanie Zandee ${ }^{8}$. Xiajun Dong ${ }^{9}$. Clemens R. Scherzer ${ }^{9}$. Alexandre Prat ${ }^{8}$. Eve C. Tsai ${ }^{1,10}$. Masashi Takanashi ${ }^{11}$. Nobutaka Hattori ${ }^{11}$. Jennifer A. Chan ${ }^{12}$. Luigi Zecca ${ }^{13}$. Andrew B. West ${ }^{14,15}$. Arne Holmgren ${ }^{5}$. Lawrence Puente $^{16}$. Gary S. Shaw ${ }^{7}$. Gergely Toth ${ }^{17}$. John M. Woulfe ${ }^{1,4} \cdot$ Peggy Taylor $^{3}$. Julianna J. Tomlinson ${ }^{1,18}$. Michael G. Schlossmacher ${ }^{1,18,19}$

Julianna J. Tomlinson

jtomlinson@ohri.ca

$\triangle$ Michael G. Schlossmacher mschlossmacher@toh.ca

1 Program in Neuroscience, Ottawa Hospital Research Institute, Ottawa, ON, Canada

2 Graduate Program in Cellular and Molecular Medicine (Neuroscience), Faculty of Medicine, University of Ottawa, Ottawa, ON, Canada

3 BioLegend Inc., Dedham, MA, USA

4 Department of Pathology and Laboratory Medicine, The Ottawa Hospital, Ottawa, ON, Canada

5 Department of Biochemistry, Karolinska Institute, Stockholm, Sweden

6 Present Address: Amity Institute of Biotechnology, Amity University, Kolkata, West Bengal 700135, India

7 Department of Biochemistry, University of Western Ontario, London, ON, Canada

8 Department of Neuroscience, Faculty of Medicine, University of Montreal, Montreal, QC, Canada

9 Ann Romney Center for Neurologic Diseases, Brigham and Women's Hospital, Boston, MA, USA

10 Division of Neurosurgery, Department of Surgery, The Ottawa Hospital, Ottawa, ON, Canada
11 Department of Neurology, Juntendo University School of Medicine, Tokyo, Japan

12 Department of Pathology and Laboratory Medicine, University of Calgary, Calgary, AB, Canada

13 Institute of Biomedical Technologies, Italian National Research Council, Segrate, Milan, Italy

14 Department of Neurobiology, Duke University, Durham, NC, USA

15 Department of Pharmacology and Cancer Biology, Duke University, Durham, NC, USA

16 Proteomics Core Facility, Ottawa Hospital Research Institute, Ottawa, ON, Canada

17 Institute of Organic Chemistry, Research Center for Natural Sciences, Budapest, Hungary

18 University of Ottawa Brain and Mind Research Institute, Ottawa, ON, Canada

19 Division of Neurology, Department of Medicine, The Ottawa Hospital, Ottawa, ON, Canada

20 Department of Cellular and Molecular Medicine, University of Ottawa, Ottawa, ON, Canada

21 Present Address: Hotchkiss Brain Institute, University of Calgary, Calgary, AB, Canada 